UNIVERSIDADE DE SÃO PAULO

ESCOLA DE ENGENHARIA DE SÃO CARLOS

INSTITUTO DE FÍSICA DE SÃO CARLOS

INSTITUTO DE QUÍMICA DE SÃO CARLOS

\title{
CORRELAÇÃO ENTRE OS MÉTODOS TRADICIONAIS DE QUANTIFICAÇÃO DE FASES E O MÉTODO QUE UTILIZA O SISTEMA DE ANÁLISE DE IMAGENS EM AÇOS AO CARBONO COMUM
}

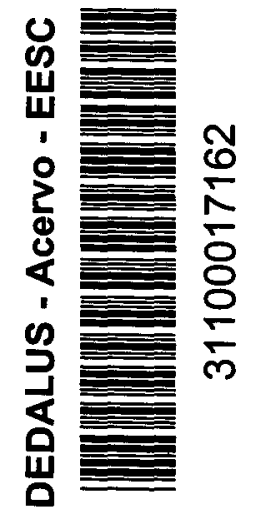

ORIENTADOR:

\section{Eng $^{\circ}$ EUCLIDES CASTORINO DA SILVA}

Dissertação apresentada à área interunidades em Ciência e Engenharia de materiais, da Universidade de São Paulo, como parte dos requisitos para obtenção do título de Mestre em Ciência e Engenharia de Materiais

Prof'. Associado : JOÃO MANUEL DOMINGOS DE ALMEIDA ROLLO

São Carlos, 1997

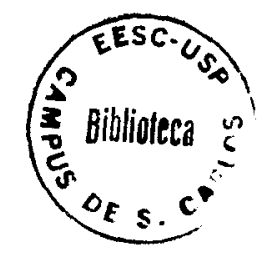


Clam $\frac{765685}{5476}$

Tombo 2,12197

st 0934307

Ficha catalográfica preparada pela Seção de Tratamento da Informaçăo do Serviço de Biblioteca - EESC-USP

Silva, Euclides Castorino da
Correlação entre os métodos tradicionais de
quantificaço de fases e o método que utiliza o
sistema de análise de imagens em aços ao carbono
comum/ Euclides Castorino da Silva. -- São
Carlos, 1997.
Dissertação (Mestrado). -- Área Interunidades:
Escola de Engenharia de São Carlos, Instituto de
Fisica de São Carlos, Instituto de Quimica de São
Carlos-Universidade de São Paulo, 1997.
Orientador: Prof. Dr. João Manuel Domingos de
Almeida Rollo
1. Quantificação de fase. 2. Sistema de análise
de imagem. 3. Aços ao carbono comum. I. Título.


Área Interunidades

Ciência e Engenharia de Materiais

UNIVERSIDADE DE SÃO PAULO

Escola de Engenharia de São Carlos

Instituto de Física de São Carlos

Instituto de Química de São Carlos
CAIXA POSTAL - 369

CEP 13560-970 - São Carlos/SP - Brasil

Tel/Fax: (016) 274-9285

MEMBROS DA COMISSÃO JULGADORA DA DISSERTAÇÃO DE MESTRADO DE EUCLIDES CASTORINO DA SILVA APRESENTADA A ÁREA INTERUNIDADES EM CIÊNCIA E ENGENHARIA DE MATERIAIS, DA EESC-IFSC-IQSC, UNIVERSIDADE DE SÃO PAULO, EM 03/10/1997.

COMISSÃO JULGADORA:

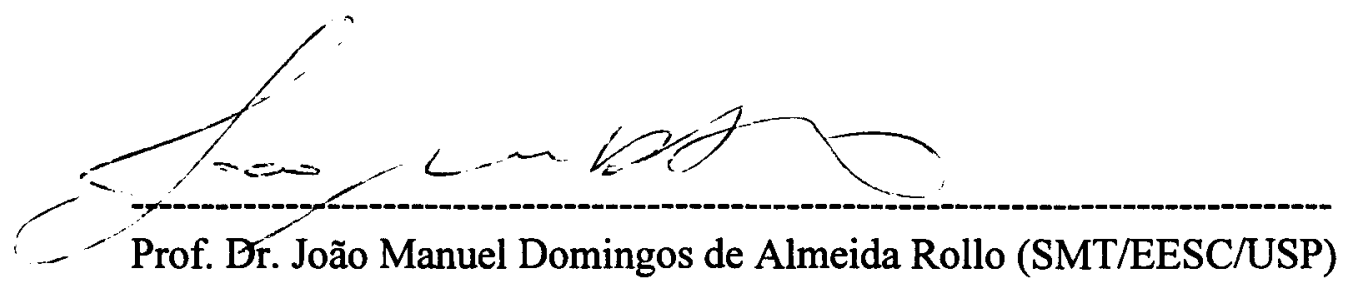

Prof. Dr. João Manuel Domingos de Almeida Rollo (SMT/EESC/USP) Wimbith hazolitr

Profa. Dra. Elisabeth Loshchagin Pizzolitto (UNESP-Araraquara)

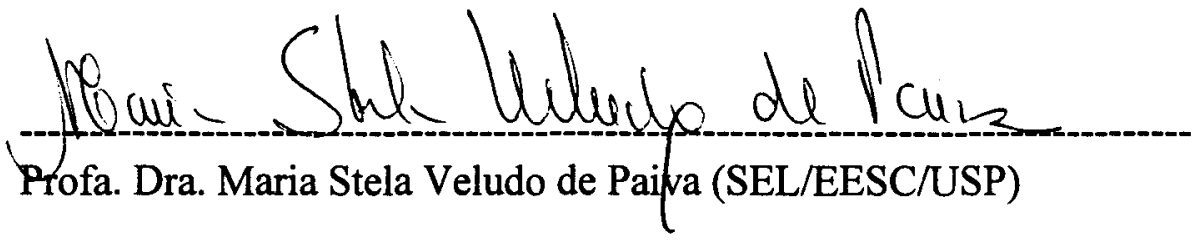

C: Meus DocumentosiSCMIdefesas Wefesa Euctides doo 


\section{DEDICATÓRIA}

"É impossivel para um homem que faz uma pesquisa sobre o que já foi conhecido, não ver uma imensidão (de coisa). Em cada ramo da ciência que ainda está por ser descoberto"

THOMAS JEFFERSON

MONTICELLO, JUNE 18, 1799

À minha mãe

Cidinha 


\section{AGRADECIMENTOS}

Bom poder dizer obrigado!

Meus ternos agradecimentos à minha família. Obrigado por vocês acreditarem em mim.

Ao Prof. Associado João Manuel Domingos de Almeida Rollo, do Departamento de Materiais da Escola de Engenharia de São Carlos, pela valiosa orientação dedicada a este trabalho e pela postura durante nosso convívio.

Ao Prof. Associado Samuel Irati Novaes Gomes, do Departamento de Materiais da EESC-USP, pelo incentivo e pelas sugestões.

Aos demais professores do Departamento de Materiais da EESCUSP, minha gratidão.

Aos técnicos e funcionários do Departamento de Materiais EESCUSP e, em especial, ao Pedro Luiz Di Lorenzo, pela valiosa colaboração na parte prática deste trabalho.

Aos funcionários da biblioteca central de EESC-USP, minha gratidão.

Aos colegas do Departamento de Materiais de EESC-USP pela convivência agradável durante o decorrer deste Trabalhos.

A todos que, direta ou indiretamente, contribuíram para esta realização.

À Coordenação de Aperfeiçoamento de Pessoal de Nível Superior (CAPES) pela bolsa de estudo concedida. 


\section{SUMÁRIO}

Página

LISTA DE FIGURAS.

LISTA DE TABELAS ...................................................... viii

LISTA DE ABREVIATURAS, SIGLAS, SÍMBOLOS .............. ix

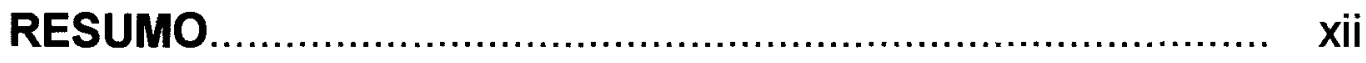

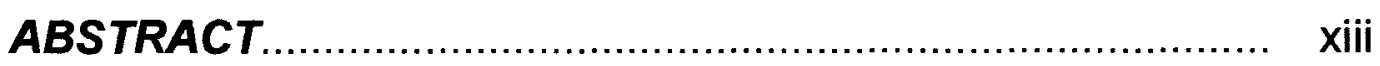

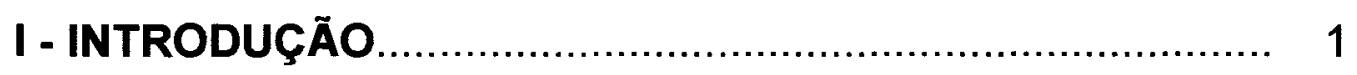

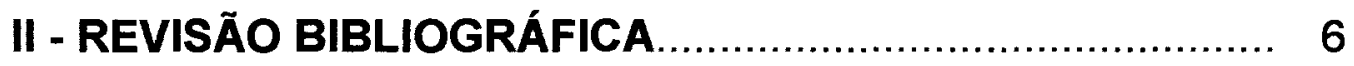

II.1 - Chapas de aço carbono laminado a quente................ 6

II.2 - Método teórico de quantificação de fases................... 17

II.3 - Microscópio óptico................................................ 20

II.3.1 - Elementos mecânicos do microscópio óptico........ 21

II.3.1.1 - Estativa.................................................... 21

II.3.1.2 - Platina ...................................................... 21

II.3.1.3 - Tubo de encaixe....................................... 21

II.3.1.4 - Focalização................................................. 22

II.3.1.5 - Revólver porta-objetiva................................. 22

II.3.2 - Microscópio óptico Leitz DMRX.................... 23

II.3.3 - Sistema de iluminação do microscópio óptico 24

II.3.3.1 - Lente coletora ou condensador ................... 25

II.3.3.2 - Lente auxiliar............................................. 26

II.3.3.3 - Diafragma de abertura ou diafragma da íris... 26

II.3.3.4 - Filtro ou polarizador................................... 26

II.3.3.5 - Diafragma de campo.................................. 28

II.3.3.6 - Lente de centralização.................................. 28

II.3.3.7 - Amostra................................................... 28

II.3.3.8 - Objetiva................................................ 28

II.3.3.9 - Semi-espelho 50/50 ................................ 28

II.3.3.10 - Tubo de lente................................................ 28

II.3.3.11 - Analisador rotativo........................................ 29 
II.3.3.12 - Acessórios.................................................. 29

II.4 - Método manual de quantificação de fase manuais........... 30

II.5 - Método manual de contagem de pontos manual............. 31

II.5.1 - Número de campos necessário............................... 35

II.6 - Método automático de quantificação de fases.................. 37

II.6.1 - Captura de imagem........................................ $\quad 39$

II.6.2 - Câmera com tecnologia de estado sólido............. 40

II.6.3 - Formação de imagens coloridas.......................... 41

II.6.4 - Segmentação de imagens................................ 42

II.6.5 - Ajuste da iluminação.......................................... 43

II.6.6 - Dispositivos digitalizadores de imagens.............. 45

II.6.7 - Processamento de imagens digitalizadas............. 48

II.8.8 - Operações com filtros ...................................... 50

III - MATERIAIS E MÉTODOS ......................................... 52

III.1 - Preparação das amostras........................................ 52

III.2 - Determinação do tamanho de grãos das amostras.... 54

III.3 - Método teórico de quantificação de fase .................. 55

III.3 - Obtenção de imagens fotográficas ........................... 57

III.4 - Método manual de contagem de pontos.................. 58

III.5 - Método que utiliza o sistema de análise de imagem 69

III.5.1 - Calibração das microestruturas.......................... 81

IV - RESULTADOS E DISCUSSÃO................................... 87

IV 1 - Determinação do tamanho de grão.......................... 89

IV.2 - Método teórico....................................................... 90

IV.3 - Método de contagem de pontos............................. 93

IV.4 - Método que utiliza o sistema de análise de imagens.. 97

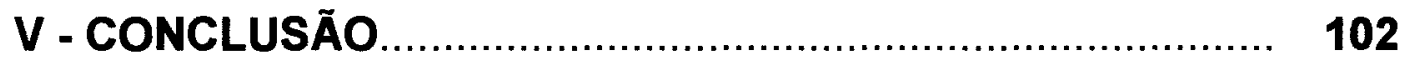

VI - SUGESTÕES PARA TRABALHOS FUTUROS................ 104

V - REFERÊNCIAS BIBLIOGRAFIAS ............................. 105 


\section{LISTA DE FIGURAS}

FIGURA 1 : Aparência de várias colônias perlíticas com

PÁGINA orientações diferentes no aço A.S.T.M. 1056, no estado recozido. Observam-se as lamelas de cementita (branca) em fundo (preto) de ferrita (Nital 2\%,MEV, 5000X)

FIGURA 2 : llustra o diagrama de fase ferro carbono. A linha pontilhada representa o equilibrio $\mathrm{Fe}-\mathrm{C}$ e linha cheia 0 equilíbrio $\mathrm{Fe}^{-\mathrm{Fe}_{3} \mathrm{C}}$ A.S.M. 1972 Vol.8.

FIGURA 3: Ilustra as mudanças de fases durante 0 resfriamento de uma liga de ferro carbono. MEl \& SILVA (1988)

FIGURA 4 : Ilustra a faixa do diagrama que predomina a solução sólida de carbono no ferro $\alpha$ A.S.M. (1972) Vol.8

FIGURA 5 : Representa o esquema da nucleação e crescimento da perlita segundo MEHL (1941)

FIGURA 6 : Demonstra que, nos aços ao carbono no estado normalizado, 0 aumento da porcentagem em peso de carbono aumenta a porcentagem de perlita e conseqüentemente 0 limite da resistência à tração.

FIGURA 7 : Demonstra o aumento do limite de resistência a tração com 0 aumento da variação da porcentagem em peso do manganês.

FIGURA 8 : llustra um segmento de reta que liga os pontos representativos das composições de duas fases em equilíbrio. 
FIGURA 9 : Diagrama de fases $\mathrm{Fe}^{-} \mathrm{Fe}_{3} \mathrm{C}$, onde observamos as fases Perlita $(P)$, Ferrita $(\alpha)$, Austenita $(\gamma)$, Cementita $\mathrm{Fe}_{3} \mathrm{C}$

FIGURA 10: Faixas de operação de microscópios em unidade de comprimento e objetos de interesse.

FIGURA 11 : llustra o revólver porta-objetiva. RICHARDSON (1971)

FIGURA 12 : Ilustra os ajustes mecânicos do microscópio óptico LEITZ DMRX, Operator's Guide LEITZ DMRX

FIGURA 13 : llustra o caminho da luz através do sistema óptico do microscópio utilizando luz polarizada. VOORT(1995).

FIGURA 14 : Observa-se que o poder de resolução decresce com o aumento da AN e com a diminuição de $\lambda$ A.S.M.,(1995).

FIGURA 15 : llustra o conjunto polarizador e analisador. A.S.M., (1995).

FIGURA 16: O gráfico mostra aproximadamente a porcentagem com que se apresentaram os constituintes das ligas ferro ao carbono simples, quando esfriadas lentamente COLPAERT (1972).

FIGURA 17 : llustra 2 campos de uma certa microestrutura.....

FIGURA 18 : llustra exemplos de quatro imagem de uma liga metálica.

FIGURA 19: llustra exemplos de ilusão ótica RUSS (1995)

FIGURA 20: Ilustra a dificuldade de perceber a real proporção de preto e de branco em uma imagem. 
FIGURA 21 : Diagrama esquemático do chip na câmera de estado sólido. Cada sensor (célula) regista o sinal da iluminação incidente proporcional à luz recebida RUSS (1995).

FIGURA 22 : Esquema de um monitor colorido (Sistema R.G.B.) A imagem do microscópio ótico captada pela câmera é transmitida para o monitor de vídeo que a explora, linha por linha.

FIGURA 23 : llustra o limite fixo que pode ser aplicado a fases bem definidas, vazios ou inclusões.

FIGURA 24 : Princípio de funcionamento dos discriminadores de tonalidade e de dimensão BARCELOS (1977).

FIGURA 25 : llustra a imagem no plano $(X, Y)$, em detalhe, região amplificada da imagem original, HEIN (1995).

FIGURA 26 : Esquema da digitalização das fotomicroestruturas utilizado pela varredura "scanner" ..............................................................

FIGURA 27 : Esquema da digitalização de imagem imagens de vídeo.

FIGURA 28 : Perspectiva do corte das amostras, quatro no sentido vertical e um no sentido horizontal.

FIGURA 29 : llustra o embutimento das amostras.

FIGURA 30 : Tamanho de grão A.S.T.M.; (Figura fora de escala).

FIGURA 31 : Escala de conversão do número de grão A.S.T.M. em diâmetro médio equivalente (Figura fora de escala). SILVA \& MEI (1988). 
FIGURA 32 : llustra o microscópio óptico LEITZ- DMRX, utilizando na obtenção das imagens.

FIGURA 33 : Ilustra quatro campos diferente da amostra do aço A.S.T.M. 1005 com uma rede de 49 pontos..

FIGURA 34 : Ilustra a fotomicrografia da amostra 1 do aço 1005 com uma rede de 100 pontos sobreposta.

FIGURA 35 : Amostra do aço A.S.T.M. 1005, no campo 4, ataque com Nital $2 \%$.

FIGURA 36 : llustra o microconstituinte perlita no contorno de grão ferritico do aço A.S.T.M. 1005; M.E.V., ataque com Nital $2 \%$.

FIGURA 37 : Amostra de aço A.S.T.M. 1005 no campo7, ataque com Nital $2 \%$

FIGURA 38 : Amostra do aço A.S.T.M. 1006 no campo 3, ataque com Nital $2 \%$.

FIGURA 39 : Amostra do aço A.S.T.M. 1014 no campo 7, ataque com Nital $2 \%$.

FIGURA 40 Amostra do aço A.S.T.M. 1009 no campo 1, ataque com Nital $2 \%$.

64

FIGURA 41 : Amostra do aço A.S.T.M. 1008 no campo 4, ataque com Nital $2 \%$

FIGURA 42 : Amostra de aço A.S.T.M. 1011 no campo 6, ataque com Nital $2 \%$.

FIGURA 43 : Amostra do aço A.S.T.M. 1012 no campo 9, ataque com Nital $2 \%$.

FIGURA 44 : llustra a perlita no contorno de grão ferrítico do aço A.S.T.M. 1012 MEV, ataque com Nital $2 \%$. 
FIGURA 45 : Amostra de aço A.S.T.M. 1056; no campo 3, ataque com Nital $2 \%$

FIGURA 46 : llustra a perlita e a ferrita do aço A.S.T.M. 1056.MEV, ataque com Nital $2 \%$

67

FIGURA 47 : Amostra de aço A.S.T.M. $1056 ; 0,7 \%$ de Manganês, no campo1, ataque com Nital $2 \%$.

68

FIGURA 48 : llustra a perlita e a ferrita do aço A.S.T.M. 1056 $\% 0,7$ de manganês MEV, ataque com Nital $2 \%$

FIGURA 49 : Esquema do sistema de análise de imagem....... 69

FIGURA 50: llustra que o nível de cinza zero deve corresponder à intensidade mínima e o nível de cinza de 255 à intensidade máxima no campo observado.

FIGURA 51 : llustra o programa "Mocha" versão 1.1 Observase ao fundo a microestrutura A.S.T.M.1005. Com o histograma de distribuição de níveis de cinza.

FIGURA 52 : llustração do software Adobe Photoshop versåo.4.0.

FIGURA 53 : Aço A.S.T.M. 1005; digitalizado pela placa "Frame grabber", com a utlilização do utilizando software especifico "Mocha", versão 1.1. Observa-se a diferença de intensidade de iluminação e o risco na bordas indicado pela seta.

FIGURA 54 : Ilustra a imagem digitalizada da amostra de aço A.S.T.M. 1005 com a eliminação do risco da borda.

FIGURA 55 : Ilustra a imagem digitalizada da amostra de aço A.S.T.M. $1005 \mathrm{com}$ a borda cortada e convertida para monocromática. Observa-se a diferença da intensidade de iluminação. 
FIGURA 56 : Ilustra a imagem digitalizada do aço A.S.T.M. 1005, com um auto-ajuste do histograma de niveis de cinza.

FIGURA 57 : llustra a imagem da amostra do aço A.S.T.M. 1005, campo 4 e campo7.Nesta imagem observa-se um detalhe de uma região amplificada da imagem original (zoom), na qual se podem observar os ruídos na imagem original.

FIGURA 58 : llustra a imagem da amostra de aço A.S.T.M. 1005, campo 4 e campo7. Detalhe de uma região amplificada da imagem original.(Zoom). Nesta se observa o efeito da utilização do filtro mediano na imagem original.

FIGURA 59 : llustra a imagem digitalizada da amostra de aço A.S.T.M. 1005. Observam-se a eliminação do risco, o ajuste da intensidade de iluminação, a eliminação de ruidos e o ajuste do brilho e contraste da imagem

FIGURA 60 : llustra uma imagem de um objeto qualquer em termos de píxel. Um quadrado eqüivale a um píxel.

FIGURA 61 : llustra o nivel de cinza que melhor representa os microconstituintes na escala de distribuição dos niveis de cinza.

FIGURA 62: llustra as ferramentas do software Mocha utilizadas na eliminação de ruídos indesejáveis.

FIGURA 63 : llustra imagem digitalizada e normalizada do aço A.S.T.M. 1005. Adicionou-se à imagem original cinza (de 0 255) um sobreplano de cor vermelha, correspondendo à área da perlita no aço em questão. 
FIGURA 64 : Ilustra um detalhe de uma região amplificada da imagem original com o sobreplano, na qual se observa uma área pintada de vermelho, que não corresponde à área da perlita.

FIGURA 65 :.Observa-se a eliminação dos riscos e das inclusões localizada nos centros dos grãos, 0 qual não corresponde à área da perlita que foi pintada pelo sobreplano

FIGURA 66 : llustra o gráfico da porcentagem do microconstituinte perlita em função da porcentagem de carbono, para o método teórico

FIGURA 67 : llustra o gráfico da porcentagem de microconstituinte perlita em função da porcentagem em peso de carbono, para o método de contagem de pontos.

96

FIGURA 68 : llustra o gráfico da porcentagem em peso do microconstituinte perlita em função da porcentagem em peso de carbono, para o método utilizando o sistema de análise de imagens.

FIGURA 69 : llustra as equações lineares de $1^{a}$ ordem dos três métodos estudados. 


\section{LISTA DE TABELAS}

TABELA 1 : Composição química em peso dos aços ao carbono laminados a quente, sendo que alguns deles são objeto de estudo deste trabalho. (A.S.T.M. A 29/A 29M-93 a)

TABELA 2 : Estimativa das propriedades mecânicas dos aços ao carbono laminados a quente A.S.M. (1982)

TABELA 3 : Reticulado ou "Grade", recomendada para diferentes frações volumétricas.

TABELA 4 : Composição química (\% em peso) das chapas de aços ao carbono laminadas a quente, analisadas.

TABELA 5 : llustra a calibração por dois pontos em função do aumento, medida experimentalmente com auxílio de uma régua micro-métrica.

TABELA 6 : Porcentagem do microconstituinte perlita e da ferrita da amostras de chapas de aços ao carbono comum laminadas a quente determinado pelo método teórico.(Regra da alavanca).

TABELA 7 : Porcentagem do microconstituinte perlita para os 10 campos das amostras de chapa de aço analisado, determinado pelo método de contagem de pontos

TABELA 8 Resultados obtidos para os 10 campos de cada amostra analisada, pelo método que utiliza o sistema de análise de imagens 


\section{LISTA DE ABREVIATURAS, SIGLAS E SÍMBOLOS}
A.S.T.M. American Society for testing Materials
$\% \mathrm{C} \quad$ Porcentagem de carbono
\%E.r Precisão em porcentagem
$\gamma$
campo austenítico do diagrama Fe-C
$\alpha$
campo ferrítico do diagrama ferro carbono
$\delta$
campo da ferrita, estável acima de $1394^{\circ} \mathrm{C}$
$\lambda$
Comprimento de onda
$\Delta$
Erro experimental
$\sum$
Somatório
$\bar{A}_{A}$
Fração volumétrica média
$\mu \mathrm{m}$
micro metros
$\overline{\mathrm{P} p}$
Fração de pontos média
$P_{P}$
Fração de pontos
$\mu \mathbf{S}$
micro segundos
$\overline{\mathrm{V}} \mathbf{v}$
Fração volumétrica média
$V_{V}$
Fração volumétrica
$0,714 \mathrm{~V}$
0,714 volts
$5000 \mathrm{X}$
5000 vezes
$500 x$
500 vezes
$A / D$
Analógico / Digital
AISI
American Iron and steel Institute
Al
Alumínio
al.
Outros
AN
Abertura Numérica
A.S.M.
American Society for metals 
A.S.T.M. American Society for Testing Materials

A.S.T.M. 8 Tamanho de grão número 8

C

Carbono

$\mathrm{C}_{\mathrm{A}}$

Porcentagem da fase $\mathrm{A}$

$\mathrm{C}_{\mathrm{B}}$

Porcentagem de fase $B$

Co

Porcentagem da fase a ser determinada

CCC Cúbico de corpo centrado

CCD/RGB Change Coupled Device/ Red, Green, Blue

CFC

Cúbico de fases centrada

$\mathrm{Cr}$

Cromo

dpi

Densidade de pixel por polegada

$\mathrm{Fe}$

Ferro

$\mathrm{Fe}_{3} \mathrm{C}$

Carboneto de ferro

$\mathrm{HB}$

Dureza Brinell

Id

Intensidade de energia luminosa

$\mathrm{K}$

Constante do microscópio

psi

1 libra / pol ${ }^{2}$

L

Comprimento

LEITZ DMRX Marca do microscópio

$\mathrm{mm} \quad$ Milímetro

MEV Microscópio eletrônico de varredura

$\mathrm{Mn} \quad$ Manganês

Mo Molibidênio

$\mathrm{MPa} \quad$ Mega Pascal

n Número de campos

$\mathrm{Nb} \quad$ Nióbio

nm Nano metro

${ }^{\circ} \mathrm{C} \quad$ Graus Célsius

P Perlita 


$\begin{array}{ll}\mathrm{P} & \text { Número total de pontos no reticulado } \\ \mathrm{Pi} & \text { Número de pontos contados sobre os objetos de } \\ & \text { interesse } \\ \mathrm{Pp} & \text { Fração de pontos } \\ \mathrm{R} & \text { Resolução } \\ \mathrm{S} & \text { Enxofre } \\ \mathrm{Si} & \text { Silício } \\ \mathrm{SiO} & \\ \mathrm{SMT} & \text { Dióxido de silício } \\ \mathrm{SS} & \text { Microscópio de tunelamento } \\ \mathrm{Ti} & \text { Solução sólida } \\ \mathrm{TV} & \text { Titánio } \\ \mathrm{pt} . & \text { Televisão } \\ \mathrm{p} & \text { Parte } \\ \text { v } & \text { Página } \\ \mathrm{W} & \text { Volume } \\ \mathrm{ZOOM} & \text { Tungstênio } \\ & \text { Ampliação }\end{array}$




\section{RESUMO}

Recentemente, com o rápido progresso da informática, a qual tem criado novos sistemas semi-automáticos ou mesmo completamente automáticos para avaliar os parâmetros metalográficos, tornou-se possivel oferecer aos usuários da prática metalográfica, uma nova opção para determinar os parâmetros de interesse, cuja determinação em materiais metálicos é executada por vários métodos e utilizada extensivamente na prática metalográfica, pois estes parâmetros contribuem significativamente para a resistência mecânica dos aços ao carbono. Porém a escolha do melhor método a ser adotado é um assunto bastante discutido por vários autores. As nove amostras das chapas de aços ao carbono comum recozidas, com porcentagem de carbono variando de $0,05 \%$ a $0,56 \%$, apresentando estrutura ferrítica ou ferrítico-perlítica foram selecionadas, lobjetivando ao estudo de uma correlação entre os métodos tradicionais mais utilizados, como também o método que utiliza o sistema de análise de imagem digitalizada, que enfatiza a diferença dos níveis de cinza entre as fases presentes. Os atuais resultados dessa correlação, representam um dos primeiros trabalhos na área. Os resultados dos achados metalográficos, explorando na integra a particularidade de cada método, demonstram que o método de análise de imagem, relacionado aos métodos tradicionais, conduz a uma rápida e precisa obtenção dos parâmetros, com uma boa reprodutividade dos resultados. 


\section{ABSTRACT}

The evaluation of the metallographic parameters in metallic materials has been carried out by many methods and they have been used extensively in the metallographic practice. However, the best method to be adopted has been a subject of many discussion. Nowadays, with the fast advance of computerisation, it has been possible to create semi-automatic or completely automatic systems for evaluation of these metallographic parameters, which are very important in determining the mechanical strength of carbon steels. In this work nine samples were removed from carbon steel plates with carbon content varying from 0,05 to0,56 for evaluation of the correlation between the traditional methods, as well as with the method which use a digitised image analysis. This late method emphasise to the difference on the grey levels of the phases present. The results from this work are one of the first in this area, and they exploited the particularity of each method. Also, they demonstrated that the image analysis method, when compared with the traditional ones, gives a rapid and precise evaluation of the metallographic parameters, with a very good results reproducibility. 


\section{I - INTRODUÇÃO}

As amostras de chapas de aços ao carbono laminadas a quente correspondem ao grupo mais importante dos aços ao carbono. Objetivou-se obter a porcentagem volumétrica da perlita em sete amostras de aços laminados a quente com a porcentagem em peso de carbono na faixa de $0,05 \%$ a $0,14 \%$ e, a título complementar, duas amostras contendo $0,56 \%$ de carbono e diferenciando-se em relação aos elementos de liga. Os aços com teores de carbono inferiores a $0,77 \%$ são, portanto, ligas hipoeutetóides, que têm como com microconstituintes principais a ferrita e perlita, e que contam com a peculiaridade de serem impostas, sempre que a velocidade de resfriamento seja relativamente lenta, de forma que não ocorra a formação de fases metaestáveis. Segundo HONEYCOMBE (1982)a perlita foi identificada por SORBY* apud HONEYCOMBE (1982), que a considerou, corretamente, como uma mistura lamelar de ferrita e cementita (carboneto de ferro $\mathrm{Fe}_{3} \mathrm{C}$ ). A figura 1 ilustra a aparência metalográfica por MEV da perlita em um aço recozido contendo $0,56 \%$ de carbono.

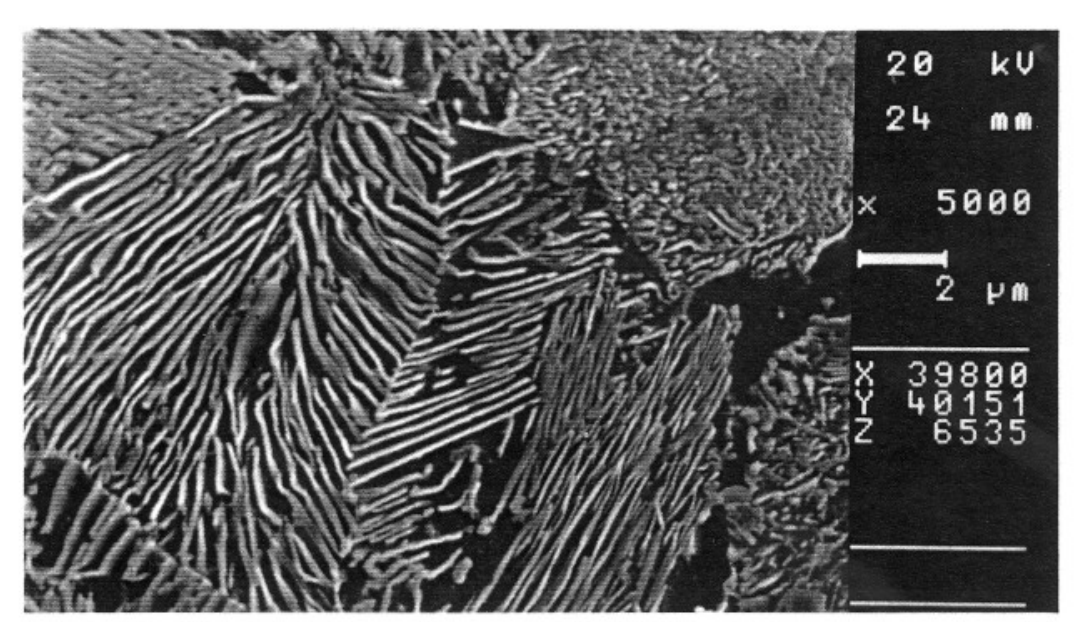

FIGURA 1 - Aparências de várias colônias perlíticas com orientações

\footnotetext{
* SORBY, H.C. (1887). Journal Iron Steel Int.., 1, P. 255-288 apud HONEYCOMBE, R.W.K.(1982) Aços microestrutura e propriedades. Tradução de: M. Amaral fortes e A. Cabral ferro. FUNDAÇÃO CALOUSTE GULBENKIAN / LISBOA.
} 
diferentes no aço ASTM 1056, no estado recozido. Observam-se as lamelas de cementita (branca) em um fundo (preto) de ferrita (Nital $2 \%$, MEV, 5000X).

O nome perlita, segundo CHIAVERINI (1984), é devido à "nuança" de cores da madrepérola que esse microconstituinte freqüentemente apresenta ao microscópio. A melhor definição para a perlita é que ela não é uma fase, e sim uma mistura de duas fases, ferrita e cementita, que ocorre sob forma de lamelas paralelas. As propriedades mecânicas dos aços com estruturas perlíticas são, portanto, intermediárias entre as da ferrita e as da cementita.

PICKERING (1978) destaca que a importância de quantificar com precisão a microestrutura perlítica está no fato de que esta contribui significativamente para a resistência mecânica dos aços ao carbono hipoeutetóides normalizados.

RHINES (1945), COLPAERT (1957), MEI \& SILVA (1988) mencionam, em suas revisões, que uma das primeiras formas de quantificação de fase foi através do método teórico que emprega uma relação geométrica, denominada regra da alavanca ou dos segmentos inversos. A regra da alavanca tem sua aplicação restrita ao equilíbrio entre os estados termodinâmicos das fases, conforme PORTER \& EASTERLING (1990). Ela determina, através de um segmento de reta entre dois pontos, aplicada no diagrama de fase, a porcentagem das fases que compõem as ligas metálicas. No entanto, este método não leva em consideração a porcentagem dos elementos de ligas adicionais, notoriamente presentes nas ligas metálicas. Sendo assim, segundo MEI \& SILVA (1988), deveríamos ter um diagrama de fase específico para cada liga metálica para se obter um resultado com precisão.

Segundo GLADMAN \& WOODHEAD (1960), MENEZES \& BASTIAN (1974), foram desenvolvidos pela metalografia quantitativa 
métodos estatísticos, para determinar a porcentagem de fase em que os elementos de liga adicionais presentes nas ligas eram levados em consideração. Neste método, as medidas são efetuadas em superfícies planas, devidamente preparadas, e destas medidas devem ser obtidas relações que caracterizem tridimensionalmente a microestrutura das ligas em questão.

UNDERWOOD (1995), PADILHA \& AMBROZIO (1985), MENEZES \& BASTIAN (1974) destacam que, dentro dos vários métodos manuais desenvolvidos pela metalografia quantitativa, 0 método manual mais utilizado na rotina industrial e nos meios científicos é o de contagem de pontos manual. Este método consiste em utilizar redes retangulares de pontos com 4, 9, 16, 47, 100, 126... sobre a microestrutura, porém em campos diferentes. Estes campos podem ser escolhidos de forma aleatória ou de maneiras sistemáticas.

MENEZES \& BASTIAN (1974), BARCELOS et al.(1977) mencionam que normalmente os métodos manuais para a contagem de fase são bastante lentos e cansativos. Lentos devido à necessidade de revelação das fotomicrografias e montagem das redes de pontos, e cansativos pois, mesmo colocando-se a rede de nós na ocular do microscópio, como citado por alguns autores como forma de simplificar os métodos, seriam necessárias horas de observação do conjunto e, por outro lado, a confiabilidade destes métodos dependeria ainda da habilidade do pesquisador. $O$ que restringe bastante a reprodutibilidade destes dados.

Conforme HETZNER (1992), BRESSIANI \& PINTO (1994), BARCELOS et al.(1977), até na década passada, as imagens obtidas por microscopia óptica ou microscopia eletrônica para a avaliação dos parâmetros microestruturais eram efetuadas, essencialmente, pelo emprego de métodos manuais. 
Atualmente, com o desenvolvimento das técnicas automatizadas de processamento dos parâmetros microestruturais, utilizando-se o sistema digitais, as avaliações microestruturais utilizadas pela metalografia quantitativa, passaram a ter um outro instrumento de análise. Segundo ROCHA \& PACIORNIK (1994), HETZNER (1992), PINTO \& BRESSIANI (1994), SANTOS et al. (1995), IMAGE- PROPLUS (1995); LEGO INSTRUMENTS LIMITED (1991); CASTORINO \& ROLLO (1996), RICHTER, J. ; WENDROCK, H. (1992), existem vários solftwares específicos utilizados para análises de imagens, citados pela literatura, tais como "Mocha" versão 1.1, "Adobe photoshop" versão 4.0, "Imago", "Quantimet600", "Quantikov" que utiliza o método "saltykov", "Image-pro-plus", "Leco" 2005... etc.

$\mathrm{Na}$ determinação da fração volumétrica dos microconstituintes perlita e da fase ferrítica das chapas de aços ao carbono laminadas a quente e resfriadas lentamente, foram usadas, comparativamente as técnicas dos métodos tradicionais de quantificação de fase, com o método utilizado pelo sistema automatizado de análise de imagens. $O$ método automatizado de análise de imagem consta de câmera CCD/RGB acoplada ao microscópio óptico, ligada a uma placa de digitalização "frame grabber", o software "Mocha" versão 1.1 e o software "Adobe photoshop" versão 4.0 como apoio ao "mocha" no melhoramento das imagens digitalizadas.

O processamento de imagens é a ciência de modificar e analisar imagens digitais. Segundo HEIN et al. (1994), PUJOL et al.(1992), esta área vem se desenvolvendo rapidamente, tornando-se uma ferramenta muito importante para diversos campos da ciência e tecnologia, tais como engenharia, medicina, astronomia, física, ciência da computação, química, arqueologia, etc....

Com os dados obtidos pelos três métodos estudados, na quantificação das porcentagens dos microconstituintes perlita, 
presentes nas nove amostras de chapas de aços ao carbono laminadas a quente, montraram-se equações de $1^{\mathrm{a}}$ ordem, utilizandose um software "Origin" versão 4.1,que relaciona a evolução da porcentagem dos microconstituintes perlita em função da porcentagem de carbono presente nos aços. (Verificaram-se comparativamente a confiabilidade entre os métodos, bem como as vantagens e desvantagens de utilização dos métodos estudados.) 


\section{II - REVISÃO BIBLIOGRÁFICA}

\section{II.1 - Chapas de aco carbono laminadas a quente}

Segundo HONEYCOMBE \& BHADESHIA (1995), o grupo mais importante das chapas de aços carbono laminadas a quente, sob o ponto de vista de conformação, possui teores de carbono inferiores a $0,25 \%$.

Desta forma, para a análise das porcentagens de fase, foram escolhidas 7(sete) amostras de chapas de aços ao carbono laminadas a quente, com porcentagem de carbono variando de $0,05 \% \mathrm{C}$ a $0,14 \% \mathrm{C}$, apresentando estrutura com fases perlíticas e ferríticas. Tais chapas são usadas em formas estruturais, tais como: pontes, barcos, depósitos sob pressão, tanques de armazenagem, vigas em I, cantoneiras, em edificios, etc. As chapas de aço carbono, com teores variando entre 0,2 a $0,5 \%$ de carbono, são também usadas na fabricação de peças forjadas em matrizes fechadas ou entre elas, cobrindo um longa faixa de aplicações. Desta forma foram escolhidas, a título complementar, 2 amostras de chapas de aço ao carbono comum, laminadas a quente, com porcentagem de $0,56 \% \mathrm{C}$, com adições diferentes de elementos de ligas.

CHIAVERINI (1984) definiu os aços ao carbono comum, produzidos industrialmente, como sendo liga de ferro e carbono, com a porcentagem de carbono compreendida entre 0,008 a $2,11 \%$ em peso de carbono, mais os elementos de liga residuais. A porcentagem em peso de carbono de 0,008 corresponde à solubilidade máxima de carbono no ferro $\alpha$ a temperatura ambiente, e à porcentagem em peso de carbono de 2,11 à porcentagem em peso máximo de carbono nos 
aços carbono na temperatura de $1148^{\circ} \mathrm{C}$. Assim, até $0,008 \%$ de carbono, o produto siderúrgico à temperatura ambiente é chamado de ferro comercialmente puro. $O$ teor de carbono $2,11 \%$ em peso de carbono é adotado como separação teórica entre os dois principais produtos siderúrgicos.

- Aços: - teores de carbono menores que $2,11 \% \mathrm{C}$.

- Ferros fundidos:- teores de carbono maiores que $2,11 \% \mathrm{C}$.

Os aços ao carbono são divididos em grupos principais e, dentro destes grupos, são classificados em familia de características semelhantes. Estas famílias são designadas por conjuntos de algarismo, em geral em número de 4, quando o teor de carbono for inferior a $1,00 \%$.

\section{$\underline{\mathbf{X}} \underline{\mathbf{X}} \underline{\mathbf{X}}$}

Familia Teor de carbono em centésimo

de porcentagem $(0,01 \%)$

Os aços ao carbono comum, segundo a norma da, ASTM A 29/A29M93a, são aços em que só são especificados os teores de carbono, silício, manganês, fósforo e enxofre, não ultrapassando os teores máximos especificados para o silício e manganês:

- Si.........................0,06\% máximo

- Mn......................1,65\% máximo

A norma ASTM A 29/A 29M-1993a classifica os aços ao carbono laminados a quente, segundo faixas e limites de seus teores de elementos de liga. Na tabela I, podem-se observar exemplos de algumas faixas de composição química dos aços ao carbono mais utilizados. 
TABELA 1 - Composição química em peso dos aços ao carbono laminados a quente, sendo que alguns deles são objeto de estudo deste trabalho. (ASTM A 29/A 29M - 93 a).

\begin{tabular}{|c|c|c|c|c|}
\hline AISI & C & $M n$ & $\mathbf{P}$ & $\mathbf{S}$ \\
\hline 1005 & 0,06máx & $0,35 \mathrm{max}$ & 0,04 máx & $0,05 m a x$ \\
\hline 1006 & 0,08máx & $0,25-0,40$ & 0,04máx & $0,05 m a x$ \\
\hline 1008 & 0,10máx & $0,30-0,50$ & 0,04máx & $0.05 m b x$ \\
\hline 1010 & $0,08-013$ & $0,30-0,60$ & 0,04máx & $0.05 m b x$ \\
\hline 1012 & $0,10-0,15$ & $0,30-0,60$ & 0,04máx & $0.05 \mathrm{max}$ \\
\hline 1015 & $0,13-0,18$ & $0,30-0,60$ & 0,04máx & $0.05 m a x$ \\
\hline 1055 & $0,50-0,60$ & $0,60-0,90$ & 0,04 máx & $0.05 \mathrm{max}$ \\
\hline
\end{tabular}

A AISI(1981) estimou as propriedades mecânicas de alguns aços ao carbono comum. A tabela II exemplifica os mais utilizados industrialmente.

TABELA 2 - Estimativa das propriedades mecânicas dos aços ao carbono laminados a quente ASM - (1982).

\begin{tabular}{|c|c|c|c|c|c|c|c|}
\hline \multirow[t]{2}{*}{ AISI: } & \multicolumn{2}{|c|}{$\begin{array}{l}\text { Limite de resistência } \\
\text { à traçăo. }\end{array}$} & \multicolumn{2}{|c|}{ 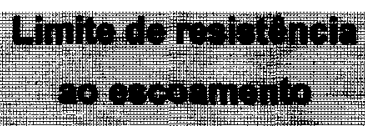 } & \multirow{2}{*}{$\begin{array}{c}\text { Alonga- } \\
\text { mento } \\
\%\end{array}$} & \multirow{2}{*}{ 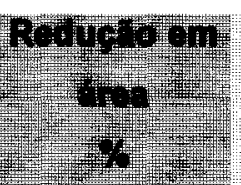 } & \multirow[t]{2}{*}{$\begin{array}{r}\text { Dureza } \\
\text { HB }\end{array}$} \\
\hline & Mpa & psi & Apa & $-4 p 1$ & & & \\
\hline 1006 & 295 & 43 & 165 & 240 & 30 & $55=$ & 86 \\
\hline 1008 & 305 & 44 & 170 & 24.5 & 30 & 55 & 86 \\
\hline 1010 & 325 & 47 & 180 & $26.0^{-3}$ & 28 & 50 & 95 \\
\hline 1012 & 330 & 48 & 185 & 26.5 & 28 & 50 & 95 \\
\hline 1015 & 345 & 50 & 190 & 27.5 & 28 & 50 & 101 \\
\hline 1056 & 650 & 94 & 355 & 51.5 & 12 & 30 & 197 \\
\hline
\end{tabular}


Nos aços ao carbono resfriados lentamente, a formação do microconstituinte perlita depende principalmente da porcentagem em peso de carbono. No entanto, a presença dos elementos de liga na composição química do aço influencia a formação do microconstituinte perlita.

A perlita funciona como uma barreira para os planos de deslocamento da fase ferrítica, aumentando, conseqüentemente, o limite da resistência à tração e à taxa de encruamento, diminuindo o alongamento dos aços. Conseqüentemente, com o endurecimento destes, um fator predominante se faz presente, a fragilização.

Para representar os aços ao carbono comum, utiliza-se o diagrama de fase ferro- $\mathrm{Fe}_{3} \mathrm{C}$, que é uma representação gráfica dos limites de temperatura e composição das zonas de domínio das fases presentes nestas ligas, bem como das reações entre estas fases.

SHIRO BAN-YA et al. (1970) reúne informaçōes de vários

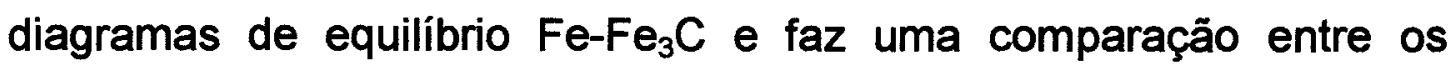
pontos de transformação obtidos por estes. CHIPMAN (1973) estudando diagramas de fase $\mathrm{Fe}-\mathrm{Fe}_{3} \mathrm{C}$, traçados termodinamicamente por vários autores, reproduziu o diagrama de fase $\mathrm{Fe}-\mathrm{Fe}_{3} \mathrm{C}$, até então o mais utilizado nos meios científicos e na rotina industrial.

Existem algumas diferenças notórias entre os traçados, porém estamos adotando para este trabalho o diagrama de fase, editado por CHIPMAN (1972), conforme ilustra a figura 2.

Este diagrama é o ponto de partida para o estudo da constituição e estrutura de qualquer aço ao carbono comum, pois constitui uma sólida base sobre a qual se desenvolve o conhecimento dos aços ao carbono comum e dos aços ligados na sua imensa variedade. 


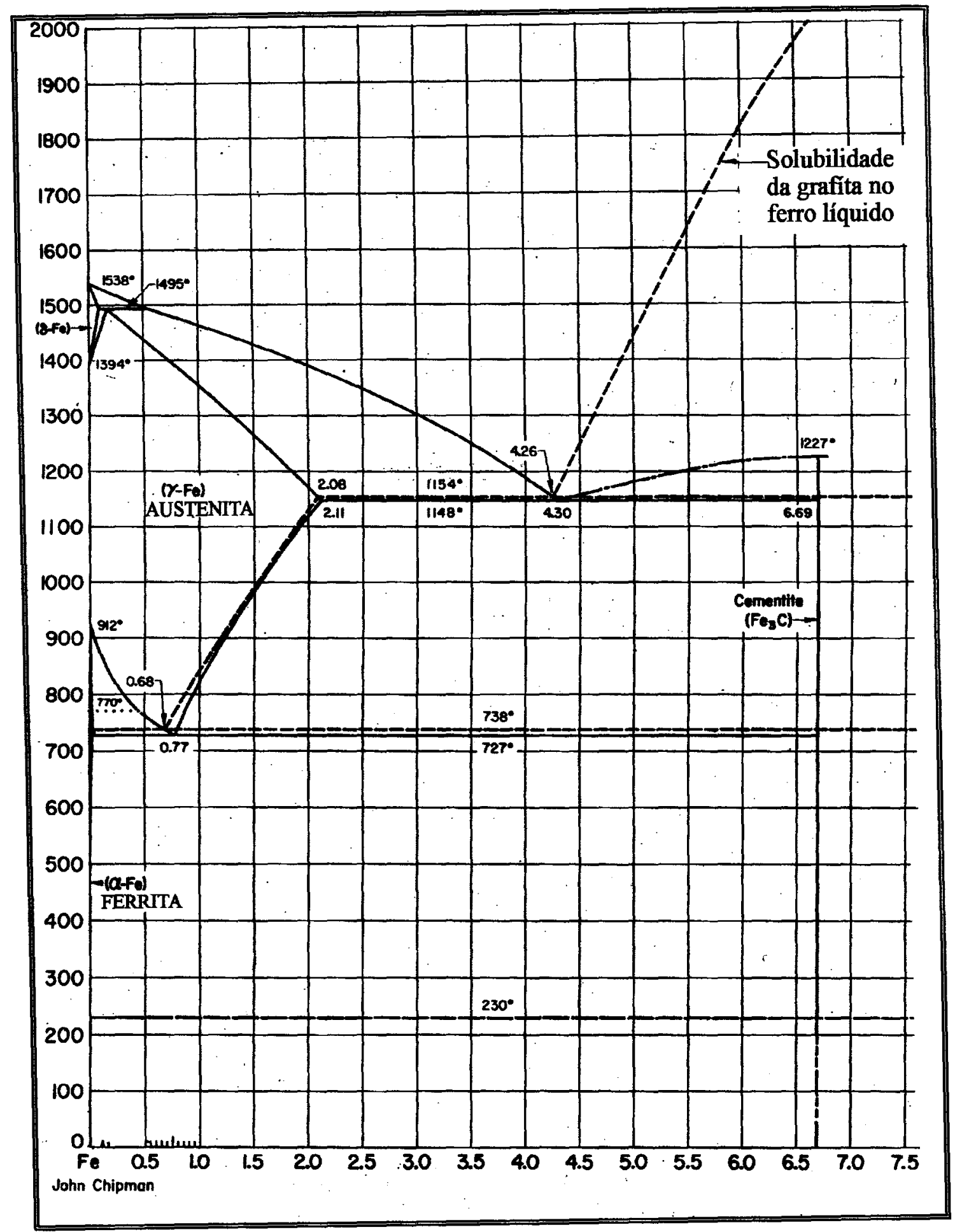

FIGURA 2 - llustra o diagrama de fase ferro carbono. A linha pontilhada representa o equilíbrio $\mathrm{Fe}-\mathrm{C}$ e a linha cheia, o equilíbrio $\mathrm{Fe}_{\mathrm{Fe}} \mathrm{C}$, A.S.M. (1972) Vol.8 
Observa-se pelo diagrama de fases proposto por CHIPMAN (1972) uma série de transformações no processo de solidificação de um lingote de aço, desde o estado líquido até a temperatura ambiente, conforme ilustra a figura 3 .

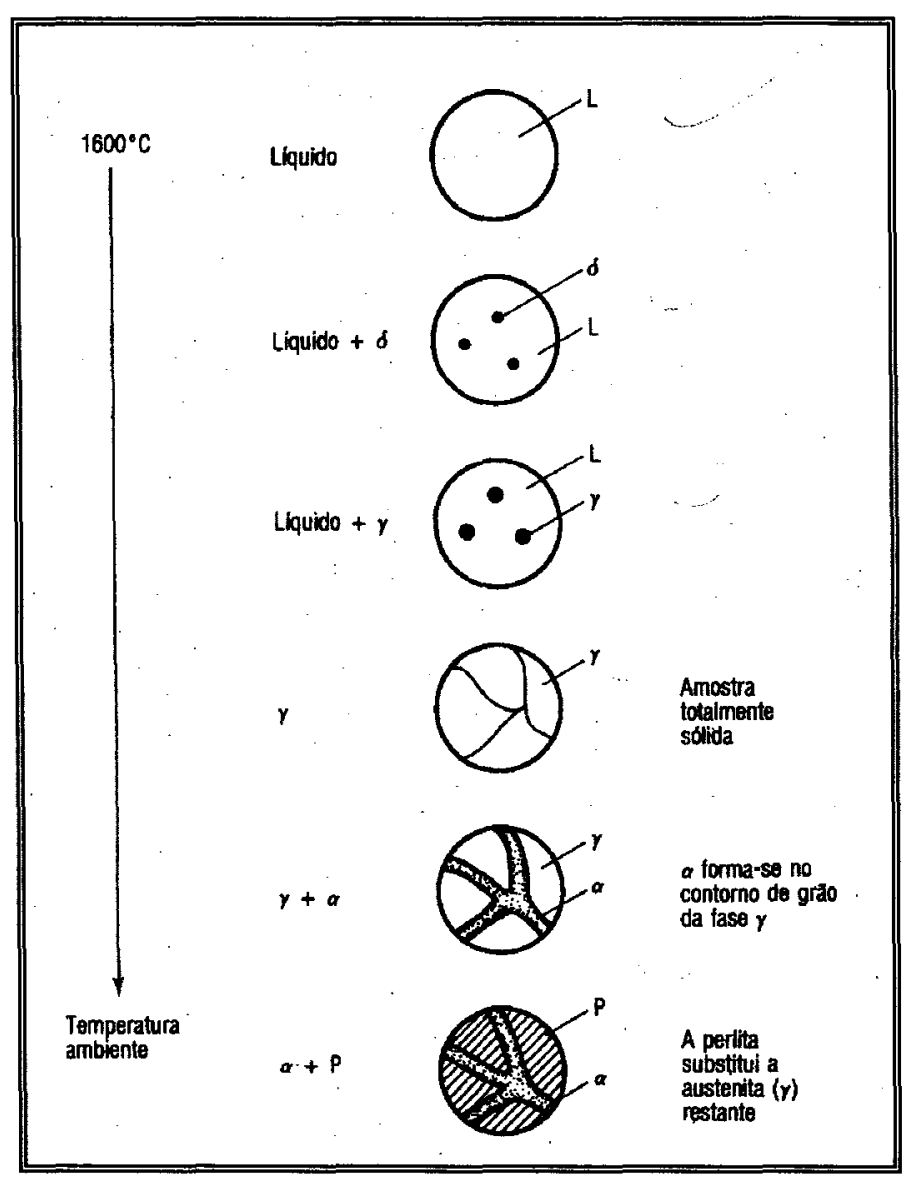

FIGURA 3 - llustra as mudanças de fases durante o resfriamento de uma liga de ferro carbono. MEI \& SILVA (1988).

Isto, obviamente, se ele for obtido através de um resfriamento lento (dentro do forno ou resfriamento ao ar). Se o resfriamento for mais rápido (em óleo, em água etc..), aparecerão outras fases, metaestáveis, e que não são previstas pelo diagrama de fase $\mathrm{Fe}$ $\mathrm{Fe}_{3} \mathrm{C}$. 
As fases presentes nos aços ao carbono comum quando resfriados lentamente são:

- Fase austenita (Y): denominada como sendo uma solução sólida de carbono em ferror, que existe entre as temperaturas de 912 e $1495^{\circ} \mathrm{C}$, e com solubilidade máxima de carbono no ferro de $2,11 \%$ a $1148^{\circ} \mathrm{C}$.

- Fase ferrítica $(\alpha)$ : solução sólida de carbono em ferro $\alpha$, existente até a temperatura de $912^{\circ} \mathrm{C}$. Nesta faixa de temperatura, conforme figura 5, a solubilidade do carbono no ferro é muito baixa, chegando ao máximo de $0,0218 \% \mathrm{C}$ a $727^{\circ} \mathrm{C}$.

A ferrita tem estrutura cúbica de corpo centrado(C.C.C.) e fator de empacotamento de 0,68; a austenita apresenta estrutura cúbica de fase centrada (C.F.C.) e fator de empacotamento 0,74. A ferrita em comparação com a austenita é mais compacta, apresenta interstícios tetraédricos menores e tem, conseqüentemente, menor capacidade de dissolver carbono.

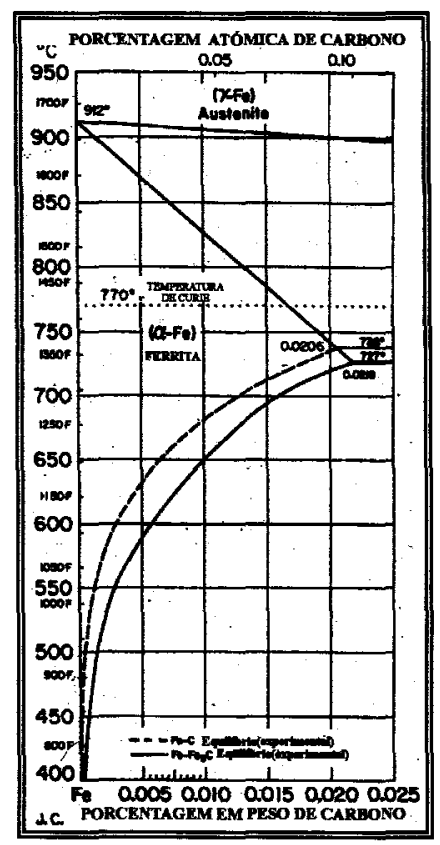

FIGURA 4 - Ilustra a faixa do diagrama em que predomina a solução sólida de carbono no ferro $\alpha$ A .S.M. (1972); Vol.8. 
O carbono que é rejeitado pela ferrita, dá origem à cementita, que é uma fase rica em carbono, de composição $\mathrm{Fe}_{3} \mathrm{C}$.

- Fase cementita $\left(\mathrm{Fe}_{3} \mathrm{C}\right)$ é um carboneto de ferro com estrutura ortorrômbica de alta dureza e elevada fragilidade.

Segundo SILVA \& MEI (1988), a perlita não é uma fase, como consideram, erroneamente alguns autores, e sim um microconstituinte de duas fases, ferrita e cementita, que ocorre sob a forma de lamelas.

No diagrama de fase ferro cementita, é exibida a ocorrência da reação invariante caracterizada pelos pontos.

$\gamma_{0,77} \rightarrow \propto_{0,02} \% \mathrm{C}+\mathrm{Fe}_{3} \mathrm{C}$ à temperatura de $723^{\circ} \mathrm{C}$

As curvas que compõem o diagrama de fase, segundo CHIAVERINI (1984), são curvas de transformação, que, ao serem cruzadas, provocam mudança de fases. Os fatores que influenciam a posição das curvas de transformação são: velocidade de resfriamento e composição química presente nas ligas.

Segundo MEHL* apud SILVA \& MEI (1988) a perlita nucleia-se preferencialmente nos contornos de grão da austenita homogênea (composição uniforme). Porém, quando a austenita apresenta gradientes de concentração de carbono ou partículas dispersas, a nucleação da perlita ocorre também no interior do grão austenítico. A figura 5 explica o mecanismo de crescimento da perlita, com base na nucleação de cementita a partir do contorno de grão austenítico. À medida que essa partícula de cementita cresce, ela diminui o teor de carbono das regiōes vizinhas, até ocorrer a formação de ferrita. Com o crescimento da ferrita, há segregação de carbono para a austenita, até ser atingido o nível de carbono da cementita, quando esta, então se nucleia. $E$ assim sucessivamente, com o crescimento para a frente $e$

\footnotetext{
"Mehl, R. F. e Hagel, W.C., The austenite- pearlite reation. Prog. Met. Physics, 6, ed.B. Chalmers e r. King, Pergamon press, 1956, apud SILVA, A. L. C., MEI, P.R.; (1988) Aços e ligas especiais. 2ed. Sumaré. Eletrometal: Metais especiais.
} 
para os lados. Esse processo de nucleação de uma fase no contorno de grão de uma matriz, segundo AARONSON, H. et al. (1976) é conhecido como nucleação "simpatética" (sympathetic nucleation) Uma outra hipótese para explicar o crescimento da perlita segundo HILLET (1962), baseia-se em que o crescimento seja por ramificações da perlita. Observou também que a perlita era nucleada tanto a partir da ferrita como da cementita, dependendo do teor de carbono.

Posteriormente, HONEYCOMBE \& BHADESHIA observou que o crescimento da perlita ocorreria tanto por ramificações como por crescimento lateral, e que nódulos perlíticos eram nucleados a partir da ferrita ou da cementita.

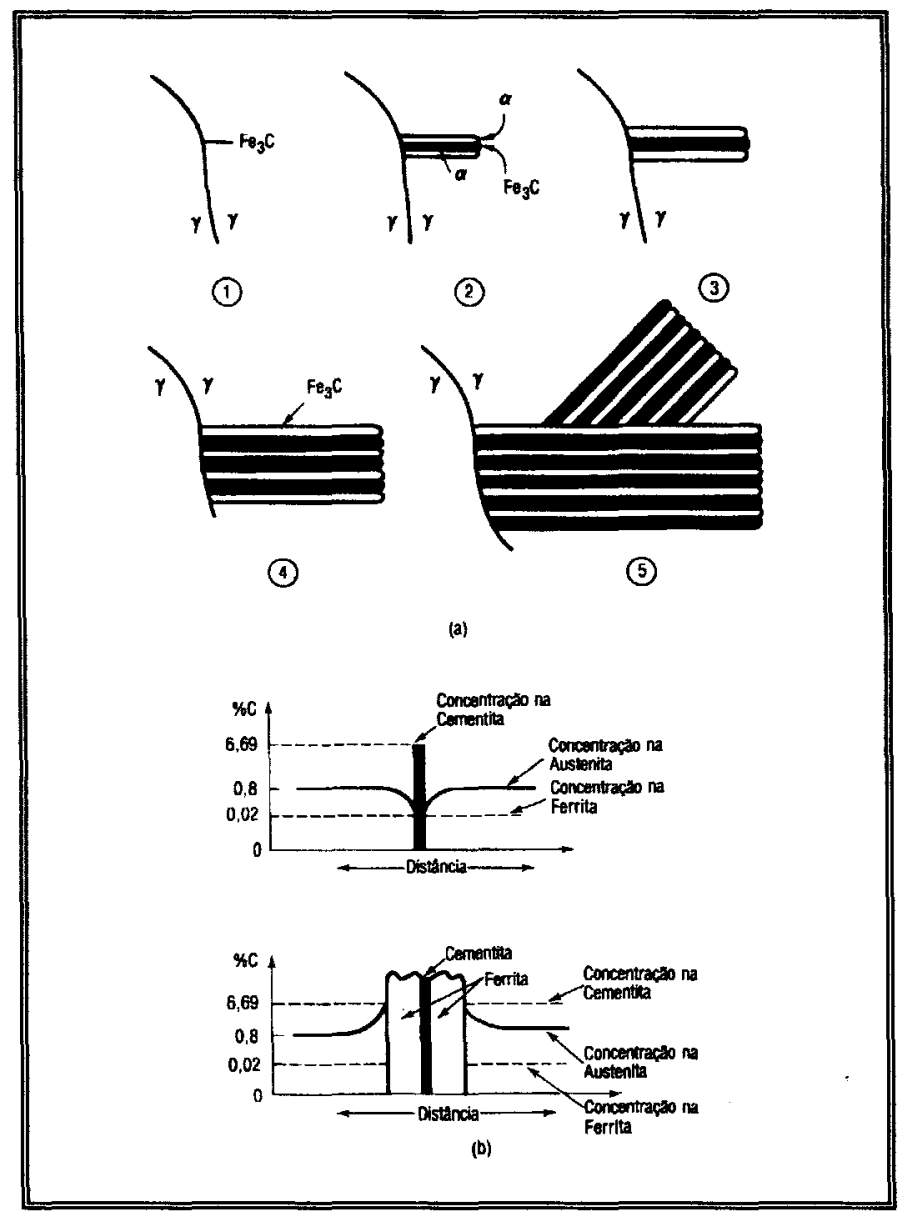

FIGURA 5 - Representa o esquema da nucleação e crescimento da perlita segundo MEHL apud SILVA \& MEI (1988).

a) 
1. Núcleo inicial de cementita.

2. Nucleação de lamelas de ferrita ao lado da cementita.

3. Crescimento lateral e frontal da colônia.

4. Novo núcleo de cementita formado com orientação diferente dos anteriores.

5. Crescimento da nova colônia.

b) Perfil de concentração da austenita na vizinhança de lamelas de cementita e ferrita, o que favorece o aparecimento de lamelas alternadas das duas fases.

Segundo HONEYCOMBE \& BHADESHIA (1995), PICKERING (1978), os aços ao carbono ferrítico-perlíticos são essencialmente aços cujas propriedades dependem da presença do carbono, conforme ilustra a figura 6 .

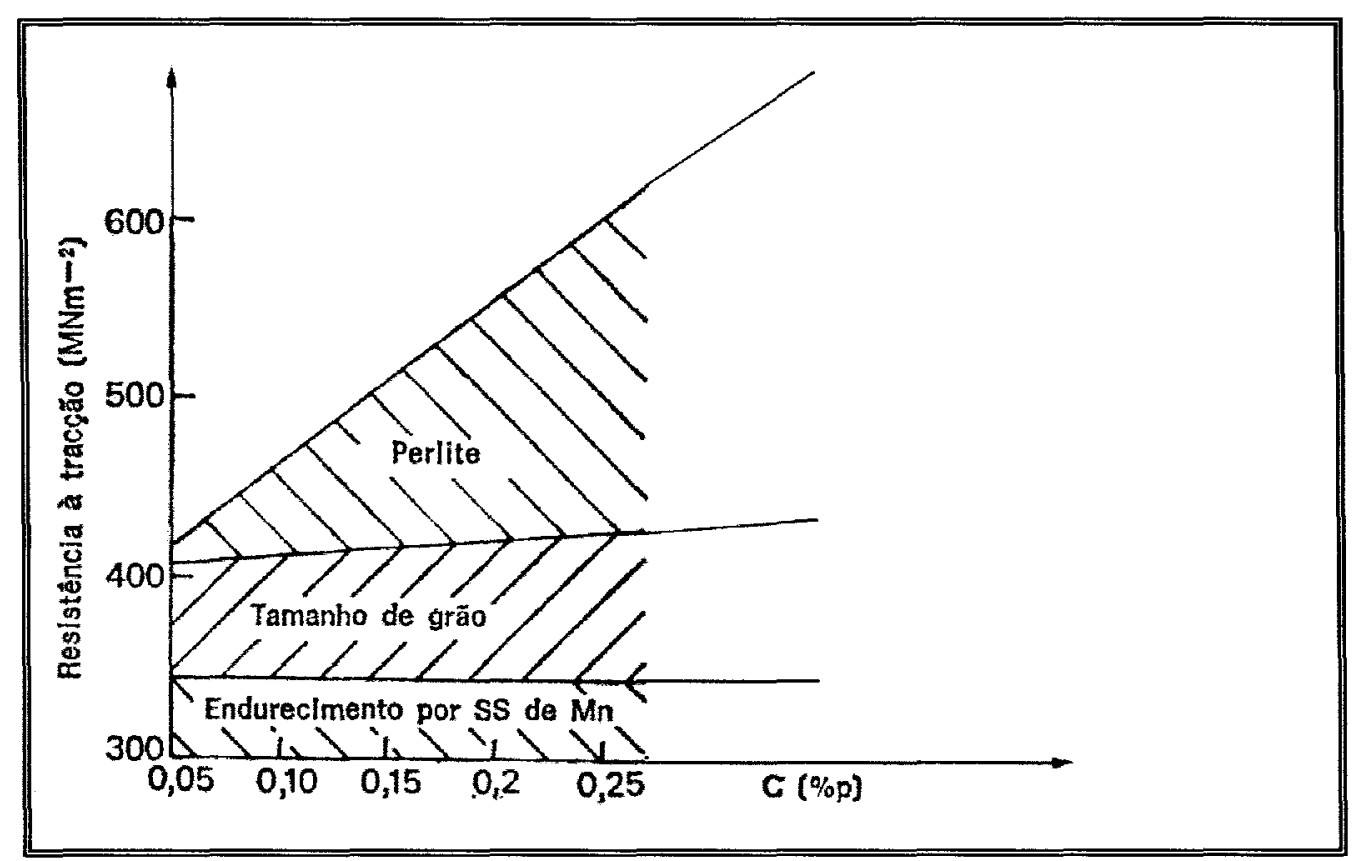

FIGURA 6 - Demonstra que, nos aços ao carbono no estado normalizado, o aumento da porcentagem em peso de carbono, faz crescer a porcentagem de perlita e conseqüentemente o limite da resistência à tração. 
No entanto, os elementos de liga, principalmente o manganês, podem influenciar a formação da perlita, conseqüentemente o limite de resistência à tração, conforme a figura 7 .

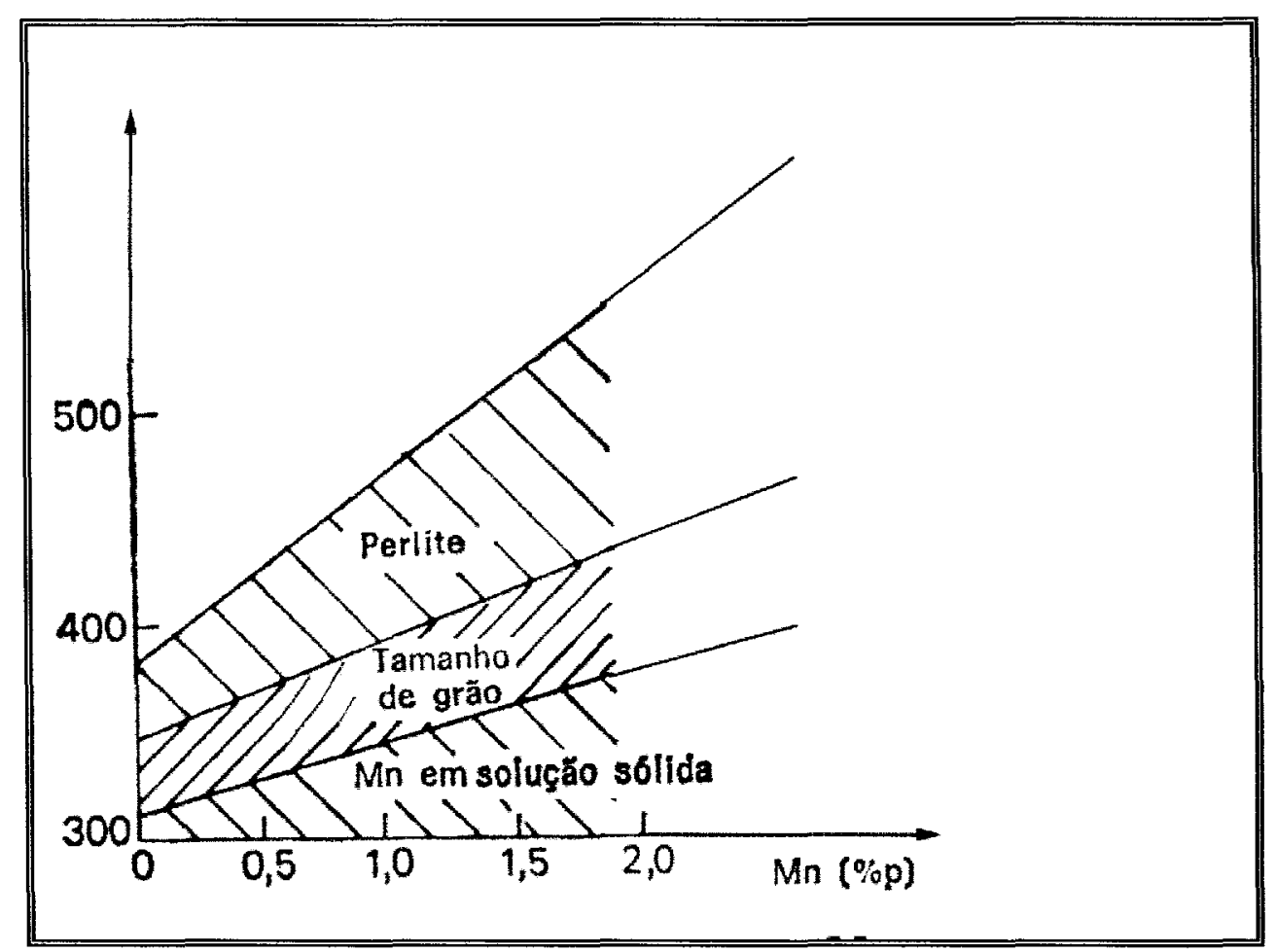

FIGURA 7 - Demonstra o aumento do limite de resistência à tração com aumento da variação da porcentagem em peso do manganês.

Segundo PICKERING (1978), dizer que os aços estão normalizados, significa eles possuem também tamanhos de grão razoavelmente semelhantes.

\section{II.2 - Método teórico de quantificação de fases}


No método teórico de quantificação de fase, é empregada a técnica da regra da alavanca. Segundo VAN VLACK (1984), MEI \& SILVA (1988),WEST (1982), essa técnica consiste em utilizar um segmento de reta que liga os pontos representativos das composições de duas fases em equilíbrio. Isto implica que um segmento da reta é isobárico e isotérmico e como tal sua projeção vertical se apresenta em verdadeira grandeza sobre a composição, conforme o diagrama hipotético ilustrado pela figura 8.

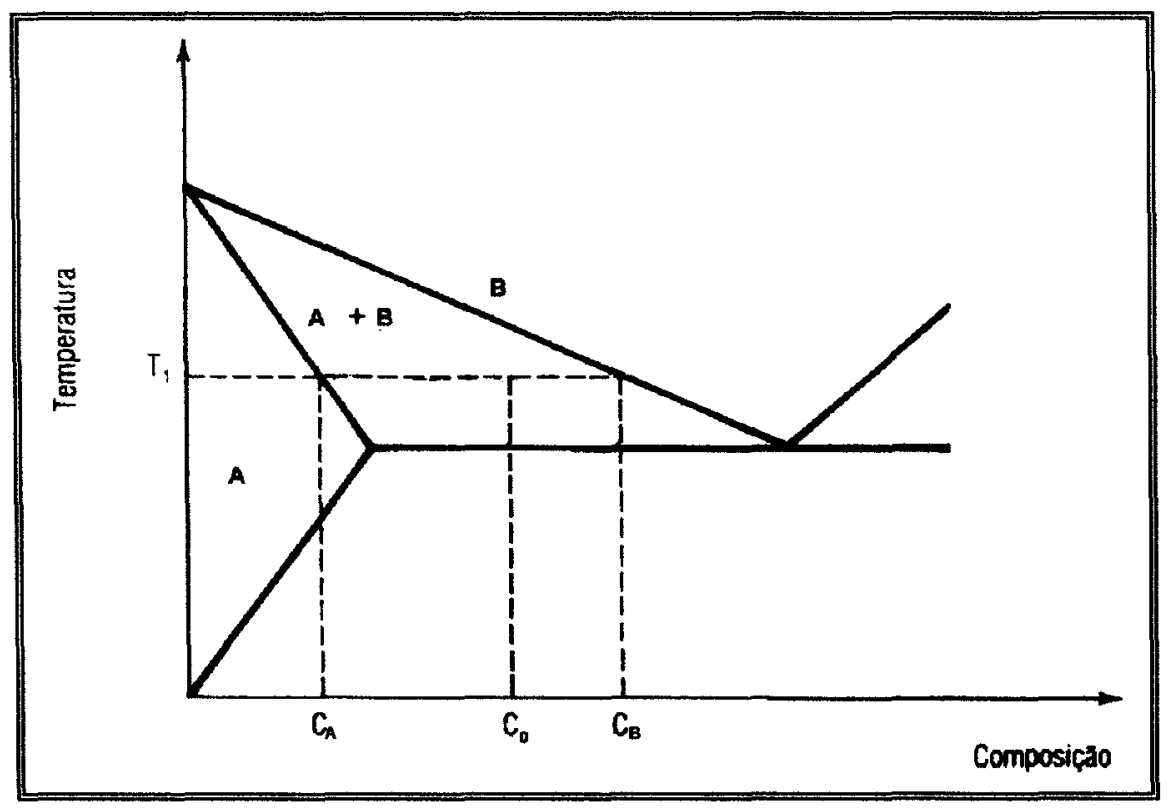

FIGURA 8 - llustra um segmento de reta que liga os pontos representativos das composições de duas fases em equilíbrio.

Assim, através da composição química predeterminada, é possivel prever aproximadamente a porcentagem de fases de uma liga metálica. Sendo assim, tomou-se como exemplo uma isotérmica $T_{1}$ e determinou-se a porcentagem da fase $\mathrm{A}$ e a da fase $\mathrm{B}$, no ponto de concentração Co, conforme as equações 1 e 2.

$\%$ FASE $A=\frac{\left(C_{B}-C_{0}\right)}{\left(C_{B}-C_{A}\right)} 100$ 
\% FASE B $=\frac{\left(\mathrm{C}_{\mathrm{o}}-\mathrm{C}_{\mathrm{A}}\right)}{\left(\mathrm{C}_{\mathrm{B}}-\mathrm{C}_{\mathrm{A}}\right)} 100$

Conforme GOODMAN et al. (1981), PORTER \& EASTERLING (1990), HERTZ (1992), se considerar o diagrama de fase ferro- $\mathrm{Fe}_{3} \mathrm{C}$ em equilibrio termodinâmico, observam-se várias fases para diferentes temperaturas, conforme ilustra a figura 9.

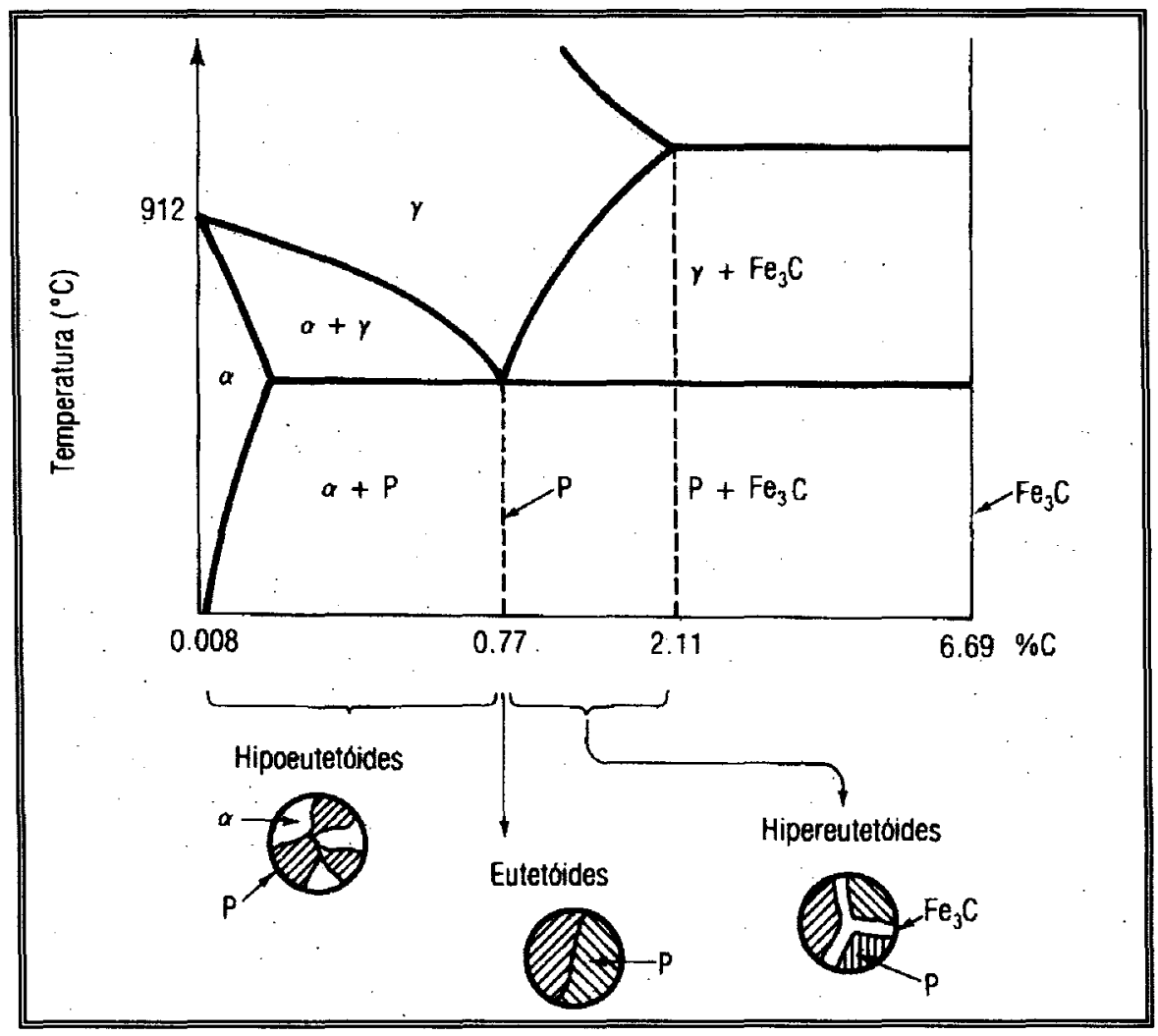

FIGURA 9 - Diagrama de fases $\mathrm{Fe}-\mathrm{Fe}_{3} \mathrm{C}$, onde se observam as fases Perlita $(P)$, Ferrita $(\alpha)$, Austenita $(\gamma)$, Cementita $\mathrm{Fe}_{3} \mathrm{C}$.

HERTZ (1992), em suas revisões, relata que essa relação geométrica é, por sua vez, resultado da aplicação do princípio da conservação da matéria. Quando se determina a porcentagem de

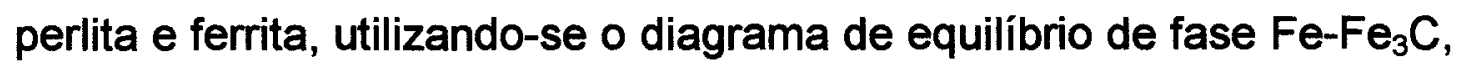
considera-se 0 aço ao carbono comum como sendo uma liga binária adição. A porcentagem de elementos de liga não é levada em consideração. Segundo CHIAVERINI (1984), MEI \& SILVA (1988), a presença dos elementos alfagênios acarreta a ampliação do campo 
correspondente à ferrita, aumentando sua estabilidade e diminuindo o campo de estabilidade da austenita. A literatura exemplifica alguns elementos alfagênios tais como $\mathrm{Cr}, \mathrm{Mo}, \mathrm{Ti}, \mathrm{Al}, \mathrm{W}, \mathrm{V}, \mathrm{Si}, \mathrm{Nb}$ etc.

Outros elementos quando adicionados são classificados como gamagênios, ex. $\mathrm{Mn}, \mathrm{Ni}$, Co etc., que atuam no sentido de ampliar o campo de existência da austenita, reduzindo ou mesmo eliminando o campo de existência da ferrita. A temperatura eutetóide diminui e o ponto eutetóide é deslocado para a esquerda. Assim, mesmo com o resfriamento muito lento da ligas de aço ao carbono, a porcentagem de microconstituinte perlita formada é influenciada pelo elemento de liga residual.

Sendo assim, na utilização do método teórico de quantificação de fase, cada liga requer um diagrama específico devido à influência dos elementos de liga que estão presentes. Segundo CHIAVERINI (1984), MEI \& SILVA (1988), no método teórico de quantificação de fase, considera-se a quantificação de fase de uma liga com aproximações. Isto porque, para obtermos com precisão a porcentagem de fase, utilizando o método teórico, teriamos de ter um diagrama específico para cada liga conforme VAN VLACK (1984), HONEYCOMBE \& BHADESHIA (1995).

No entanto, estes métodos ainda são empregados na indústria e no meio científico com grandes restrições à sua viabilidade técnica, em virtude da elevada demanda de tempo na construção de diagramas específicos da cada liga metálica.

\section{II.3 - Microscópio óptico}


A história do microscópio óptico, segundo THOMAS (1995), começa na antigüidade clássica com a lente de aumento simples, e apresenta um "renascimento" no século XVII. Desde então, sua tecnologia foi aperfeiçoada até atingir, no começo deste século, as limitações de resolução impostas pela luz visível. Segundo MAKEMSON et al. (1995), atualmente existem técnicas de microscopia que não utilizam luz visível (Ultravioleta, raios - X, microscópio eletrônico, microscópio acústico, microscópio de tunelamento e de força atômica (SMT), etc...) e que permitem em alguns casos atingir resoluções da ordem atômica No entanto, conforme PADILHA (1997), o microscópio óptico é o instrumento mais prático e simples para a observação de microestruturas na faixa entre 1 centímetro e 1 mícron.

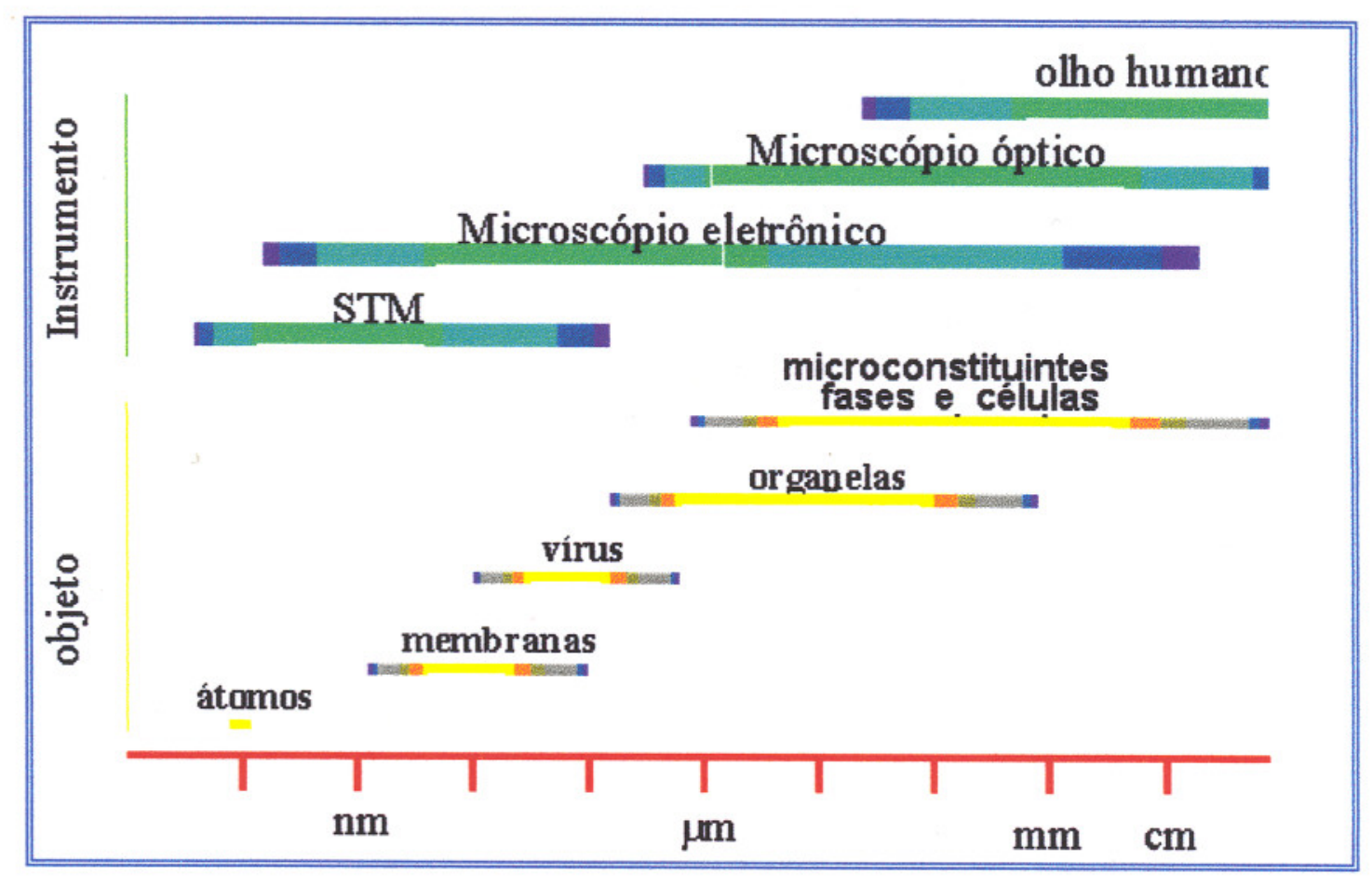

FIGURA 10 - Faixas de operação de microscópios em unidade de comprimento e objetos de interesse.

\section{II.3.1 - Elementos mecânicos do microscópio óptico}


Segundo KEHL (1949), FASANO (1980), é um conjunto de peças mecânicas de precisão com a finalidade de posicionar, deslocar e focalizar as amostras. Os elementos mecânicos subdividem-se em:

\section{II.3.1.1- Estativa}

A estativa é um suporte ou a base do aparelho, de construção sólida e pesada para evitar vibrações. Sustenta os demais elementos mecânicos, ópticos e fotográficos.

\section{II.3.1.2 - Platina}

A platina, de formato circular ou quadrado é onde se deposita a amostra para observação. Geralmente contém um dispositivo deslizante denominado Charriot. Dependendo da posição da platina, será denominado de platina invertida ( ou Le Chatelier) e de observação direta.

\section{II.3.1.3 - Tubo de encaixe}

O tubo de encaixe, que pode ser tanto monocular como binocular, possui formato cilíndrico, desde o encaixe da ocular até 0 revólver porta-objetivas. O comprimento, denominado de mecânico, é responsável pelo desempenho óptico do aparelho, sendo, pois a sua observação, condição indispensável para o pleno aproveitamento de suas qualidades ópticas. Usualmente é de $160 \mathrm{~mm}, 170 \mathrm{~mm}$ ou mesmo de outra medida.

\section{II.3.1.4 - Focalização}


A focalização consiste em um sistema mecânico de precisão composto de cremalheira e pinhão. A focalização macrométrica ou grosseira permite variar a distância entre a amostra e a objetiva; enquanto a micrométrica ajusta com precisão o tubo de encaixe, tendo geralmente um curso de deslocamento máximo de $2 \mathrm{~mm}$.

\section{II.3.1.5 - Revólver porta-objetiva}

O revólver porta-objetiva, segundo RICHARDSON (1971), é um tambor rotativo com 4 ou 5 orifícios providos de rosca, nos quais são alojadas as objetivas, que devem sempre ser colocadas em ordem crescente de aumentos.

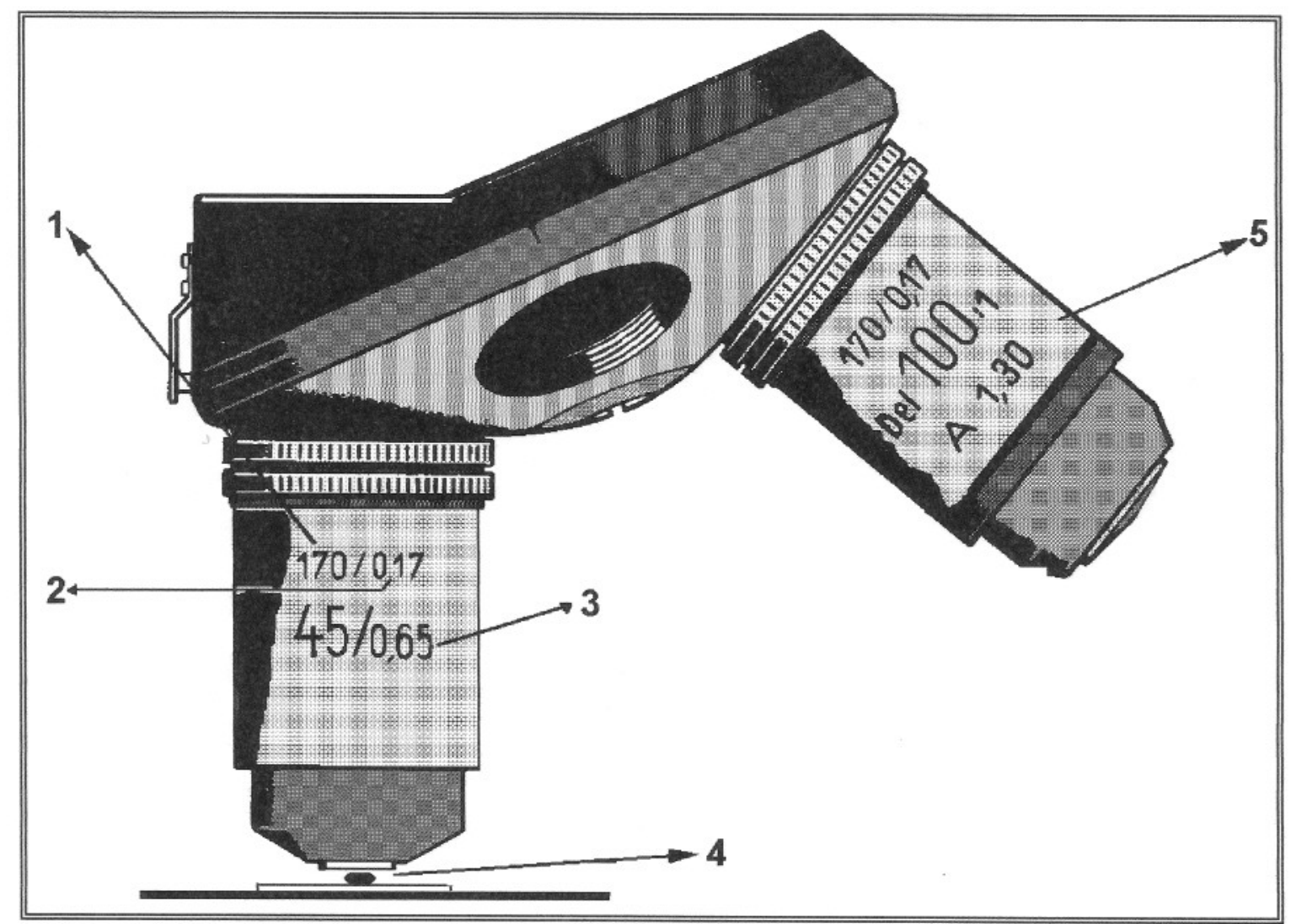

FIGURA 11 - Ilustra o revolver porta objetiva (RICHARDSON 1971). Legenda:

1. A objetiva é corrigida para um comprimento de tubo $170 \mathrm{~mm}$

2. Espessura da tampa de vidro 
3. A escala da imagem intermediária é $45: 1$, a abertura numérica da objetiva 0,65 .

4. Distância livre de trabalho

5. Imersão a óleo a escala de reprodução da imagem é 100:1, a abertura da objetiva é 1,30

\section{II.3.2 - Microscópio óptico LEITZ DMRX (LEICA)}

O microscópio óptico LEITZ DMRX, está representado pela figura 12, na qual observa-se os principais elementos mecânicos de controle.

1. Parafuso de fixação do tubo

2. Lentes auxiliar removivel (Bertrand)

3. Refletor/ sistema de blindado (turret)

4. Polarizador luz incidente

5. Contraste de interferência da objetiva (turret)

6. Condensador blindado (turret)

7. Anel de cobertura

8. Cartucho de filtro

9. Módulo do diafragma de luz incidente 10.Controle da movimentação superior da platina 11.Chave de sustentação da platina

12.Botão de ajuste macrométrico e micrométrico 13.Interruptor (seletor) para luz incidente e luz transmitida 14. Interruptor da luz

15. Cartucho de filtro para luz transmitida 


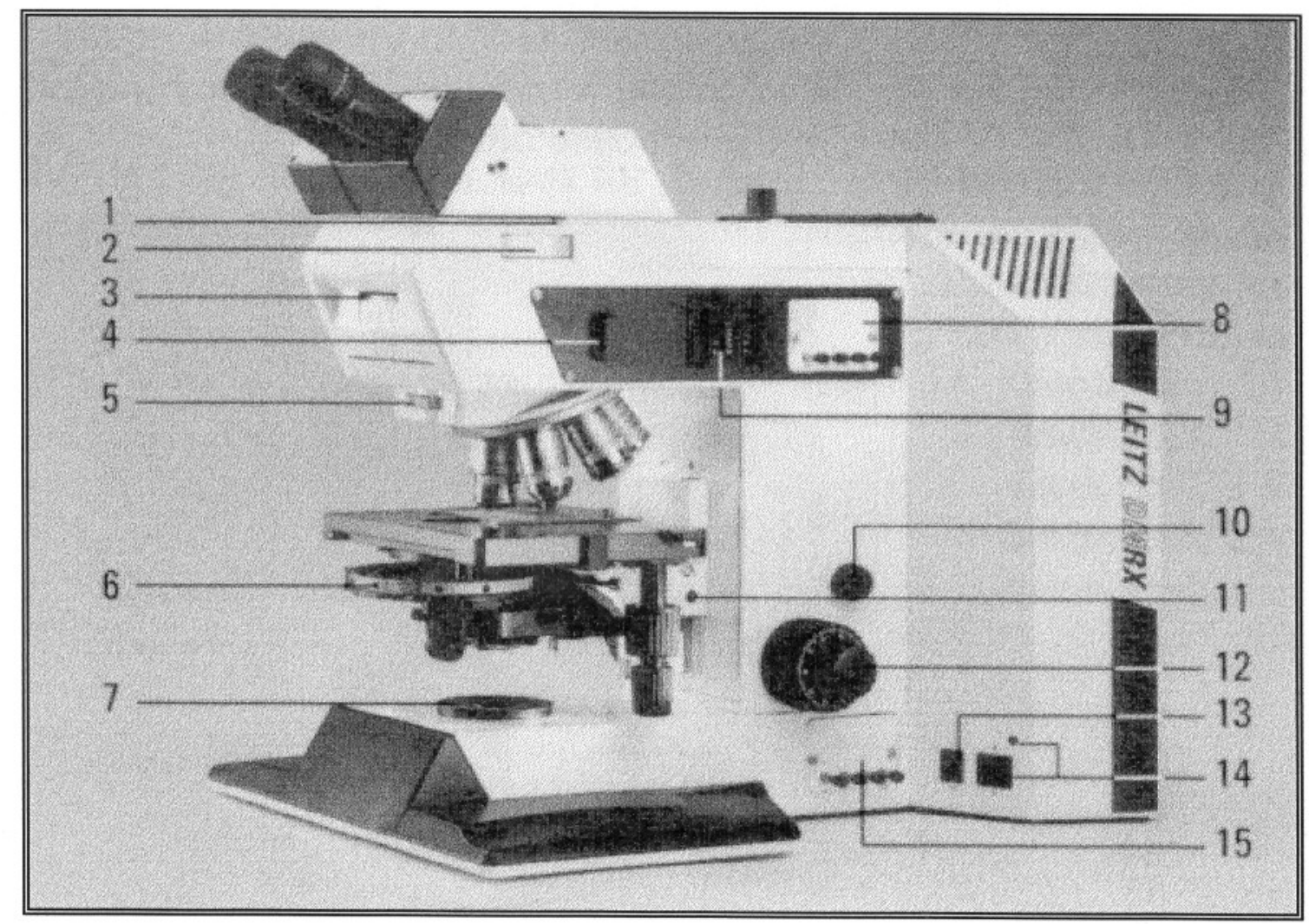

FIGURA 12 - Ilustra os ajustes mecânico do microscópio óptico LEITZ DMRX, Operator's Guide LEITZ DMRX.

\section{II.3.3 - Sistema de iluminação do microscópio óptico}

Segundo VOORT (1995), além do sistema de formação de imagens, o microscópio deve ter um sistema de iluminação adequado. A lâmpada comumente utilizada é a de filamento de tungstênio para permitir o controle da sua intensidade de corrente no filamento. A figura 13 , ilustra um esquema de iluminação e formação do imagens do microscópio óptico. 


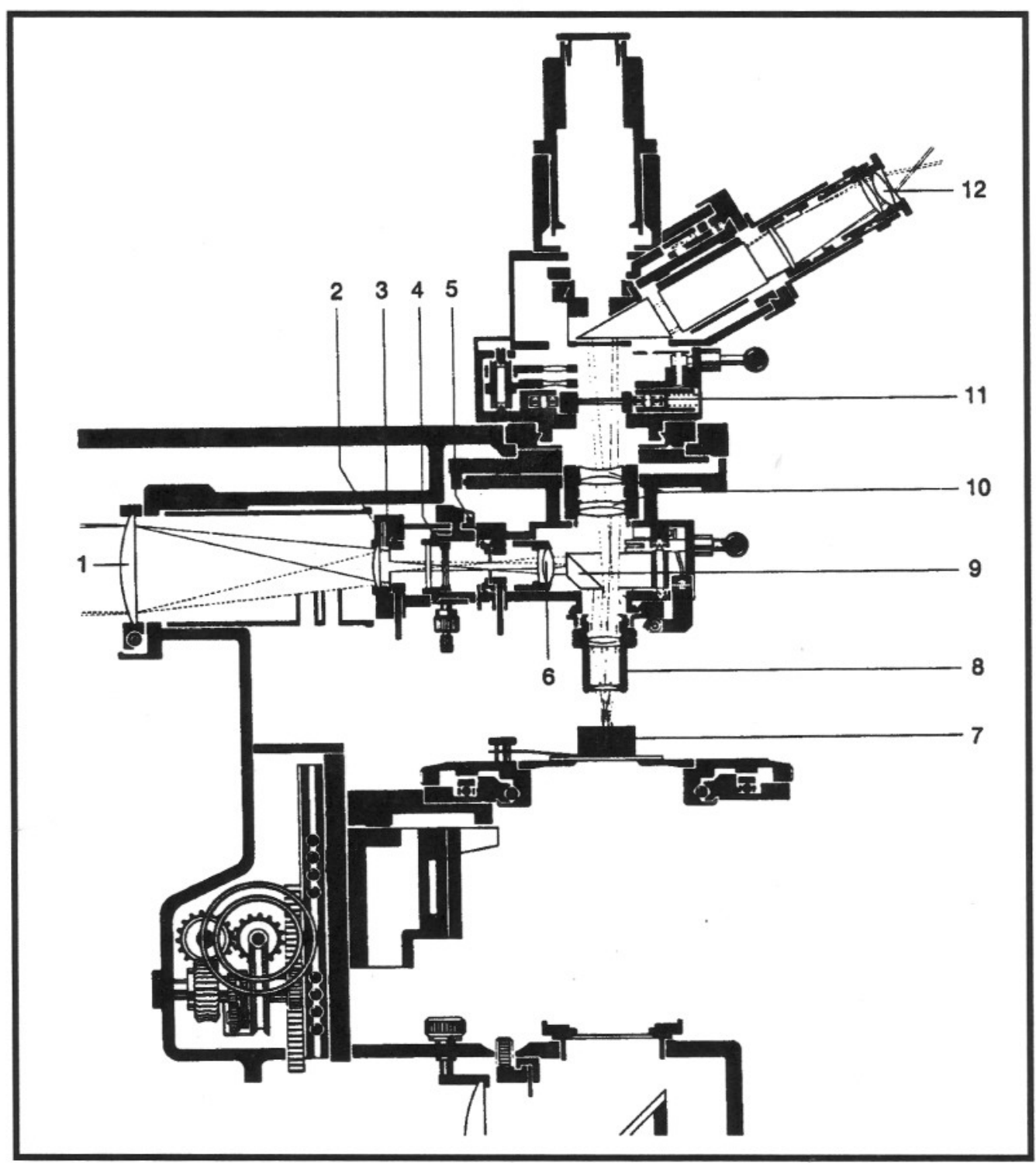

FIGURA 13 - llustra o caminho da luz através do sistema óptico do utilizando microscópio luz polarizada. VOORT (1995).

Descrição do sistema de iluminação e de formação de imagem do microscópio óptico, conforme VOORT (1995).

\section{II.3.3.1 - Lente coletora ou condensador}

O condensador consiste de um sistema de lentes convergentes, cuja finalidade é concentrar e transmitir o feixe luminoso para a lente frontal. 


\section{II.3.3.2 - Lente auxiliar}

Tem a mesma função da lente coletora e é utilizada para concentrar mais luz.

\section{II.3.3.3 - Diafragma de abertura ou diafragma da íris.}

É uma parte integrante do sistema de iluminação, usada para controlar a quantidade de luz na iluminação do objeto, visando elevar a qualidade da imagem no microscópio, da câmera fotográfica e do sistema de análise de imagem.

\section{II.3.3.4 - Filtro ou polarizador}

Filtros são dispositivos interpostos na trajetória da luz com finalidades diversas, tais como absorção de radiação ultravioleta e infravermelha. A finalidade de um filtro é absorver as radiações indesejáveis e transmitir as desejáveis numa faixa estreita e selecionada. Tais filtros são usados primeiramente para fornecer uma iluminação de qualidade, compatível com a correção correspondente a cada objetiva, assegurando uma melhor definição e resolução da imagem. O filtro verde e o filtro amarelo são aconselháveis para trabalhos com a objetiva cromática. O filtro azul é indicado para uso com objetiva apocromática. Uma vantagem que o filtro azul apresenta, em relação ao verde, é que o comprimento de onda da radiação azul é inferior ao do verde, e fornece uma resolução superior à dele. $O$ poder de resolução, portanto, pode ser definido como a capacidade de uma lente de fornecer detalhes de um objeto ou então, a menor distância entre dois pontos que se consegue definir com nitidez. 
Para visualizar detalhes microestruturais, o microscópio óptico deve possuir um bom poder de resolução segundo FASANO (1980); VOORT (1995).

A expressão matemática que permite determinar o poder de resolução (R) é dada por :

$\mathrm{R}=\frac{\mathrm{K} \times \lambda}{\mathrm{AN}}$, onde o poder de resolução $(\mathrm{R})$ é a menor distância entre dois pontos que se consegue definir com nitidez. A figura 14 ilustra a resolução em função da abertura numérica, onde $\lambda$ é o comprimento de onda (em angstrom) da luz utilizada na observação, AN é a abertura numérica da objetiva utilizada e $\mathrm{K}$ é uma constante do microscópio óptico $(0,5$ ou 0,61$)$.

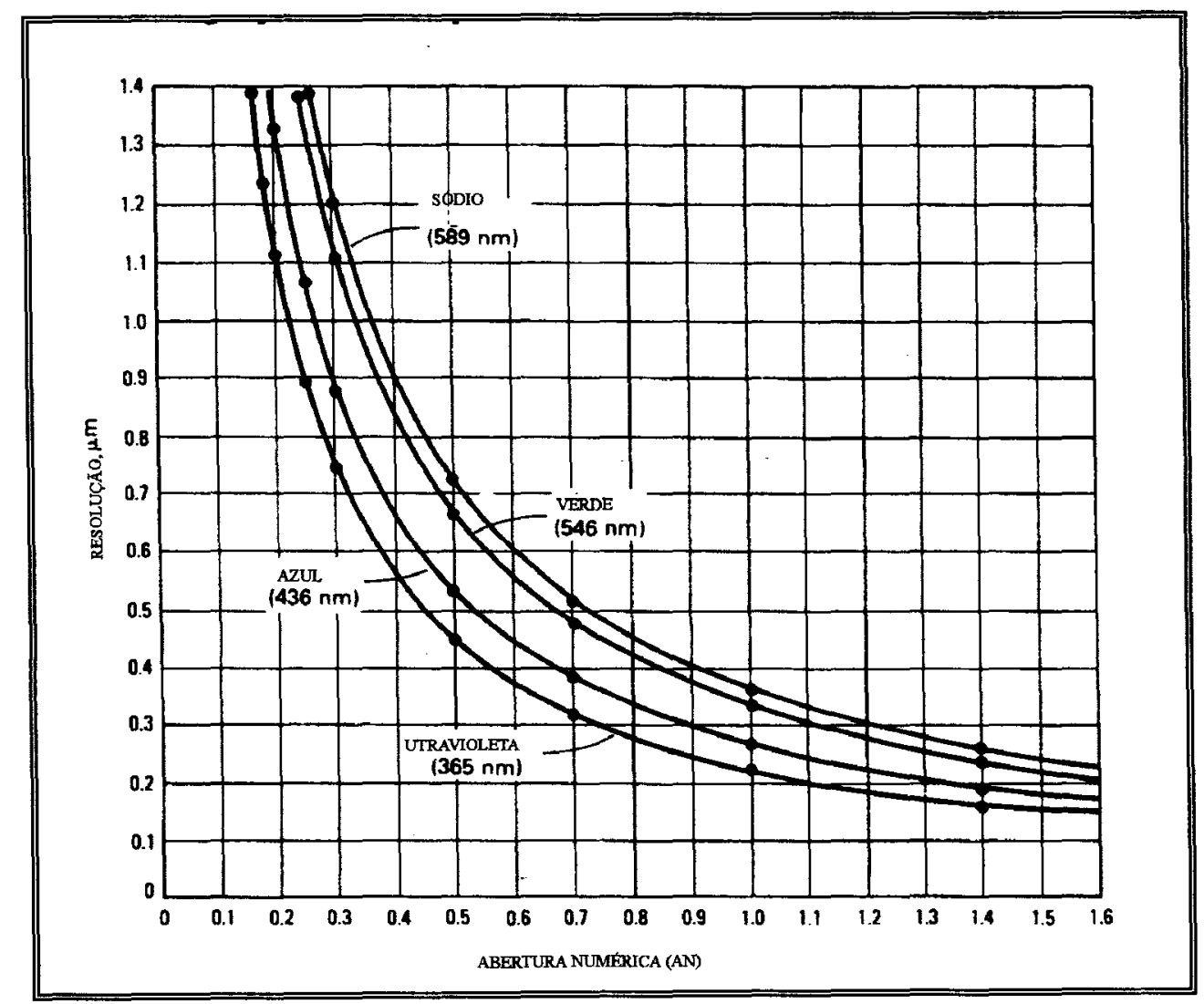

FIGURA 14 - Observa-se que o poder de resolução decresce com o aumento da AN e com a diminuição de $\lambda$ "Optical Microscopy" ASM,1995. 


\section{II.3.3.5 - Diafragma de campo}

É utilizado para a centralização da luz do campo. A descentralização provoca formação de manchas nos cantos das imagens

\section{II.3.3.6 - Lente de centralizacão}

É um dubleto ( lente dupla) utilizado para a centralização.

\section{II.3.3.7 - Amostra}

\section{II.3.3.8 - Objetiva}

O aumento é calculado pelo produto da ampliação da objetiva, pelo aumento da ocular.

\section{II.3.3.9 - Semi-espelho $50 / 50$}

A luz proveniente da lâmpada de centralização (prisma) sofre um desvio de $90^{\circ} \mathrm{em}$ direção à amostra.

\section{II.3.3.10 - Tubo de lente}

A principal função do tubo de lente é concentrar a luz.

\section{II.3.3.11 - Analisador rotativo}

Segundo VOORT (1995), em conjunto com o filtro polarizador possibilita a passagem de mais ou menos luz conforme figura 15 


\section{II.3.3.12 - Acessórios}

O microscópio metalográfico permite o acoplamento de vários acessórios:

Tais como:
a)- Câmeras (CCD/RGB).
b)- Monitor de vídeo colorido (SONY).
c)- Impressora vídeo
d)- Dispositivos fotográficos.
e)- Retículos (escala micrométrica), gravados em uma placa de vidro óptico, geralmente circular, que são montados no recesso da ocular.

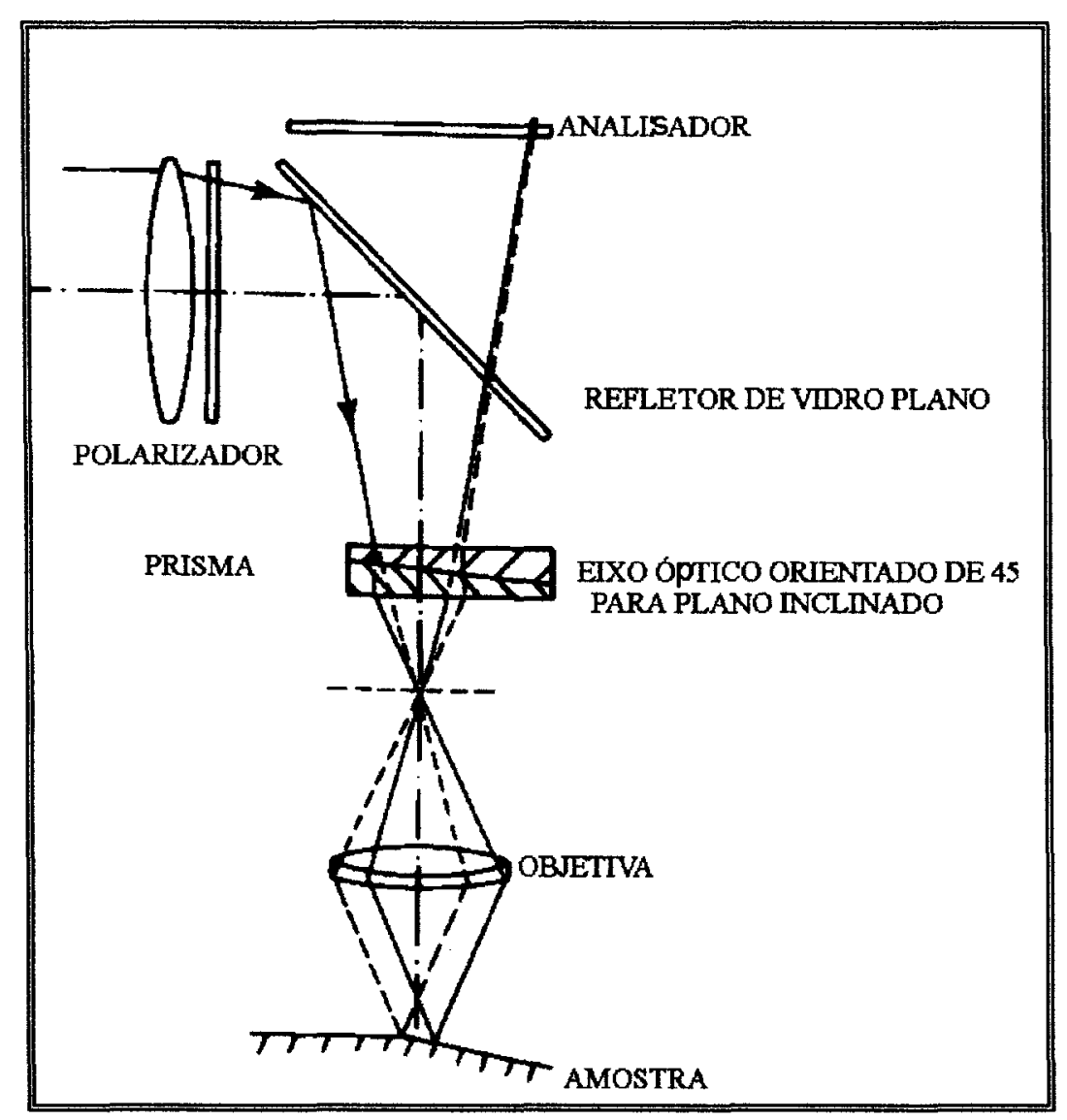

FIGURA 15 - llustra o conjunto polarizador e analisador ASM, 1995 


\section{II.4 - Método de quantificacão de fase manuais}

COLPAERT (1974) avaliou aproximadamente o teor de carbono em função da área de perlita para aços hipoeutetóides recozidos, utilizando imagens fotográficas das microestruturas com a influência dos elementos de ligas adicionais.

A técnica utilizada por COLPAERT (1974) consiste em pesar a fotografia e recortar a parte correspondente aos microconstituintes. Assim, a porcentagem de microconstituintes era dada pelo peso do papel correspondente ao microconstituintes, dividido pelo peso total do papel. Observou que a quantidade de perlita variava linearmente de $0 \%$ para o ferro puro, a $100 \%$ para aço com $0,8 \%$ de carbono.

Com os dados obtidos montou-se o gráfico, conforme a figura 16.

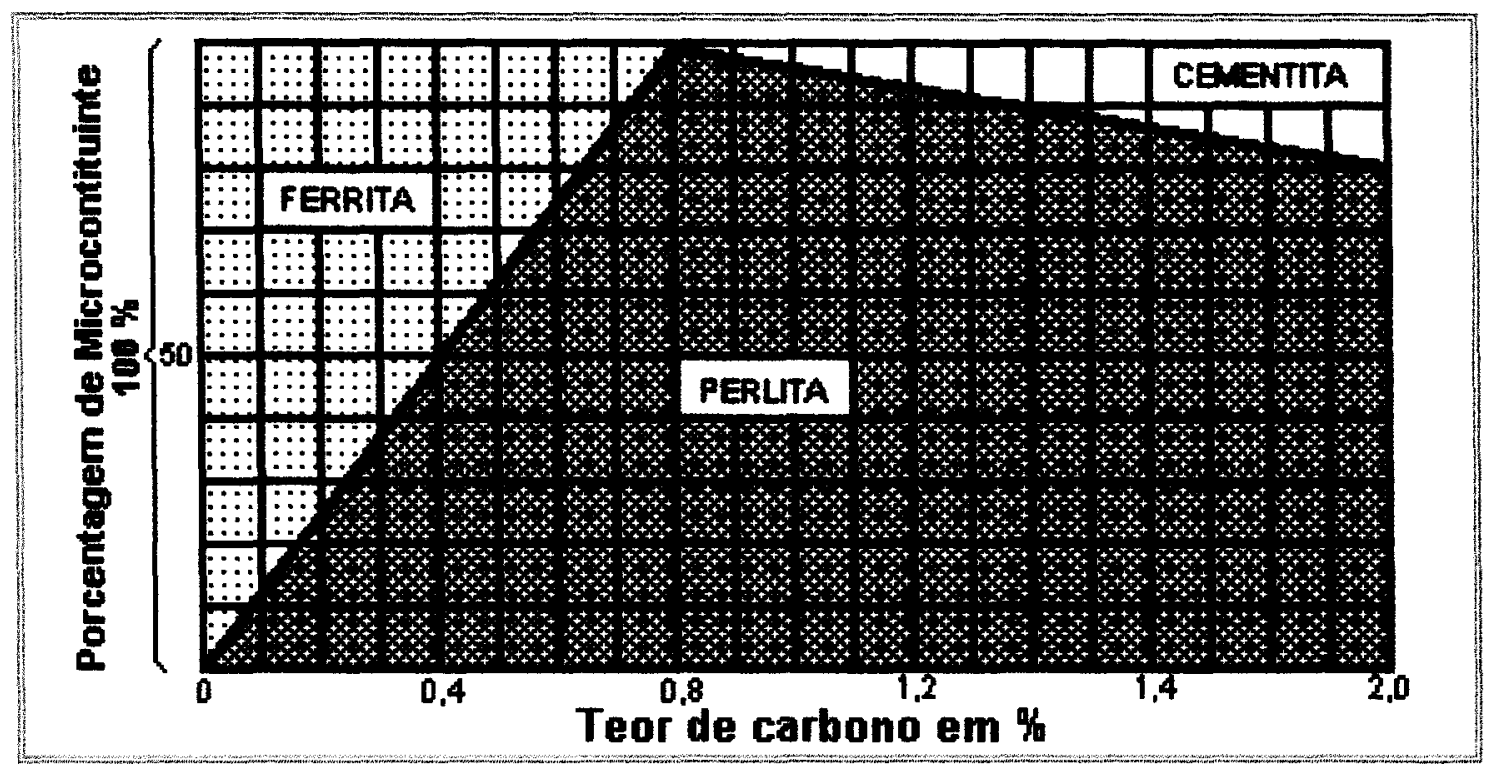

FIGURA 16 - O gráfico mostra aproximadamente a porcentagem dos microconstituintes das ligas de ferro ao carbono comuns, quando esfriadas lentamente (COLPAERT 1974).

Porém, a percentagem aparente de perlita nem sempre é proporcional ao teor de carbono. Normalmente, se o manganês for um pouco elevado, observa-se que $1 \%$ Manganês dificulta a difusão do 
carbono nos contornos de grãos da austenita, conforme COLPAERT (1974).

Conforme UNDERWOOD (1995), PADILHA (1997), a metalografia quantitativa posteriormente desenvolveu vários métodos estatísticos para quantificar com maior precisão as fases presentes, tais como: número de interseções por umidade de linha-teste, fração de pontos (número de pontos incidentes na fases de interesse pelo número total de pontos da grade), etc...

HEIN et al. (1994), em suas revisões, destacam que esses métodos estatísticos são empregados em toda a indústria e no meio científico com grandes restrições quanto à sua viabilidade técnica, em virtude da elevada demanda de tempo e baixa reprodutibilidade de resultados.

\section{II.5 - Método de contagem de pontos manual}

Segundo MENEZES \& BASTIAN (1974), PADILHA \& AMBROZIO (1985), UNDERWOORD (1995), essa técnica é a mais utilizada entre os métodos manuais de quantificação de fases manuais. Consiste basicamente na aplicabilidade de uma rede de "pontos teste" sobre uma área da fotomicroestrutura. O número de pontos que caem sobre as áreas de interesse, isto é da fase, é contado para uma primeira posição da rede de pontos. A rede é então deslocada para a posição seguinte, aleatoriamente ou em uma determinada direção, e o número de pontos que caem sobre o objeto de interesse é novamente contado.

Segundo HILIARD (1966), MENEZES \& BASTIAN (1974), ASTM E 562-1989, a fração de pontos $P_{p}$, pode ser calculada dividindo-se o número total de pontos $P_{i}$, contados sobre os objetos de interesse, 
pelo número total de pontos do reticulado $\mathrm{P}$, sendo que os pontos que eventualmente caírem nos contornos dos objetos de interesse serão contados como $1 / 2$ segundo a equação 3 , onde :

$$
P_{p}=\frac{P_{i}}{P}
$$

3

Segundo GLADMAN \& WOODHEAD (1960) a metalografia quantitativa utiliza muitas determinações que precisam ser tratadas estatisticamente. Para determinar a média aritmética da fração de ponto utiliza-se a equação 4 :

$$
\overline{\mathbf{P}}_{\mathrm{P}}=\frac{1}{\mathrm{n}} \sum_{\mathrm{i}=1}^{\mathrm{i}=\mathrm{n}} \overline{\mathbf{P}}_{\mathrm{P}}(\mathrm{i})
$$

onde: $\overline{\mathrm{P} p} \rightarrow$ é a fração de ponto média

$$
\mathrm{n} \rightarrow \text { é o número de medida. }
$$

Conforme UNDERWOORD (1995), PADILHA (1997), muitos dos parâmetros em terceira dimensão, como fração volumétrica, podem ser obtidos por meio de relações em duas dimensões. A equação 5 representa as inter-relações entre os parâmetros microestruturais.

$$
P_{P}=\bar{A}_{A}=\bar{V}_{V}
$$

onde:

$V_{V} \rightarrow$ é o valor esperado da fração volumétrica;

$A_{A} \rightarrow$ é o valor esperado da fração de área.

Estas inter-relações não são limitadas de forma alguma pela natureza geométrica do microconstituinte que deve ser avaliado, porém é necessário que se disponha de uma seção representativa da microestrutura e que esta seja uniformemente amostrada. 
O método manual de contagem de pontos, contido na norma ASTM 562-1989, trabalha com uma estimativa da precisão da fração volumétrica. Este método também necessita de um número relativamente grande de medidas, que permitam o uso dos conceitos estatísticos.

EXNER et al. (1993) exemplificaram como é efetuado o cálculo do erro experimental nas quantificações de fases, utilizando as recomendações da norma ASTM E 562-1989, e os conceitos estatísticos. Para tal procedimento tomou, como exemplo os 2 campos de uma microestrutura qualquer (hipotética), conforme ilustra a figura 17.

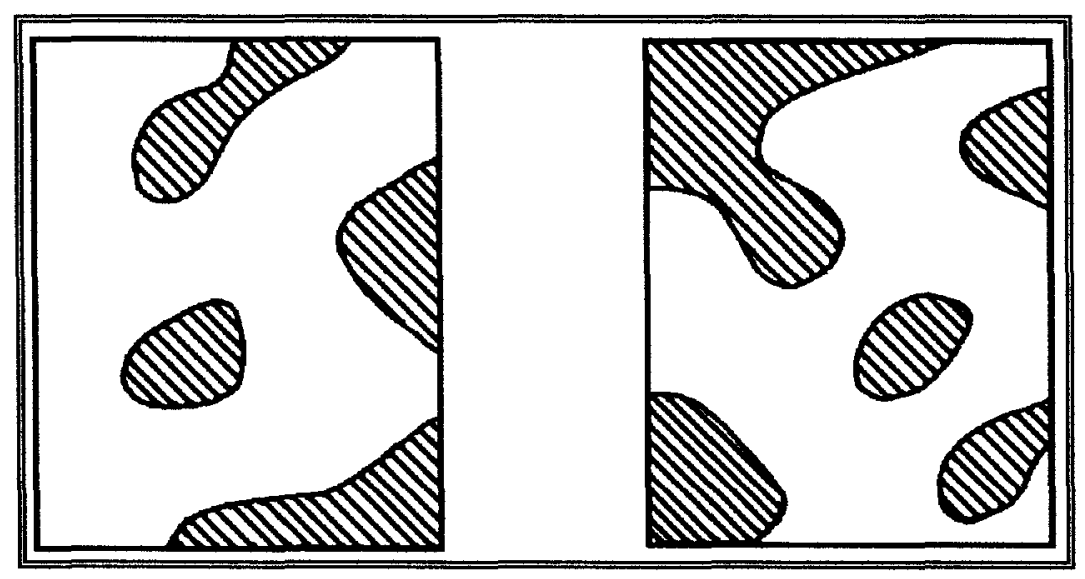

FIGURA 17 - llustra 2 campos de uma certa microestrutura.

Avaliou visualmente que o valor da fração volumétrica da fase escura da amostra encontra-se aproximadamente em torno de 0,3.

De posse deste valor avaliado e utilizando a tabela 3 , conforme editada pela ASTM E 562-89, pôde estimar qual o reticulado recomendado.

Este procedimento precede a determinação da fração volumétrica estimada. 
TABELA 3: Reticulado ou "Grade", recomendada para diferentes frações volumétricas

\begin{tabular}{|ccccccc}
\hline$V_{V}$ & $>0.2$ & $0.1-0.2$ & $0.05-0.1$ & $0.02-0.05$ & $(<0.02)$ \\
\hline Reticulado & $4 \times 4$ & $5 \times 5$ & $7 \times 7$ & $10 \times 10$ & $30 \times 30$ \\
\hline$P$ & 16 & 25 & 49 & 100 & 900
\end{tabular}

Para uma fração volumétrica avaliada visualmente em torno de 0,3 , a rede recomendada, segundo a tabela 3 , é de 16 pontos. Esta é sobreposta em 4 campos diferentes e os pontos que caem sobre os objetos das "fases escuras" foram contados.

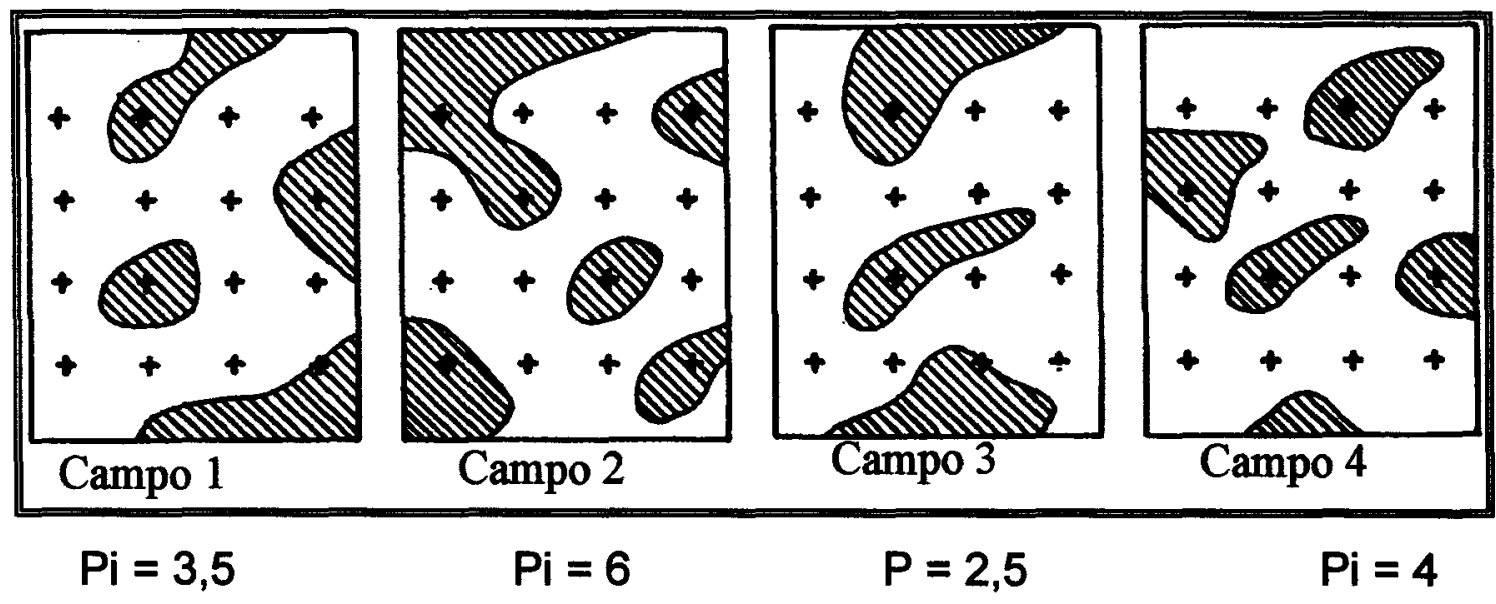

FIGURA 18 - llustra exemplos de quatro imagens de uma liga metálica.

O somatório dos números de pontos que caem dentro do contorno dos objetos é dado por:

$\sum \mathrm{Pi}_{\mathrm{i}}=3,5+6+2,5+4=16$

Para determinar a fração volumétrica estimada com $n=4$ e $P=16$, utiliza-se a equação 4. 
$\overline{\mathrm{V}}_{\mathrm{v}}=\overline{\mathrm{P}}_{\mathrm{p}}=\frac{1}{\mathrm{n}} \frac{\sum \mathrm{P}_{\mathrm{i}}}{\mathrm{P}}$

4

ou, respectivamente: $\quad \overline{\mathrm{V}}_{\mathrm{v}}=\frac{16}{4 \times 16}=0,25$

Com a fração volumétrica estimada em 0,25 e utilizando-se a tabela III, estimou-se que o número de pontos da grade $P$ é de 16 pontos, pois $\overline{\mathrm{V}}_{\mathrm{v}}^{-}>0,2$

\section{II.5.1 - Número de campos necessário}

$\mathrm{Na}$ determinação do número de campos necessário, deve-se fixar o erro relativo. No exemplo da figura 17 , fixou-se que o erro pode ser no máximo $10 \%$ do valor medido.

PADILHA \& AMBROZIO (1985) mencionam que a diferença entre escolher uma precisão de $10 \%$ e $1 \%$ corresponde respectivamente à diferença entre $1 / 2$ hora e uma semana de trabalho.

O número de pontos total contados para esta precisão fixada é dado pela equação 6 :

$$
\mathrm{P}_{\mathrm{T}}=\sum \mathrm{P}=4 \frac{1-\mathrm{V}_{\mathrm{V}}}{\mathrm{V}_{\mathrm{v}}}\left(\frac{100}{\% E . r}\right)^{2}
$$

ou, respectivamente: $\quad P_{\mathrm{T}}=\sum \mathrm{P}_{i}=4 .(1-0,25) \cdot\left(\frac{100}{10}\right)^{2}=300$

O número de campos necessários para uma precisão de $10 \%$ é determinado pela equação 7 :

$$
\mathrm{n}=\frac{\sum \mathrm{P}_{\mathrm{i}}}{\mathrm{P} \times \mathrm{V}_{\mathrm{v}}}
$$


ou, respectivamente:

$$
\mathrm{n}=\frac{300}{16 \times 0,25}=75
$$

Neste exemplo assumiu hipoteticamente que 285 pontos caem dentro dos contornos dos objetos, quando utilizamos uma rede de 16 pontos, sobre 75 campos diferentes

A fração de volume e a medida do erro experimental para a microestrutura da figura 17 , foram determinadas utilizando-se as seguintes equações 4 e 8 .

$\mathrm{V}_{\mathrm{v}}=\frac{\sum \mathrm{P}_{i}}{\mathrm{P} x \mathrm{n}}$

ou, respectivamente: $\quad \mathrm{V}_{\mathrm{v}}=\frac{285}{75 \times 16}=0,238$

$\Delta=\sqrt{\frac{\mathrm{V}_{\mathrm{v}}\left(1-\mathrm{V}_{\mathrm{v}}\right)}{\mathrm{n} x \mathrm{P}}}$

ou, respectivamente: $\quad \Delta=2 \sqrt{\frac{0,238(1-0,238)}{75 \times 16}}=0,025$

A fração volumétrica real e o erro experimental do exemplo representado pela figura 17 selecionada são $\rightarrow \overline{\mathrm{V}}_{\mathrm{v}} \pm \Delta=0,24 \pm 0,025$.

$$
\text { Conforme MENEZES \& BASTIAN }
$$

UNDERWOORD (1985) e PADILHA (1997); Doc.No.IX-1533-88), vários métodos, alternativos vêm sendo aplicados para simplificar $\mathrm{e}$ agilizar este método que necessita de um número extremamente grande de campos a serem medidos. Um dos mais utilizados na rotina industrial e nos meios científicos, segundo MENEZES \& BASTIAN (1974), consiste em fixar o número de campos em 10 e o número de pontos da rede em 100 . 


\section{II.6 - Método de quantificação de fase automática}

Segundo SAVARY (1995), a análise de imagens é uma nova ferramenta utilizada no processamento dos parâmetros microestruturais, através da quantificação dos dados visuais. Esta ferramenta vem sendo aplicada em ciência dos materiais, principalmente para melhorar a confiabilidade e a rapidez na determinação dos parâmetros microestruturais. A primeira razão da necessidade de se adotar uma avaliação visual automatizada é que o ser humano pode ser enganado pelos seus sentidos, fenômeno chamado de ilusão óptica. A figura 19 ilustra alguns exemplos de ilusão óptica.

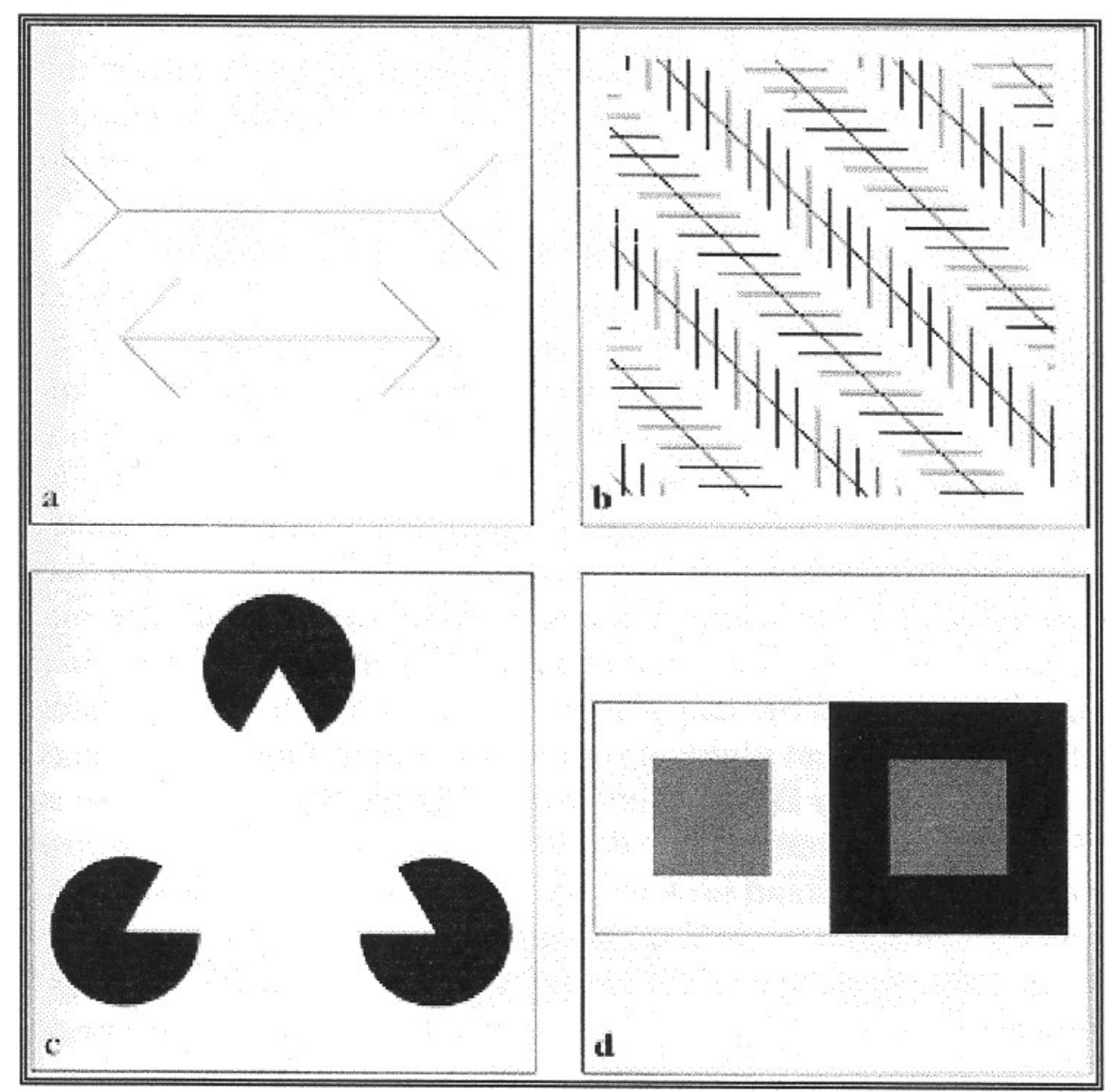

FIGURA 19 - Ilustra exemplos de ilusão ótica (RUSS 1995).

a - As linhas são idênticas em comprimento mas parecem diferentes. 
b - As linhas diagonais são paralelas.

c - O triângulo parece brilhar dentro das circunferências do papel.

d - Os dois centros dos quadrados têm brilhos iguais.

A segunda razão é que os adjetivos "grande", "pequeno", "muito" etc. não são suficientes para uma quantificação das imagens.

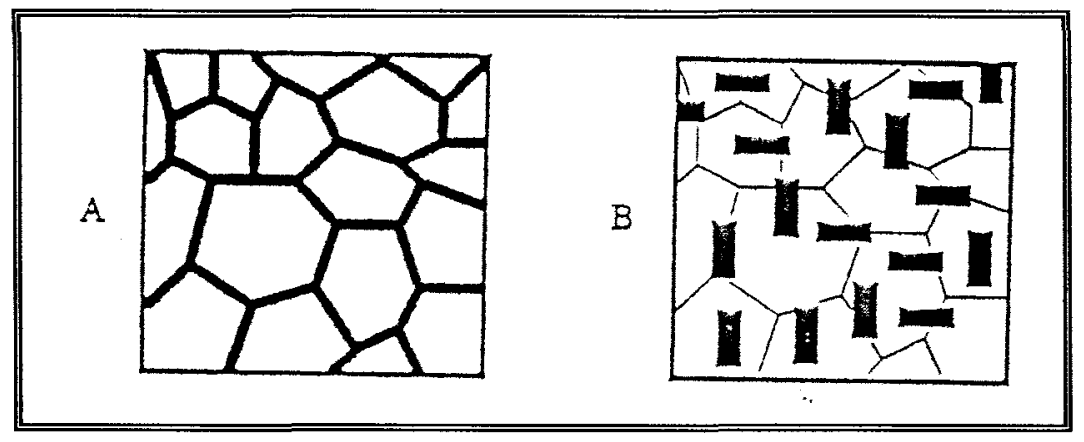

FIGURA 20 - llustra a dificuldade de perceber a real proporção de preto e de branco em uma imagem.

A terceira razão é que a imagem poderá precisar de um processamento antes da sua avaliação, seja por causa do ruído residual, seja porque a microestrutura a ser estudada não é explícita.

Finalmente, é mais fácil caracterizar um grande número de imagens através do computador que através da avaliação visual. Assim, valores estatísticos confiáveis podem ser obtidos, o que é fundamental na análise dos materiais.

Segundo SAVARY (1995), uma imagem torna-se visivel para o olho humano tal como uma série contínua de brilho e cor. $A$ análise de imagens realiza transformações sobre três tipos de imagens:

a) imagem de vídeo, que é um conjunto de sinais eletrônicos;

b) imagem digitalizada, que é uma tradução padronizada e "congelada" da imagem de vídeo; 
c) imagem binária, a partir da qual a informação desejada poderá ser extraída.

A passagem da imagem digitalizada à imagem binária se faz através de uma discriminação: os valores dos píxes, que podem variar de 1 a 255, são reduzidos para dois únicos valores: ( 0 e 1 ou preto e branco). Esta redução é feita através de algoritmos de segmentação. Geralmente, as regiões pretas correspondem aos objetos e as regiões brancas ao fundo.

\section{II.6.1 - Captura de imagem}

Segundo SAVARY (1995), a aquisição das imagens é um fator determinante para o sucesso da análise de imagens. Isto devido ao fato de a maioria das limitações e erros causados pelo processamento automátizado ter como origem uma aquisição incorreta. Um outro fator importante é não mudar as condições de trabalho como o focus, intensidade de luz, filtros polarizadores durante uma análise de um mesmo material.

Segundo PAZ \& CUNHA (1988), PACIORNIK (1996), existem vários dispositivos associados a várias aplicações que captam imagens tais como:

- Câmera fotográfica

- Câmera com tecnologia de tubo

- Câmera com tecnologia de estado sólido (CCD/RGB)

- Radar

- Ultra-som etc. 


\section{II.6.2 - Câmera com tecnologia de estado sólido}

Segundo RUSS (1995), PAZ \& CUNHA (1988), PACIORNIK (1996), as câmeras de estado sólido são as mais utilizadas para captar imagens das microestruturas, tais câmeras, usam a tecnologia CCD (Change Coupled Device). Possuem uma superfície composta de várias células formando uma matriz. Cada célula é formada por um cristal de silício fotossensível. Uma célula, ao receber um raio de luz, armazena uma carga com intensidade proporcional à luz recebida. Usando a mesma seqüência de varredura de uma $T V$, as informações são amplificadas e transferidas seqüencialmente para os dispositivos eletrônicos complementares.

Usando uma freqüência de deslocamento de 30 imagens por segundo, compatibilizamos este tipo de câmara com o padrão usado em TV. As câmeras de estado sólido são discretas tanto na horizontal quanto na vertical. Existem câmeras de baixa resolução ( $32 \times 32$ células), média

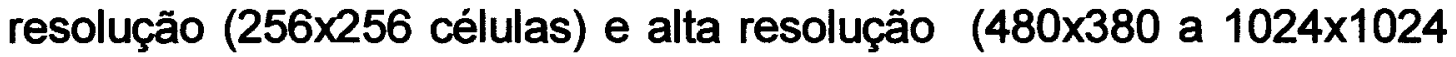
células).

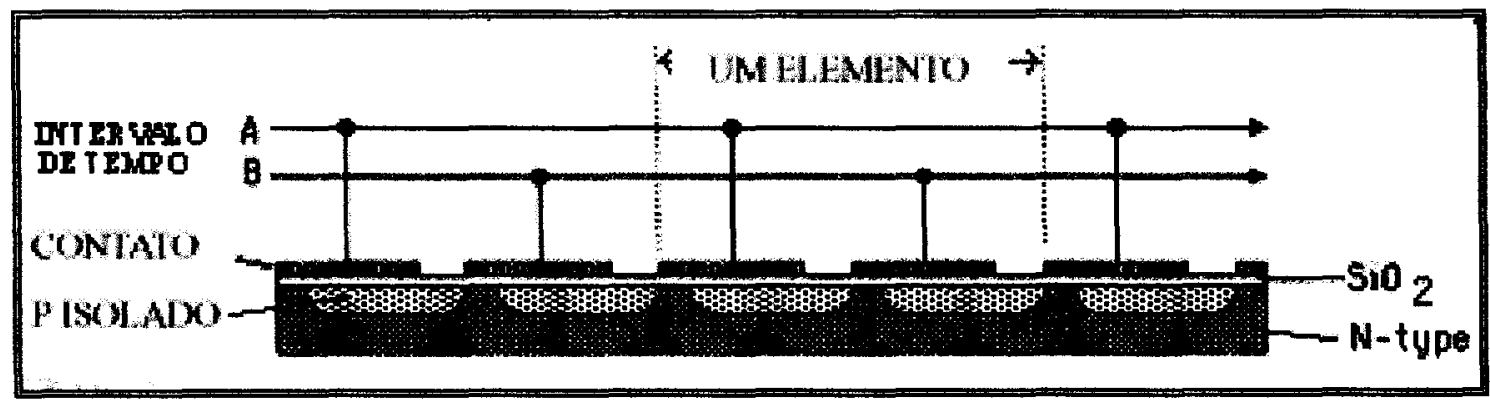

FIGURA 21 - Diagrama esquemático do chip na câmera de estado sólido. Cada sensor (célula) regista o sinal da iluminação incidente. proporcional à luz recebida. (RUSS 1995).

As informações são amplificadas e transferidas seqüencialmente para os dispositivos eletrônicos complementares. 


\section{II.6.3 - Formação de imagem colorida}

Uma imagem colorida é gerada pelo equivalente a três câmeras monocromáticas que operam conjugadas, cada qual responsável por sua cor padrão RGB ( red, green, blue). A informação coletada por um monitor de TV colorido é três vezes a de um monitor preto e branco. Um monitor de imagens coloridas possui três sistemas de geração de imagens, cada qual para a correspondente cor coletada pela câmera (RGB). A imagem é projetada em três telas distintas, conforme ilustra a figura 22, cada qual de um material emissor da cor correspondente.

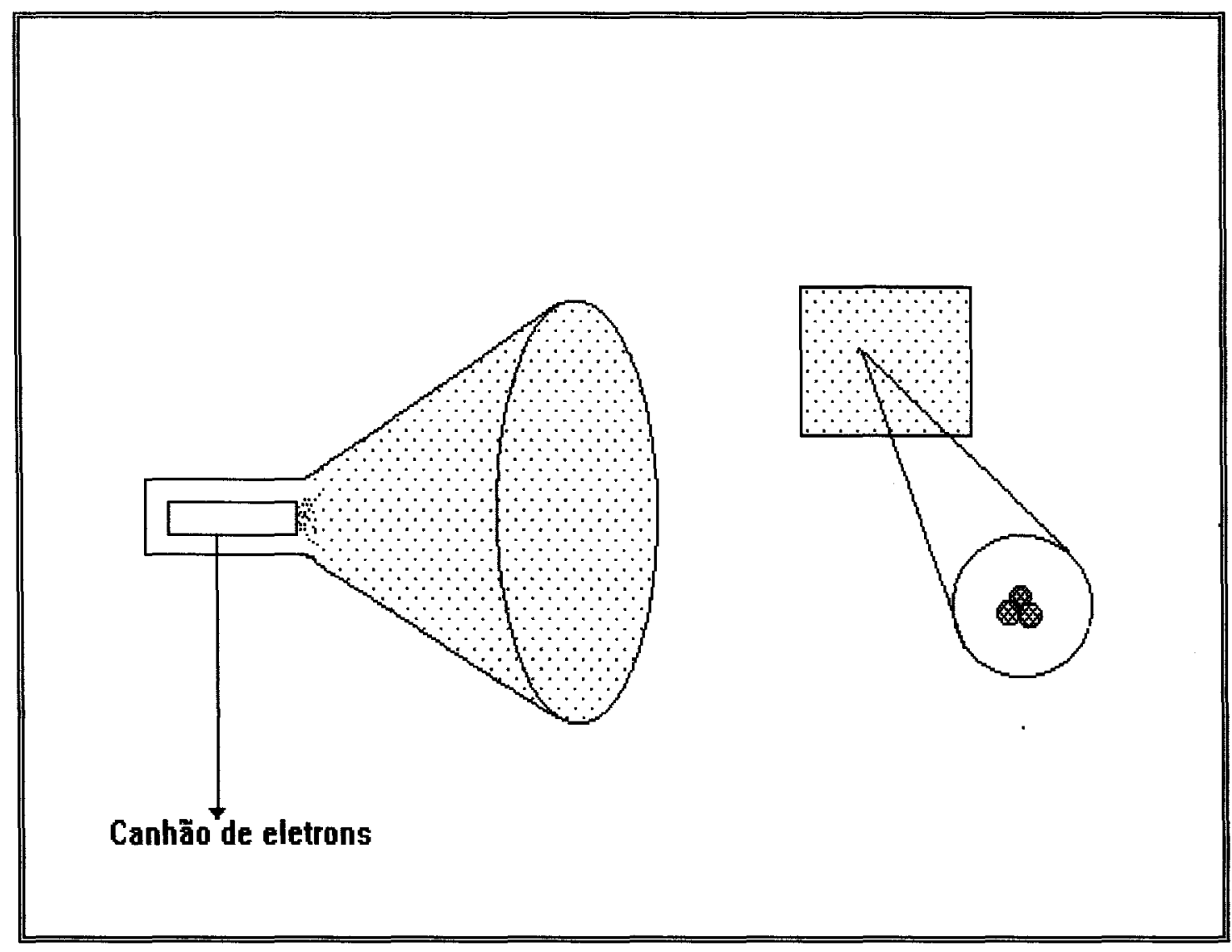

FIGURA 22 - Esquema de um monitor colorido (Sistema R.G.B.) A imagem do microscópio óptico captada pela câmera é transmitida para o monitor de vídeo, que a explora, linha por linha. 


\section{II.6.4 - Segmentacão de imagens}

Segundo RUSS (1995), SAVARY (1995), uma das operações mais difíceis na análise de imagens é a de extrair delas informações geométricas. Para se conseguir isto, é necessário simplificar o conteúdo da imagem. Exemplo: transformar os níveis de cinzas em preto ou branco.

A maneira mais simples de segmentar uma imagem é através do uso de um limite fixo ("fixed threshold"), que indica a transição entre os níveis binários 0 (=preto) e 1 (=255=branco). Vários limites podem estar presentes, mas geralmente, usa-se apenas um.

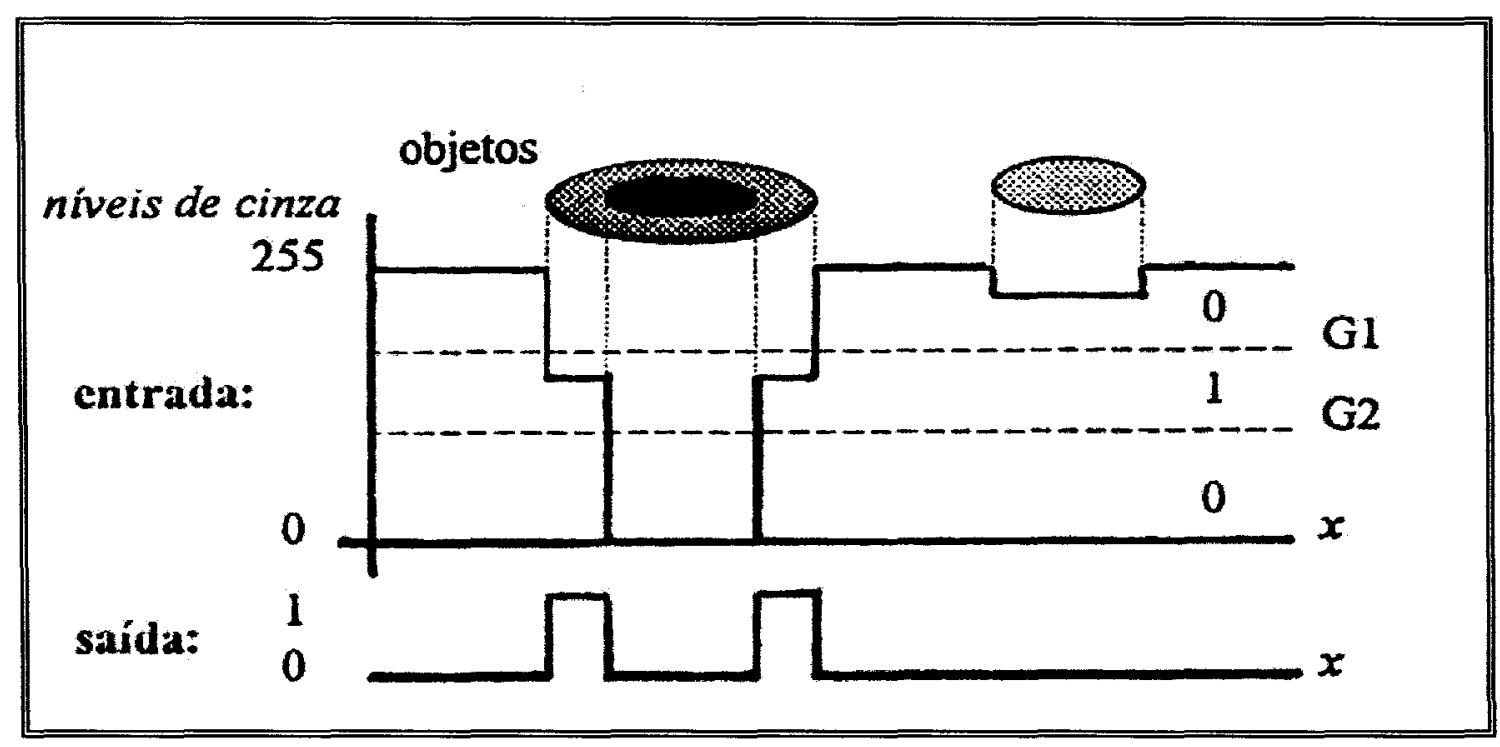

FIGURA 23 - Ilustra o limite fixo que pode ser aplicado a fases bem definidas, vazios ou inclusões. 


\section{II.6.5 - Ajuste da iluminacão}

As diversas partes do microscópio óptico devem ser ajustadas para se obter um campo com intensidade de iluminação uniforme e um bom contraste entre os microconstituintes que se deseja medir. Isto pode ser conseguido com a centragem do filamento da lâmpada, ajustagem do diafragmas de campo e abertura do microscópio. Podem-se também utilizar outras técnicas, por exemplo, o uso de filtros que melhoram o contraste. Existe também um dispositivo para compensar a perda de luminosidade em regiōes de imagem, que é controlado manualmente e uniformiza a intensidade de luminosidade.

O sinal de saída da câmera é normalmente proporcional à quantidade de luz refletida no material observado. Significa que é proporcional à capacidade reflectiva e à intensidade da fonte de luz. Uma das dificuldades em sistemas de visão é a capacidade de adaptação automática a variações na iluminação.

O ponto crítico de qualquer determinação é 0 ajuste dos discriminadores conforme ilustra figura 24.

Para materiais nos quais a diferença de tonalidades é bastante grande, por exemplo constituintes brancos em fundo negro, a discriminação é facilitada porque, após conseguir-se a do fundo negro, passa-se por todas as tonalidades de cinza até chegar ao branco. No entanto, na maioria das imagens, a diferença de tonalidades existente é bem menor, o que dificulta o ajuste dos discriminadores. 


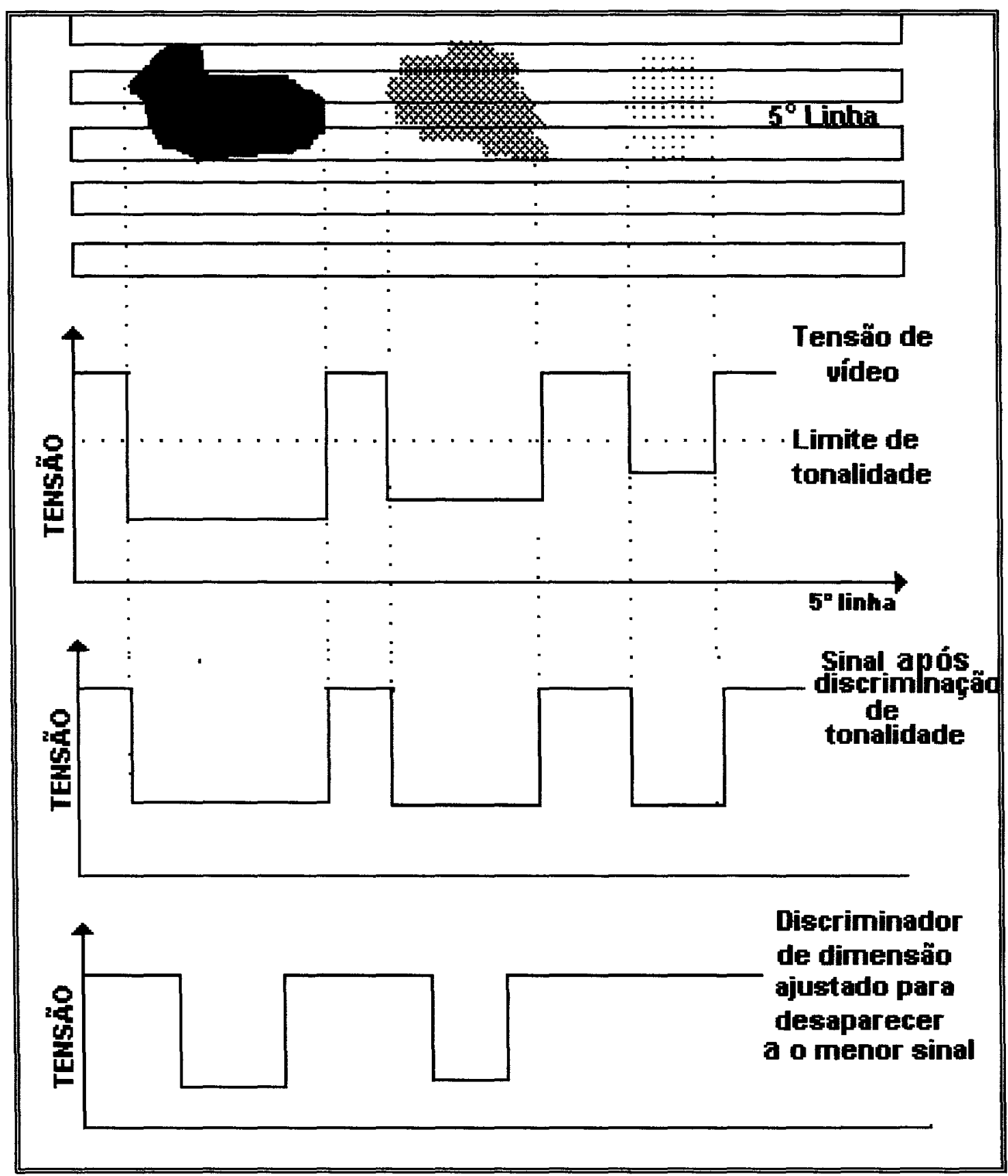

FIGURA 24 - Princípio de funcionamento dos discriminadores de tonalidade e de dimensão BARCELOS et al.(1977). 


\section{II.6.6 - Dispositivos digitalizadores de imagens}

Segundo HEIN (1995), quando uma imagem é digitalizada, ela é convertida em valores numéricos, isto é, descrita em termos matemáticos, definidos por amostragem discreta do domínio espacial em função da intensidade de energia luminosa,

$$
\text { Id. }=g(X, Y)
$$

Desta forma, a definição matemática de uma imagem pode ser dada em termos de energia luminosa (Id.) de cada ponto no plano percebida por fotossensores do dispositivo de digitalização. Podemos observar que $(\mathrm{g}(\mathrm{X}, \mathrm{Y}))$ não é uma função contínua no espaço. Mesmo a intensidade ld. assume valores discretos, geralmente inteiros, definidos pela sensibilidade dos fotossensores.

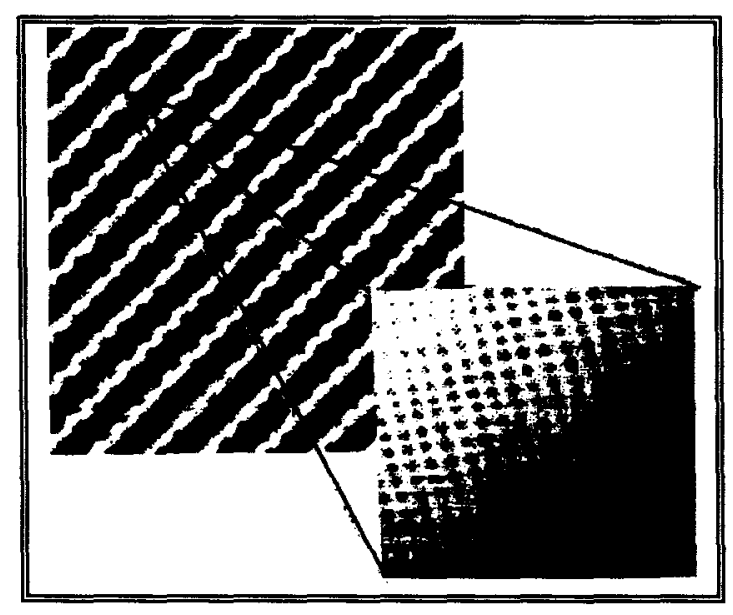

FIGURA 25 - Ilustra a imagem no plano $(X, Y)$, em detalhe, região amplificada da imagem original, HEIN (1995).

Cada ponto avaliado $(X, Y)$ é denominado Píxel, nome extraído, da expressão (Picture element).

Um píxel será um ponto qualquer no espaço amostrado, isto é, um ponto com intensidade luminosa constante. 
Para uma imagem real de tamanho definido, quanto maior for o número de píxeis que a descreve, maior será sua resolução espacial. Nos dispositivos de digitalizadores, o número de píxeis é definido pelo seu projeto. PAZ \& CUNHA (1988), PACIORNIK (1996) destacam os tipos de digitalizadores mais utilizados:

Scanner, que consiste em converter a imagem em valores analógicos digitais (digitalizada), numa resolução compatível com o seu tamanho e com o número máximo de pontos previstos e arquivados na memória do microcomputador.

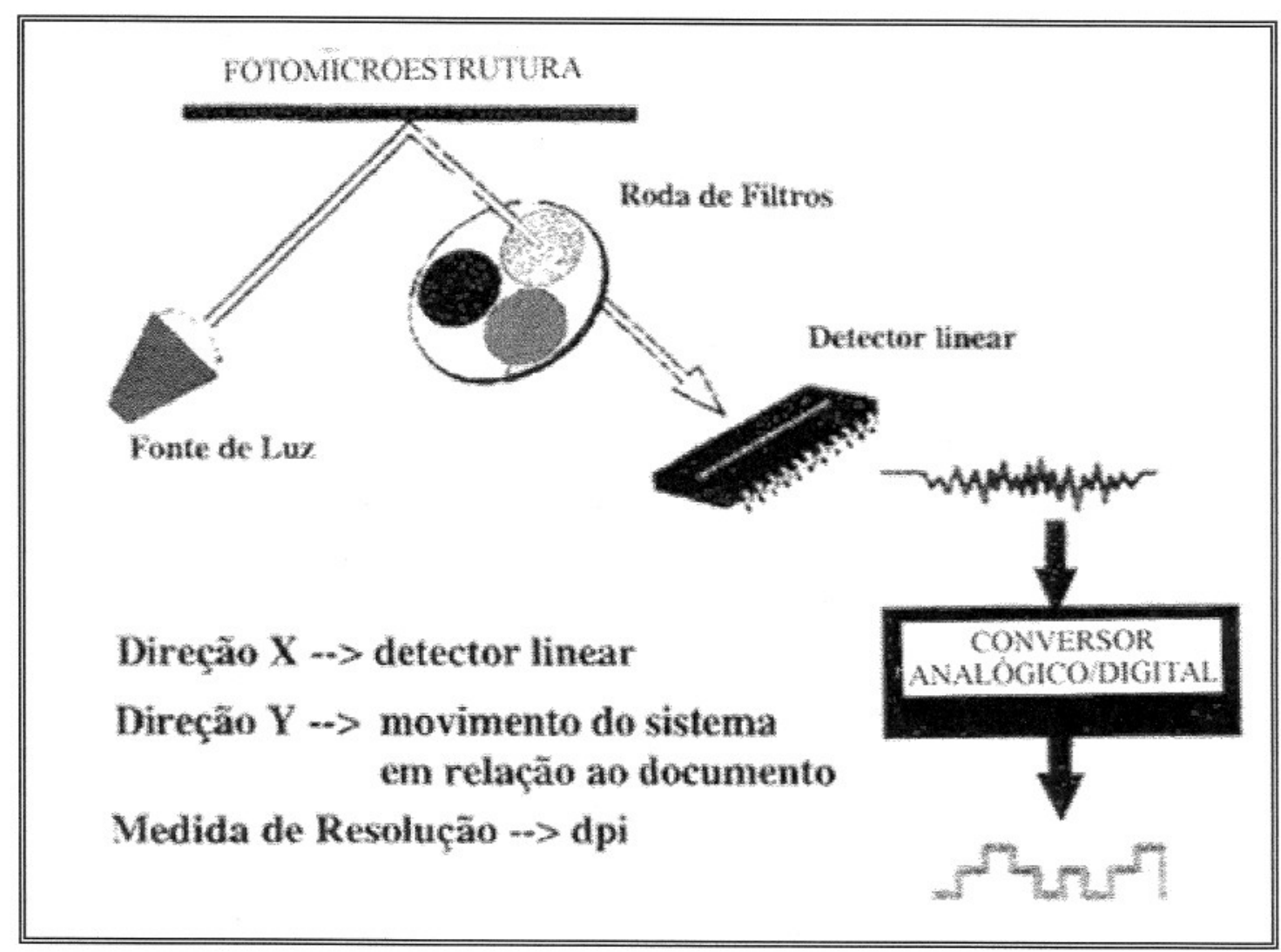

FIGURA 26 - Esquema da digitalização das fotomicroestruturas utilizado pelo scanner.

Uma outra forma de digitalização de imagem é obtida através de um digitalizador de vídeo. Neste tipo de digitalizadores, a imagem é digitalizada diretamente do monitor de vídeo. A imagem do monitor 
produzida pela câmera é convertida em valores binários através de um dispositivo eletrônico chamado convertedor A/D (analógico/Digital). Este valor convertido é armazenado no elemento da matriz do computador correspondente à imagem. Devido ao aumento eletrônico, que é cerca de 20X, consegue-se ampliação de até 4000X, no vídeo.

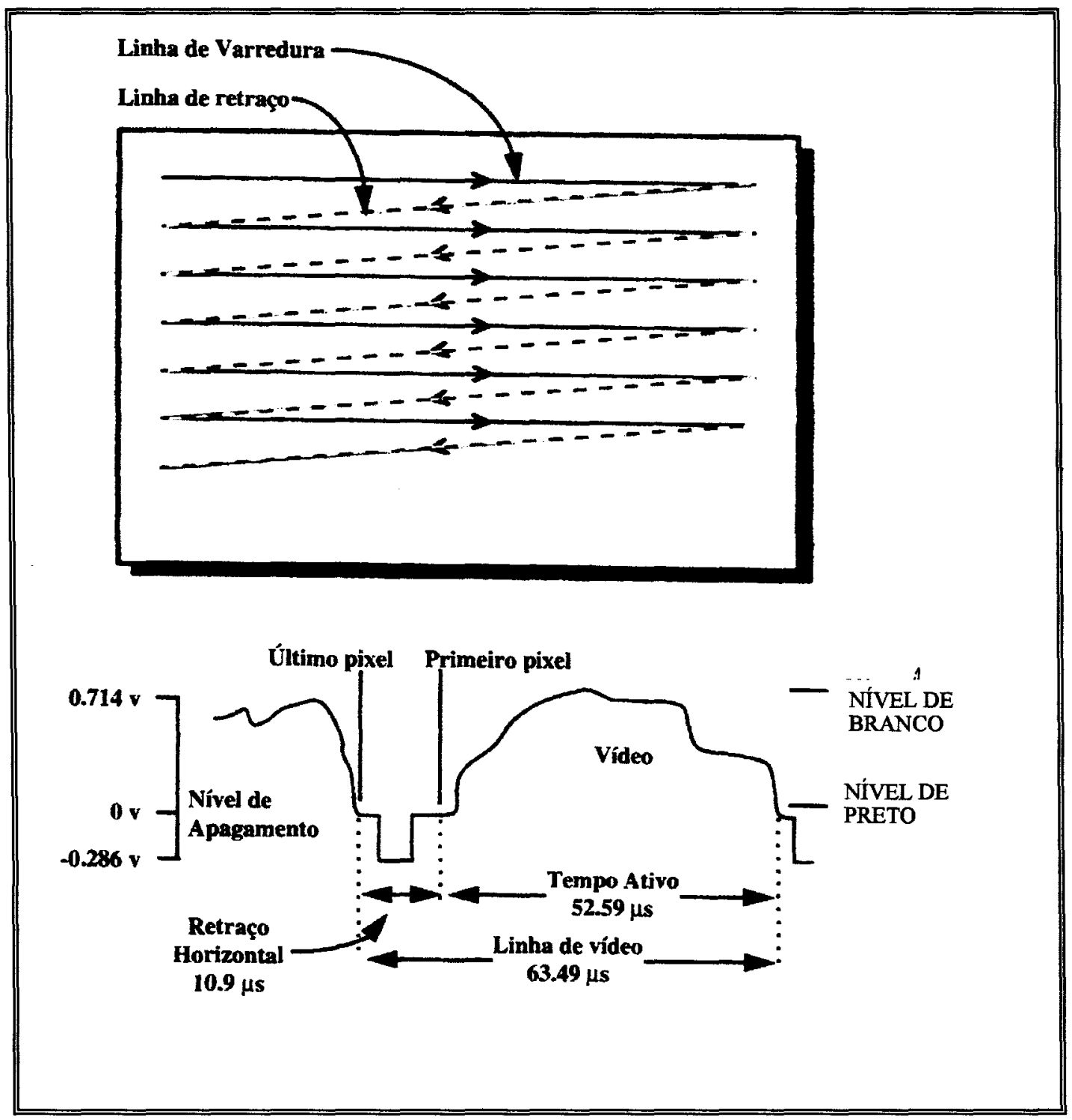

FIGURA 27 - Esquema da digitalização de imagens de vídeo. 


\section{II.6.7 - Processamento de imagens digitalizadas}

O objetivo de se processar uma imagem é gerar uma outra com melhores características de observação ou análise.

Segundo PAZ \& CUNHA (1988), quando desejamos processar (realçar) uma imagem, não temos necessariamente o objetivo de manter a fidelidade da imagem inicial. As operaçōes de realce tendem a depender tanto dos dados quanto do observador. Segundo SAVARY (1995), não existe uma teoria geral unificada para realce de imagem, pois não existe um padrão de qualidade de imagem que sirva como meta geral para todas as aplicações.

Uma das primeiras necessidades em processamento de imagens virtuais é contornar as distorções introduzidas pelas câmeras. Freqüentemente as imagens são distorcidas por estarem atuando fora do eixo óptico. Uma outra necessidade é eliminar os riscos, ruídos, artefatos indesejáveis etc...

O processamento de uma imagem se faz através de operações com histogramas e filtros. A capacidade de compensar os efeitos, tais como sombra e brilho intenso, freqüentemente determina o sucesso dos subseqüentes procedimentos. O histograma intensiométrico caracteriza-se por fornecer informações sobre a distribuição dos níveis de cinzas da luminosidade e do contraste de uma imagem.

Segundo RUSS (1995), conhecendo-se o histograma de distribuição dos niveis de cinzas, pode-se programar alterações nos valores dos elementos da imagem, obtendo-se valores de melhor qualidade. Nos histogramas de imagens em tons de cinza, convenciona-se que 0 valor zero representa 0 preto e 0 valor 1 representa o branco.

Zero $(0) \rightarrow$ Preto $\rightarrow$ Mínimo brilho 
Um (1) $\rightarrow$ Branco $\rightarrow$ Máximo brilho

Segundo WESZKA \& ROSENFELD (1978) e CHERMANT et al. (1989), a técnica para a extração de características de uma imagem baseia-se na identificação dos objetos presentes na microestrutura analisada.

A transformação de uma imagem digitalizada em imagem binária se faz através de uma discriminação de valores de píxeis. Para tal procedimento, utiliza-se um histograma de remanejamento da imagem.

As operações com histograma representam uma categoria particular de filtros, cuja função é distribuir os níveis de cinza dentro da memória disponivel.

Com os recursos do histograma, pode-se remapear a imagem de forma tal que todas as tonalidades mais escuras de um determinado valor sejam discriminadas ou vice-versa. Com o ajuste do histograma intensiométrico, somente são selecionadas partes das tonalidades dos píxeis. Segundo BARCELOS et al. (1977), as várias tonalidades existentes na imagem são transformadas em variações de tensão equivalentes. Para materiais, nos quais a diferença de tonalidade é bastante grande, por exemplo constituinte branco em fundo negro, a discriminação é facilitada porque, após conseguir-se a discriminação do fundo negro, passa-se por todas as tonalidades de cinza até chegar ao branco. Tem-se, desta forma, uma boa margem para ajustagem dos discriminadores. No entanto, na maioria das amostras a diferença de tonalidades existentes é bem menor, dificultando o ajuste dos discriminadores. Se optarmos por um número reduzido de níveis, ocorre um efeito conhecido como falso contorno. 


\section{II.6.8 - Operacões com filtros}

São operações nas quais, segundo PACIORNIK (1996), a intensidade do píxel, na posição $(X, Y)$ da imagem de saída $S$ é uma função não só da imagem de entrada mas também das intensidades dos píxeis numa vizinhança do píxel em questão. Os filtros podem ser lineares e não lineares, e formam um outro grupo de recursos que auxiliam a melhora da qualidade da imagem digitalizada.

Os filtros lineares efetuam, geralmente, adições e multiplicações ponderadas dentro de uma janela de convolução kemel (núcleo).

A operação é equivalente a uma média ponderada das intensidades dos píxeis na vizinhança. Os pesos estão contidos em uma matriz do tamanho da vizinhança, denominada kernel (núcleo). $\mathrm{Na}$ aplicação da operação, a imagem é varrida coluna a coluna e linha a linha. Isto eqüivale a uma convolução entre imagem e kemel. $O$ exemplo a seguir, proposto por SAVARY (1995), mostra como são efetuadas as operaçōes. Consideremos uma imagem de entrada $F$ $(x, y)$, composta por um conjunto de píxeis $\{F x y\}$ e uma imagem de saída $g(x, y)$, composta por um conjunto de píxeis $\{\mathrm{Gxy}\}$.

Neste exemplo, consideramos o píxel de entrada $\mathrm{Pe}=\mathrm{F}_{22}$ na imagem $f(x, y)$. Os píxeis vizinhos, incluídos numa janela de convolução $3^{\star} 3$ centrada em Pe somam oito. Assim, o valor do píxel de saída Ps $G_{22}$ é proporcional à soma dos píxeis $\left\{F_{11} \ldots F_{33}\right\}$ ponderada pelos fatores $\left\{Z_{11} \ldots Z_{33}\right\}$ do operador $Z$.

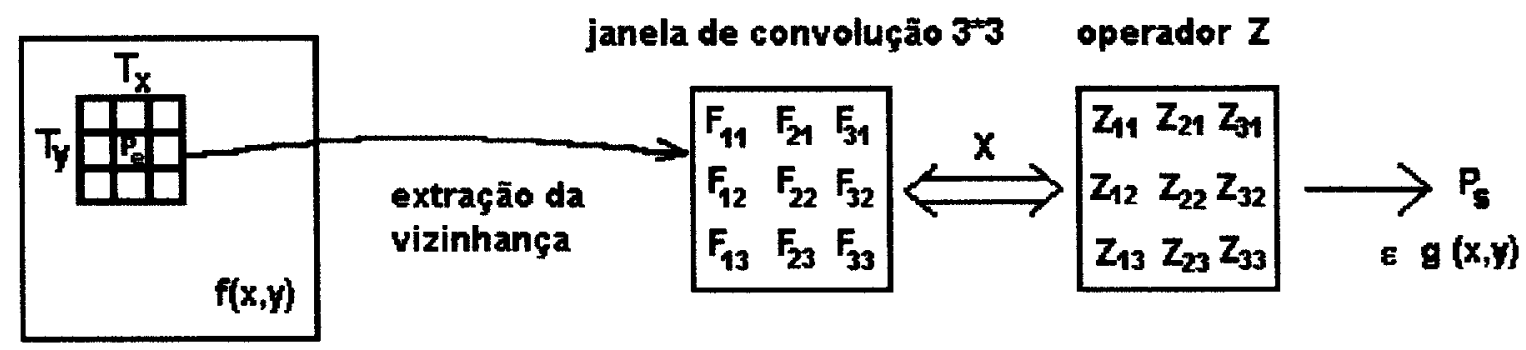


$P s \alpha Z_{11} F_{11}+Z_{21} F_{21}+Z_{31} F_{31}+Z_{12} F_{12}+Z_{22} F_{22}+Z_{32} F_{32}+Z_{13} F_{13}+Z_{23} F_{23}$ $++Z_{33} F_{33}$ $\mathrm{P}_{\mathrm{s}}=\sum_{\mathrm{i}=0 \mathrm{j}=0^{-}}^{\mathrm{T}_{\mathrm{x}}} \sum_{\mathrm{y}}^{\mathrm{T}_{\mathrm{y}}}\left[\mathrm{Zij}^{*} \mathrm{Fij}\right]$ ou, globalmente, $g(x, Y)=f(x, y)$ * Zij

Os filtros não lineares são também baseados no princípio da janela, porém neste caso, não existe um operador mostrando fatores multiplicativos.

O exemplo abaixo ilustra o filtro não-linear mediano Exemplo de uma janela de convolução (3*3) $\left|\begin{array}{lll}4 & 6 & 7 \\ 6 & 8 & 9 \\ 5 & 7 & 9\end{array}\right|$ Píxel de entrada é 8 $[4,5,6,6,7,7,8,9,9]$ classificação em ordem crescente $\left|\begin{array}{lll}4 & 6 & 7 \\ 6 & 7 & 9 \\ 5 & 7 & 9\end{array}\right|$ Píxel de saída é 7

O software Mocha possui uma série de tipos de filtros cinzas, que operam como matrizes $m \times n$ (Kemel mxn). Entre os principais filtros destacam-se: o convolution (Kernel 3x3), Averaging (filtro mediano que elimina ruídos de alta freqüência, Laplace, Sobel, Ranking (filtro que pode atuar simultaneamente como erosão, dilatação e realce de imagem). 


\section{III - MATERIAIS E MÉTODOS}

Foi estudado o microconstituinte perlita em 9 (nove) amostras de chapas de aço ao carbono laminadas a quente com espessura máxima de $5 \mathrm{~mm}$. A composição química das amostras está representada pela TABELA 4.

TABELA 4 - Composição química (\% em peso) das chapas de aço ao carbono, laminadas a quente, analisadas.

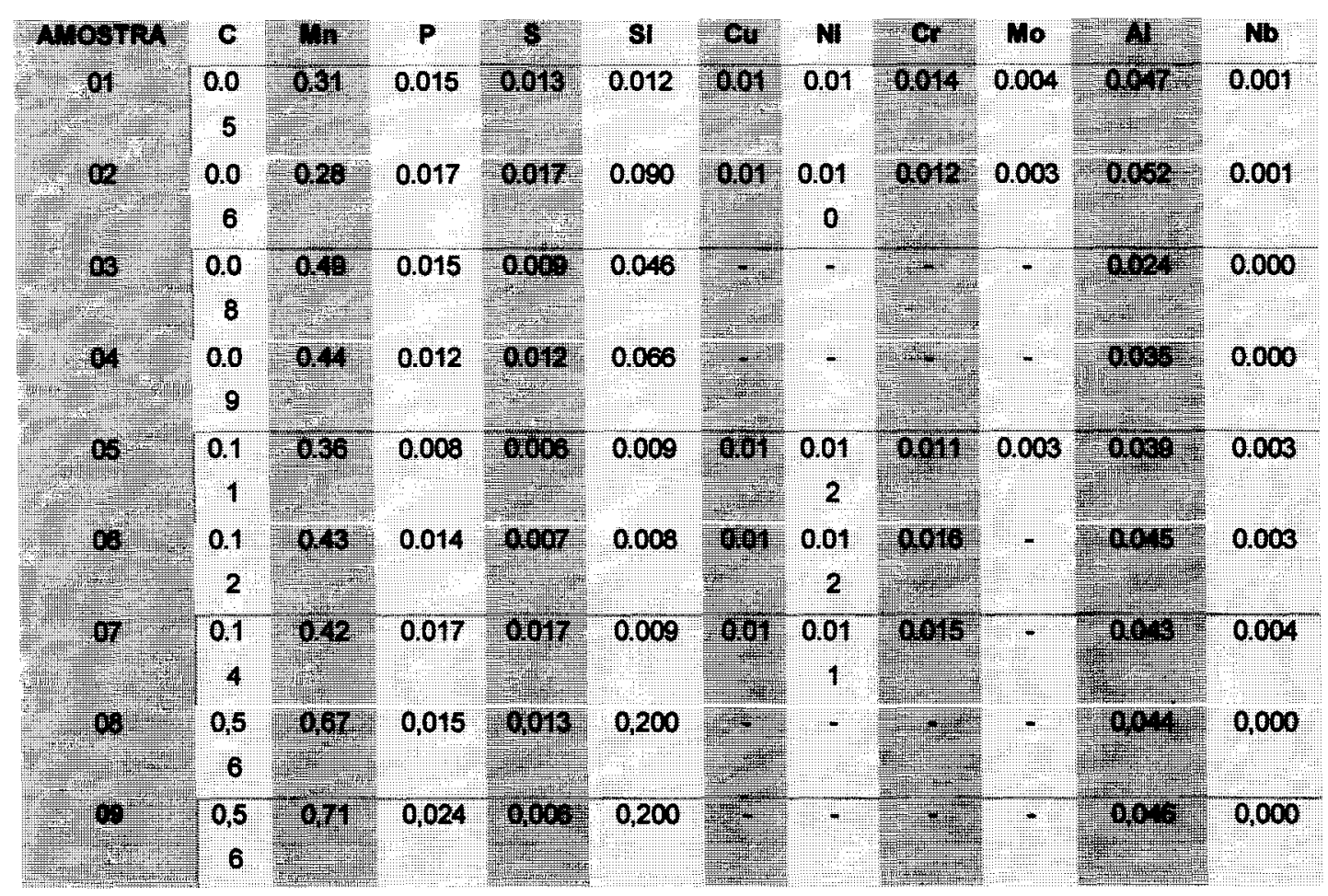

\section{III.1 - Preparacão das amostras}

As amostras para a análise metalográfica foram preparadas segundo a norma ASTM: E 3 - 1986. Para cada amostra de chapas de aço laminado a quente, fezeram-se cortes para retiradas das amostras, conforme ilustra a figura 28 , sendo posteriormente "embutidas" em resina, conforme ilustra a figura 29. 


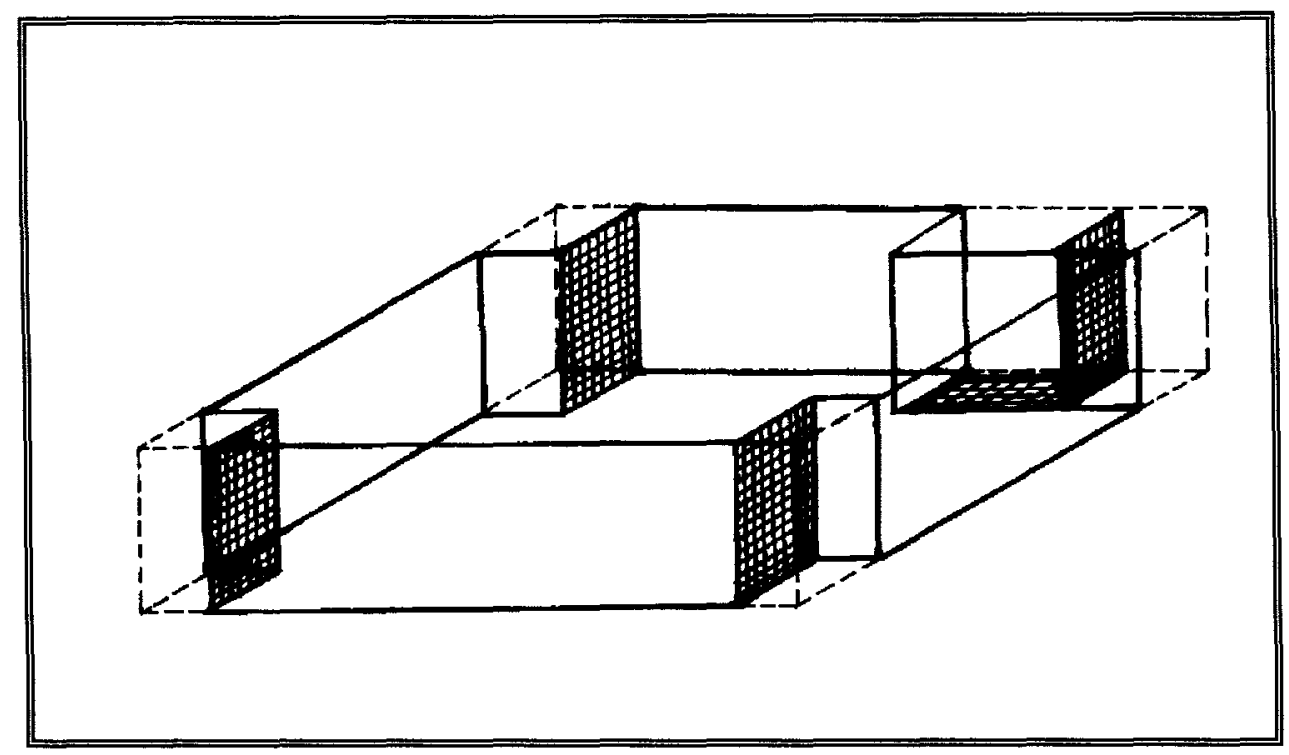

FIGURA 28 - Perspectiva do corte das amostras, quatro no sentido vertical e um no sentido horizontal.

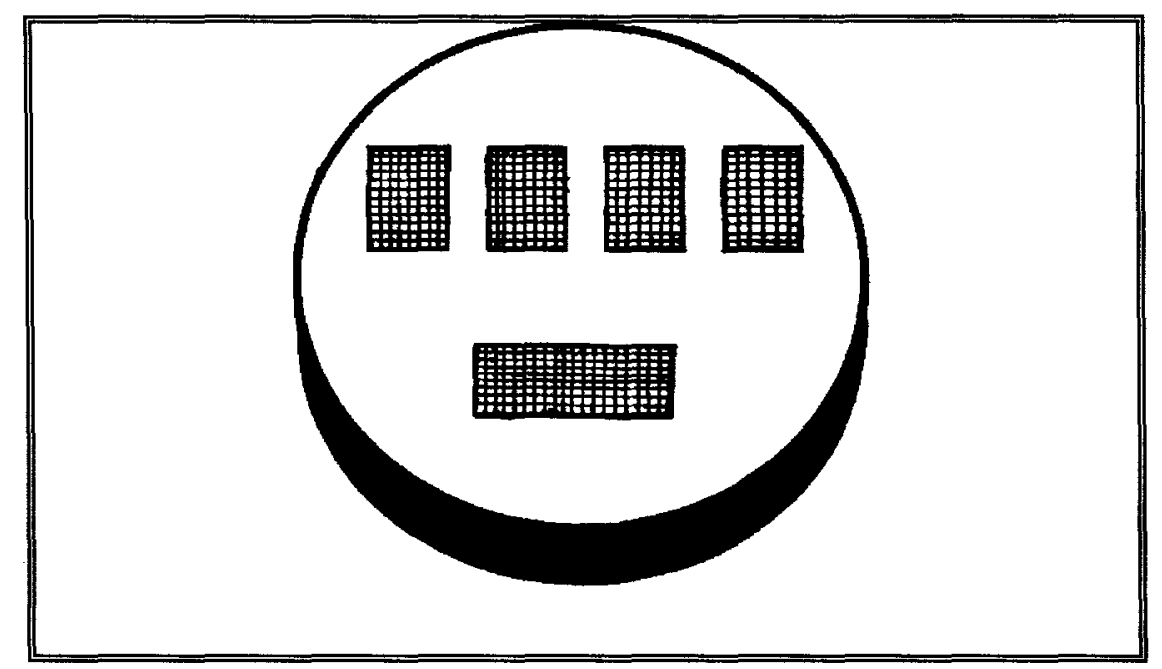

FIGURA 29 - llustra o embutimento das amostras

Utilizou-se, como reagente químico, para revelar 0 microconstituinte perlita, o Nital $2 \%$. O preparo do reagente químico obedeceu à norma ASTM: E 407 -1970. Fixou-se o tempo médio de ataque em 25 segundos para cada amostra. 


\section{III.2 - Determinação do tamanho de grão das amostras}

Determinou-se o tamanho de grão utilizando-se uma escala graduada, segundo a norma ASTM E112-88.

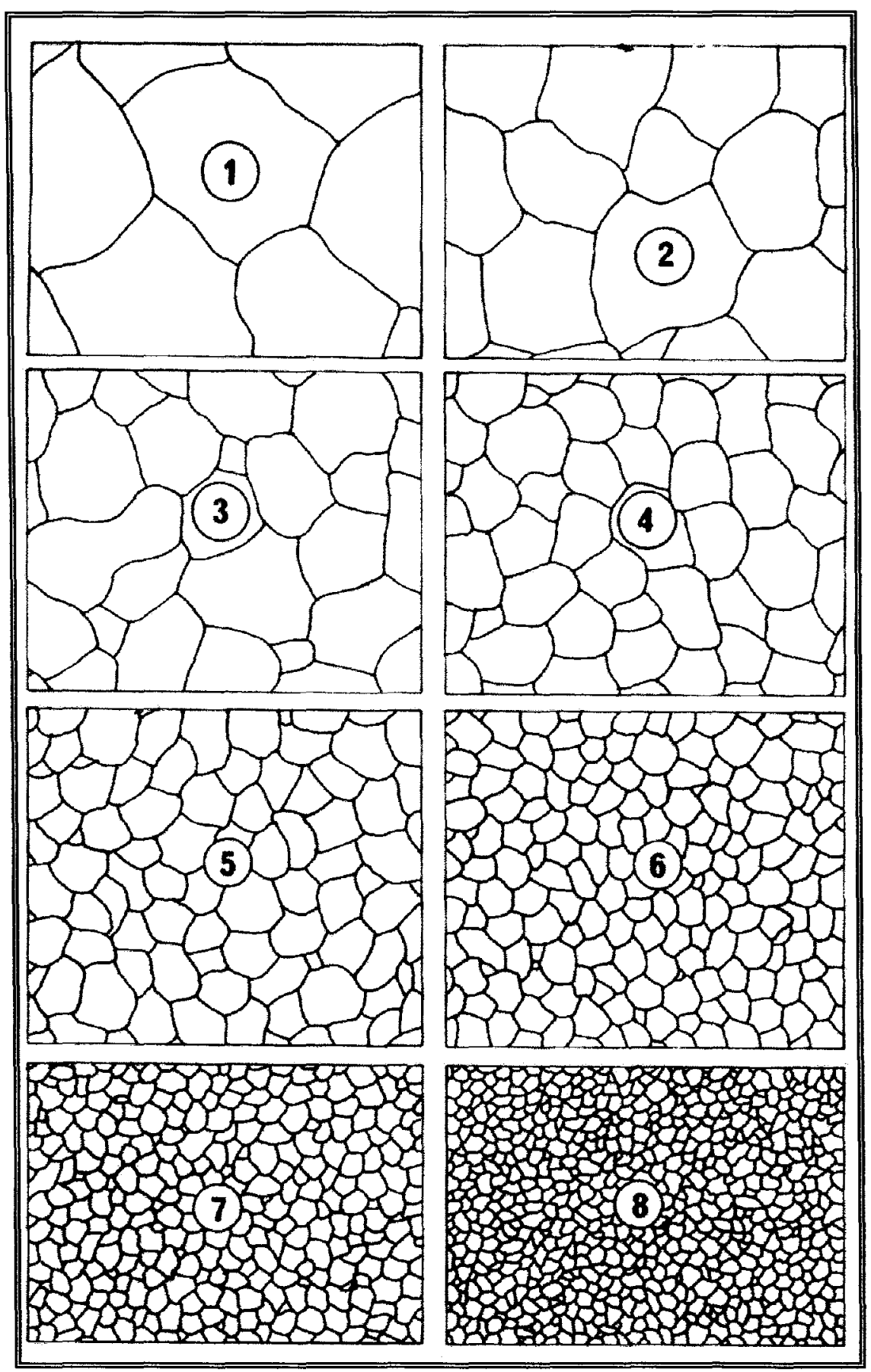

FIGURA 30 - a) - Tamanho de grão ASTM 1 à ASTM 8; (Figura fora de escala). 


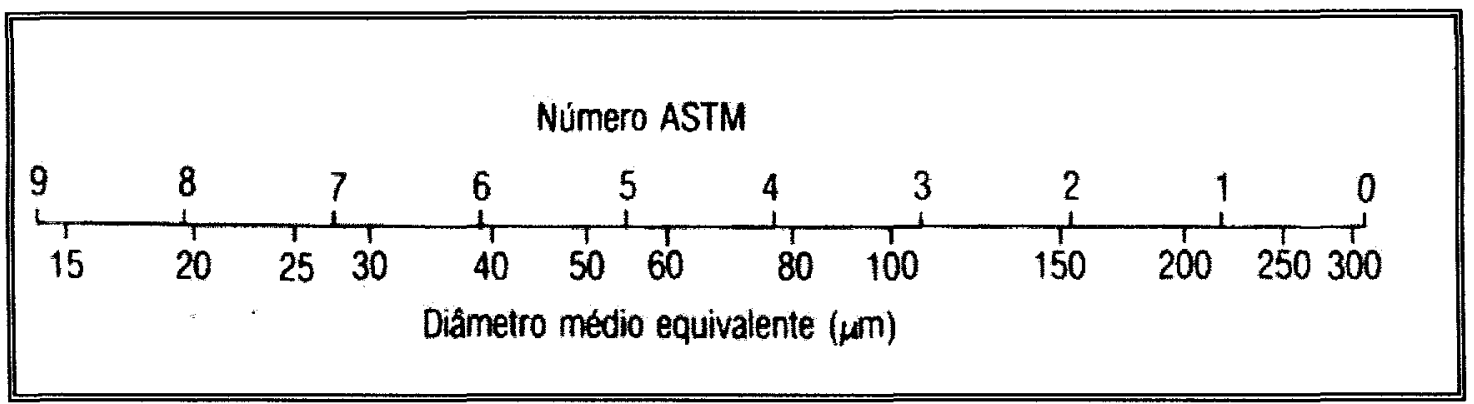

FIGURA 31 - Escala de conversão do número de grão ASTM em diâmetro médio equivalente (Figura fora de escala). SILVA \& MEI (1988).

Adaptou-se uma escala padrão, segundo a norma ASTM E 11288 de conversão de tamanho de grão na ocular do microscópio óptico e com o aumento de 100X, fez-se uma correlação entre a microestrutura observada e o tamanho médio do grão da escala.

\section{III.3 - Método teórico de quantificacão de fases}

Conforme RHINES (1945), COLPAERT (1974), VAN VLACK (1984), MEI \& SILVA (1988), a regra da alavanca é considerada o método teórico de quantificação de fases. Segundo os mesmos autores, através da porcentagem em peso de carbono em uma liga de aços ao carbono comuns, pode-se determinar aproximadamente a porcentagem de fase durante cada etapa da temperatura de resfriamento desse aço.

Os aços ao carbono dividem-se em hipoeutetóide, cuja porcentagem de carbono encontra-se na faixa de 0,0218 a 0,77 por cento em peso de carbono e em hipereutetóide com porcentagem em peso de carbono de 0,77 a 2,11 por cento. 
Dos vários diagramas de fases de ferro ao carbono, adotou-se como referência o proposto por CHIPMAN (1972) conforme ilustra a figura 3.

Os aços da tabela IV estudados são classificados como hipoeutetóides. Sendo assim, no resfriamento lento, neste diagrama à temperatura de $727^{\circ} \mathrm{C}$, ocorre a total transformação da fase austenita em microconstituinte perlita e uma fase ferrítica.

O método da regra da alavanca, quando aplicado a temperatura de $727^{\circ} \mathrm{C}$, permite o cálculo da porcentagem do microconstituinte perlita. Conforme a equação 1 e 2 da pagina 17, temos

$\%$ de Ferrita $=\frac{C_{B}-C_{o}}{C_{B}-C_{A}} 100 \%$

$\%$ de Perlita $=\frac{C_{o}-C_{A}}{C_{B}-C_{A}} 100$

$\mathrm{Na}$ temperatura de $727^{\circ} \mathrm{C}$, temos no diagrama proposto por CHIPMAN (1972) que: $C_{B}=0,77$ e $C_{A}=0,0218$

A amostra da tabela 4 exemplifica a aplicação da regra da alavanca, na determinação teórica da porcentagem do microconstituinte perlita e da ferrita. Conforme a análise química, a porcentagem de carbono é 0,05 e, utilizando-se a equação um e 2, temos:

$\%$ de Perlita $=\frac{0,05-0,0218}{0,77-0,0215} 100=0,038$

$\%$ de Ferrita $=\frac{0,77-0,05}{0,77-0,0215} \quad 100=0,96$

Os mesmos cálculos foram efetuados para as demais amostras. 


\section{III.4 - Obtencão de imagens fotográficas}

Com o auxilio do microscópio óptico LEITZ-DMRX, conforme ilustra a figura 32 , fezeram-se as fotomicrografias das microestrutura das amostras da tabela 4.

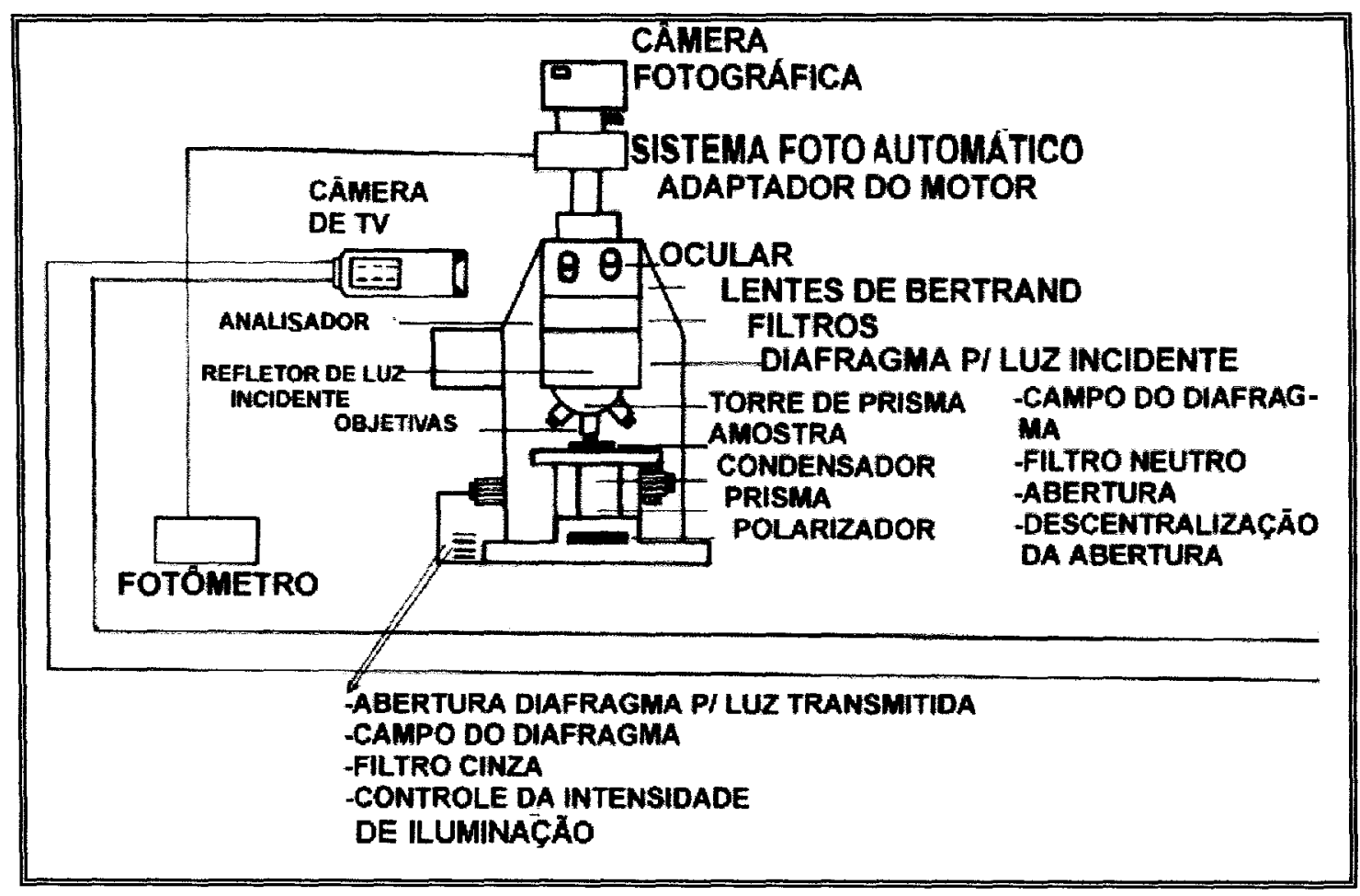

FIGURA 32 - Ilustra o microscópio óptico LEITZ- DMRX, utilizando na obtenção das imagens.

Padronizaram-se a intensidade de luz 0 , filtro e a polarização do microscópio óptico para todas as imagens estudadas segundo CALVO et al.(1991). Para calibrar o aumento total sofrido pela amostra, fotografou-se uma escala micrométrica.

O tempo médio de exposição para cada fotografia foi de 8 segundos ASTM E 883-86. 


\section{III.5 - Método de contagem manual de pontos}

Utilizando-se a tabela 3, página 34 da norma ASTM E 562-89, fez-se uma previsão da rede recomendada para as amostras 1 a 7 .

Avaliou que a porcentagem dos microconstituintes perlita encontra-se na faixa de aproximadamente 5 a 10\%, conforme calculado pelo método teórico e observado visualmente. Sendo assim, a rede recomendada, segundo a tabela 3 , é de 49 pontos para as 2 duas amostras complementares. Seguindo o mesmo procedimento, a fração volumétrica encontra-se na faixa de maior que 0,2 e, neste caso, a tabela recomenda uma rede de 16 pontos.

Tomando-se como exemplo a amostra 1 , conforme figura 33 , a rede de 49 pontos foi sobreposta em 4 campos diferentes da amostra 1

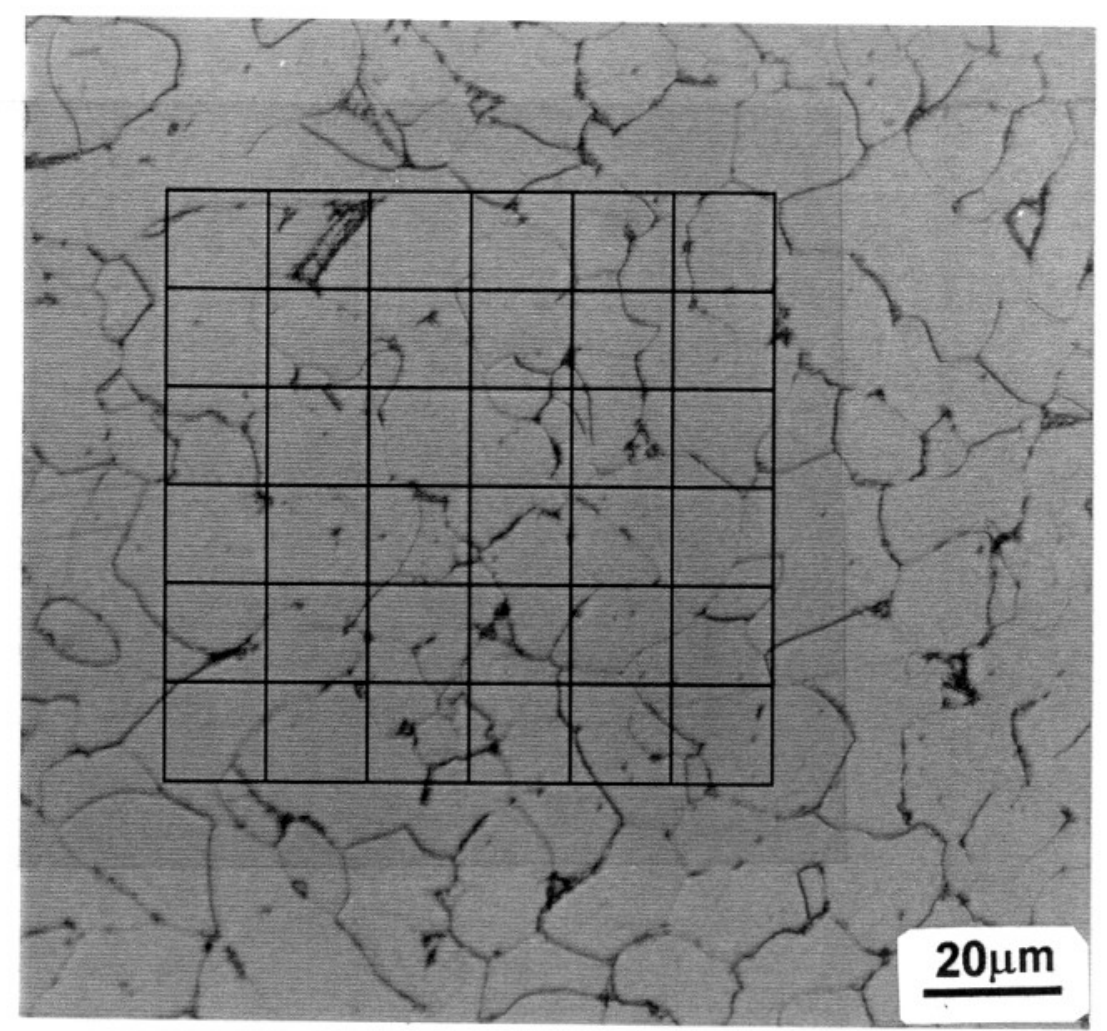

CAMPO 1 

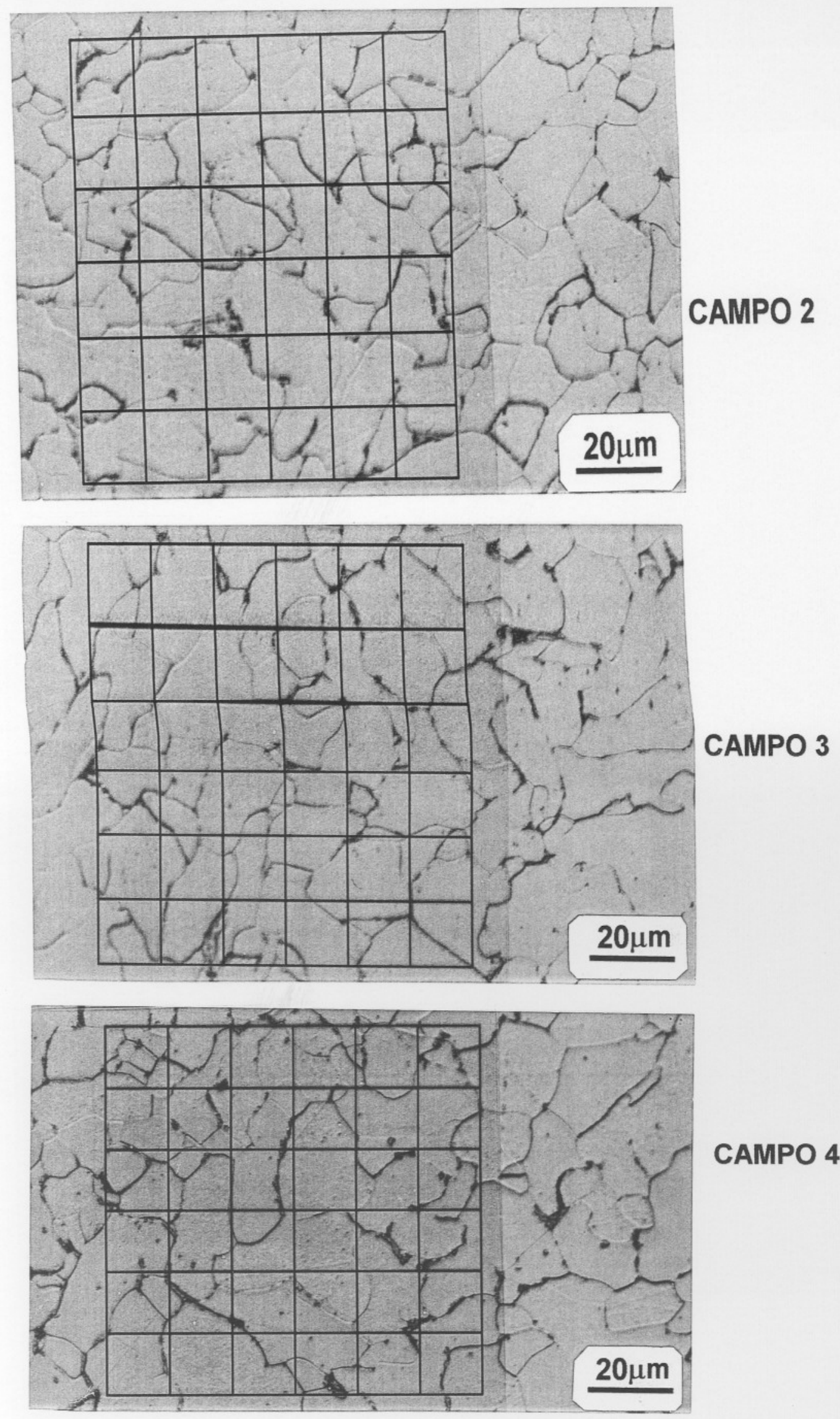

\section{CAMPO 4}

Figura 33 - Ilustra quatro campos diferente da amostra do aço ASTM 1005 com uma rede de 49 pontos Os pontos que caem dentro dos contornos dos microconstituintes foram contados para os 4 campos diferentes.

$$
\sum \mathrm{P}_{\mathrm{i}}=2+3+4+3=12
$$


Assim, temos: $\mathrm{V}_{\mathrm{v}}=\frac{12}{4 \times 49}=0,0612$

Para determinar-se o número de número de campos necessário, utilizou-se a equação 5 , fixando-se a precisão no máximo de $10 \%$.

$\mathbf{P}_{\mathrm{T}}=\sum \mathrm{P}=4 x(1-0,06) x\left(\frac{100}{10}\right)^{2}=376$

O número de campos necessário a ser analisado para uma precisão de $10 \%$ é dado pela equação 6 .

Assim, temos: $\mathrm{n}=\frac{376}{0,06 \times 49} \cong 128$ campos.

Utilizando-se uma rede de 49 pontos sobreposta em 128 campos diferentes da amostra 1 , determinou-se que o somatório dos pontos coincidentes sobre os microconstituintes (perlita) era de 370 .

Em seguida, determinou-se o valor real da fração volumétrica utilizando-se a equação 4 ..

$$
\mathrm{V}_{\mathrm{v}}=\sum \mathrm{P}=\frac{370}{49 \times 128}=0,059
$$

O erro experimental é calculado pela equação 7. Assim, temos: $\Delta=2 \sqrt{\frac{(1-0,059) \times 0,059}{128 \times 47}}=0,006$

onde: $V_{\mathrm{v}} \pm \Delta=0,059 \pm 0,006$

Conforme MENEZES \& BASTIAN (1974), EXNER et al. (1993), BARCELOS et al. (1977); Doc.No.IX-1533-88), pode-se utilizar um reticulado, que produz um resultado mais rápido. Na rotina industrial e nos meios científicos, normalmente a rede utilizada e de 100 pontos e o número de campos é fixado em 10. A figura 34 ilustra a rede de 100 pontos, que foi sobreposta sobre a fotografia da amostra 1 da tabela 4 


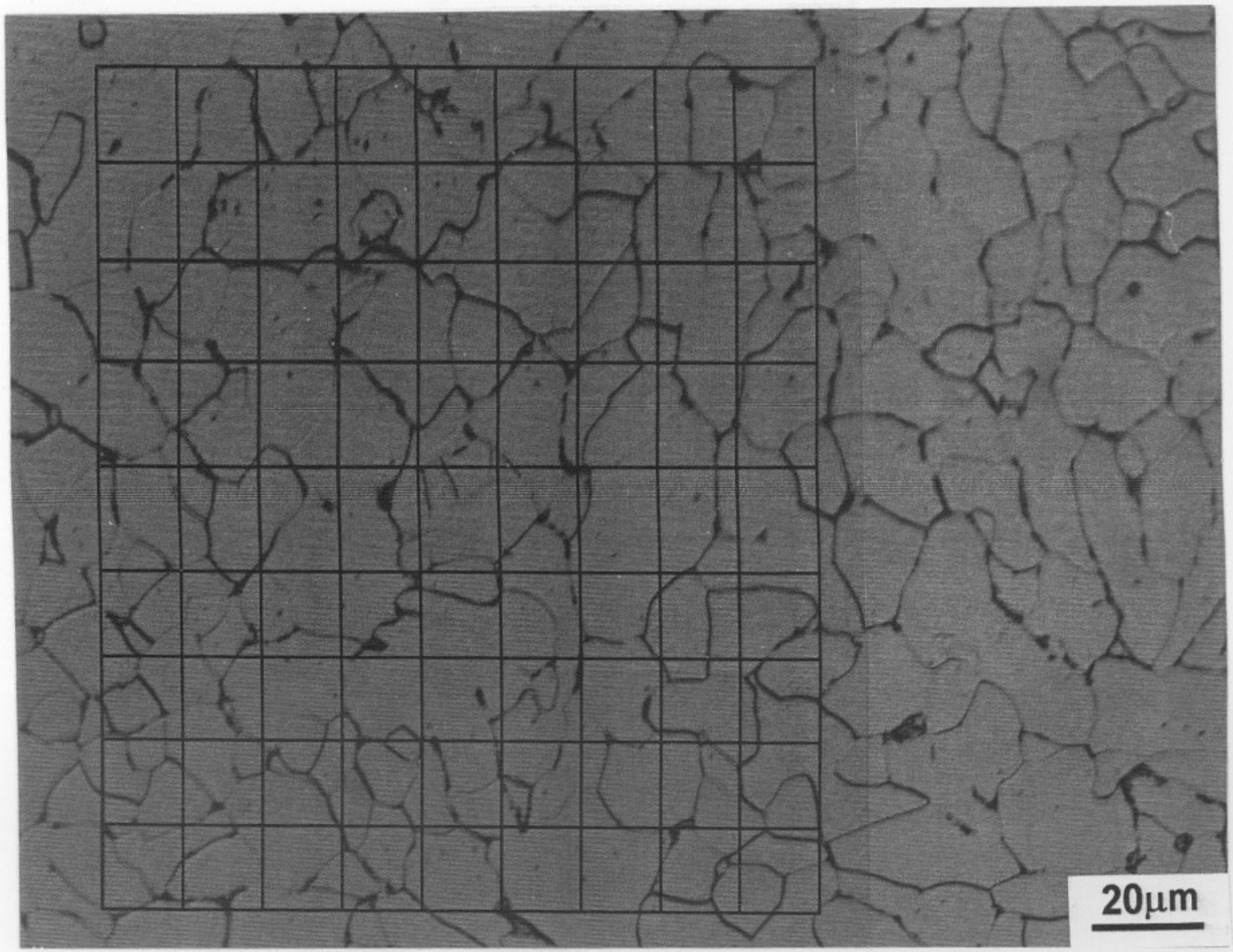

Figura 34 - llustra a fotomicrografia da amostra 1 do aço ASTM 1005 com uma rede de 100 pontos sobreposta.

Duas recomendações básicas foram seguidas conforme HILIARD (1966), MENEZES \& BASTIAN (1974), UNDERWOORD (1985), PADILHA (1997); EXNER et al. (1993).

Os pontos que parecem estar em um contorno devem ser contados como $1 / 2$. Foi selecionada uma rede de pontos, na qual, em média, não mais que um ponto incida sobre um mesmo objeto de interesse em que o espaçamento da rede seja próximo do espaçamento entre os objetos de interesse. Os pontos que se encontram nos contornos foram contados como $1 / 2$.

As figuras de 35 a 48 exemplificam as fotografia das amostras de 1 a 9 estudadas. 


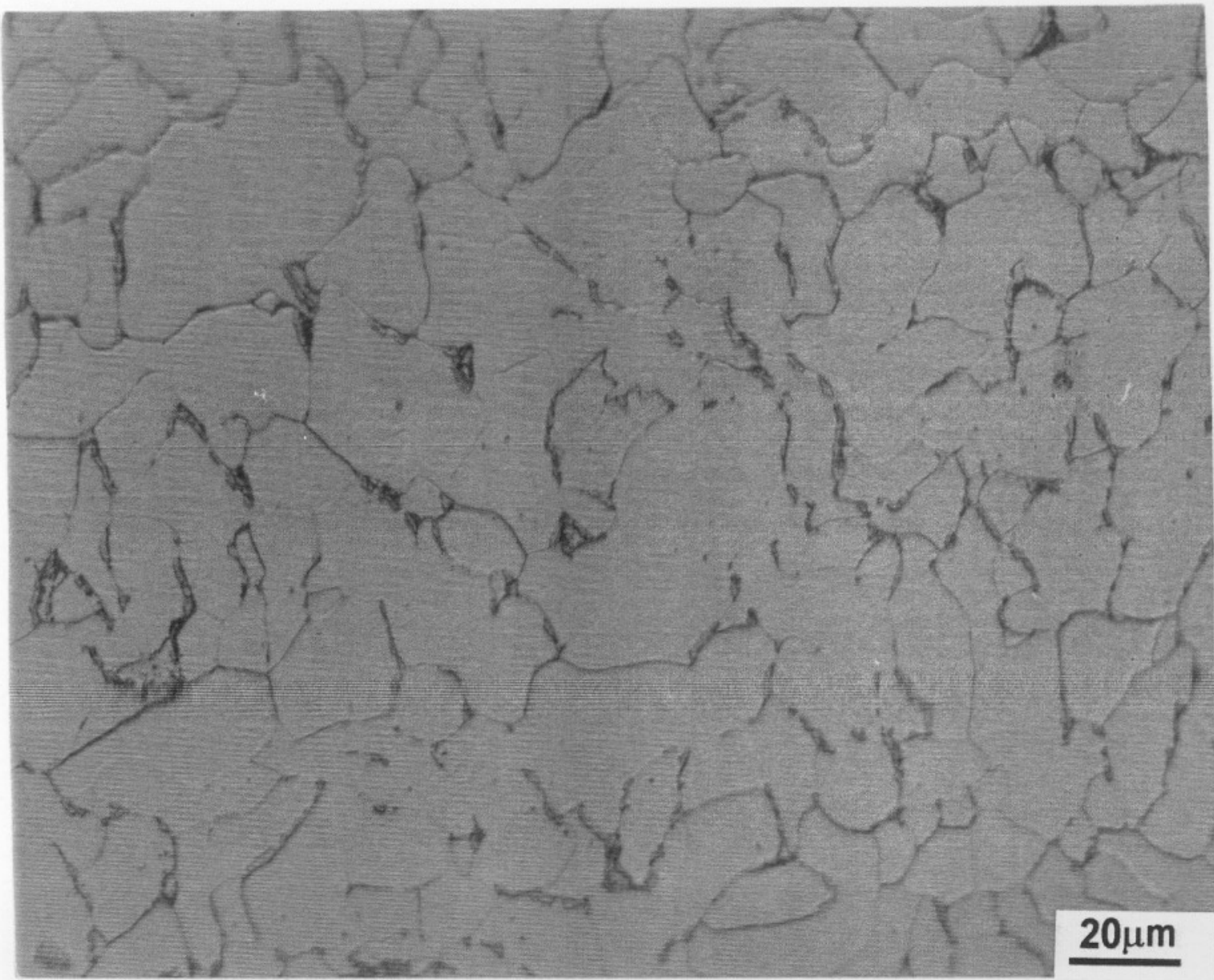

FIGURA 35 - Amostra do aço ASTM 1005; no campo 4, ataque com Nital $2 \%$

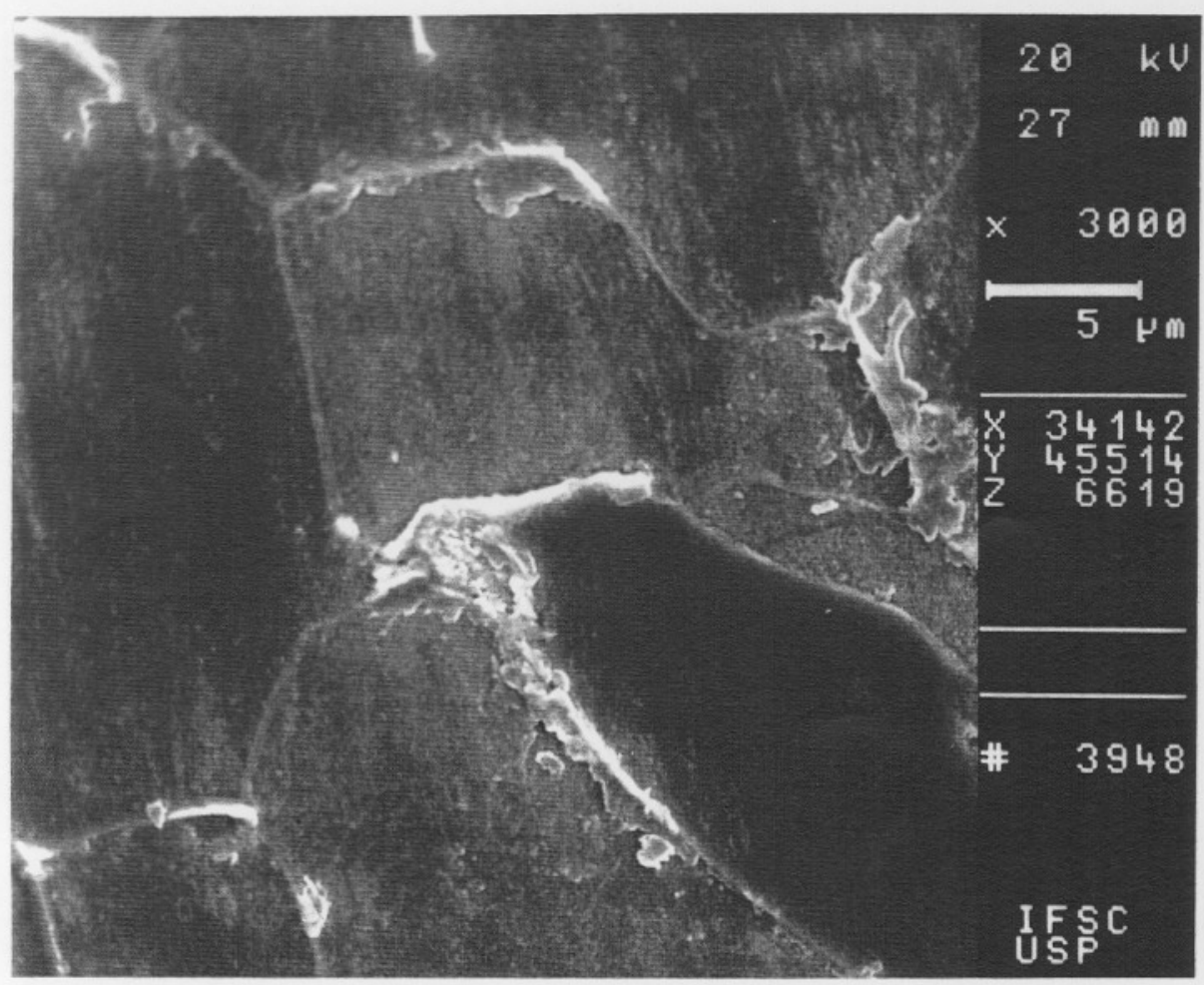

FIGURA36 - llustra o microconstituinte perlita no contorno de grão ferrítico do aço ASTM 1005 MEV, ataque com Nital 2\% 


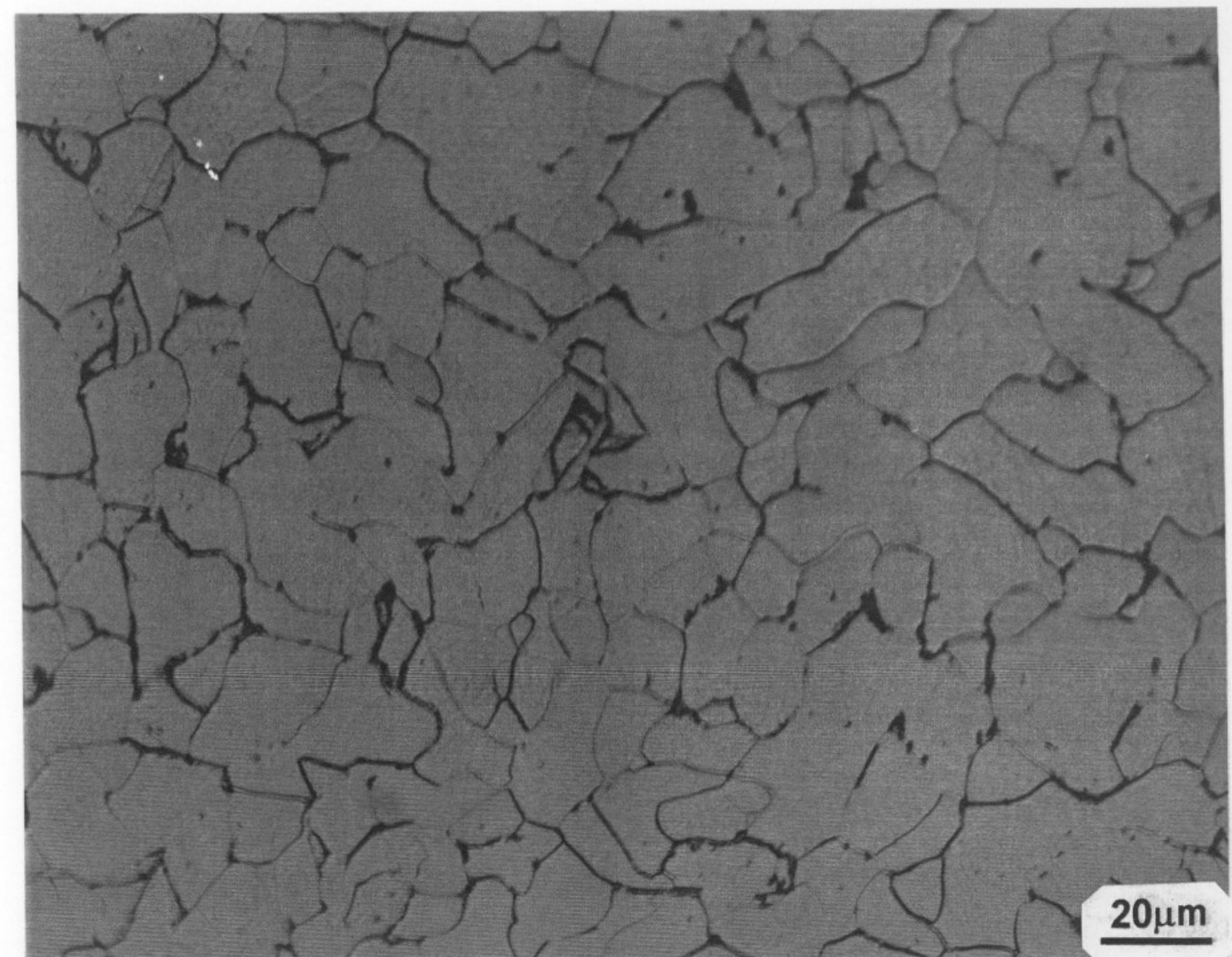

FIGURA 37 - Amostra de aço ASTM 1005; no campo 7, ataque com Nital 2\%

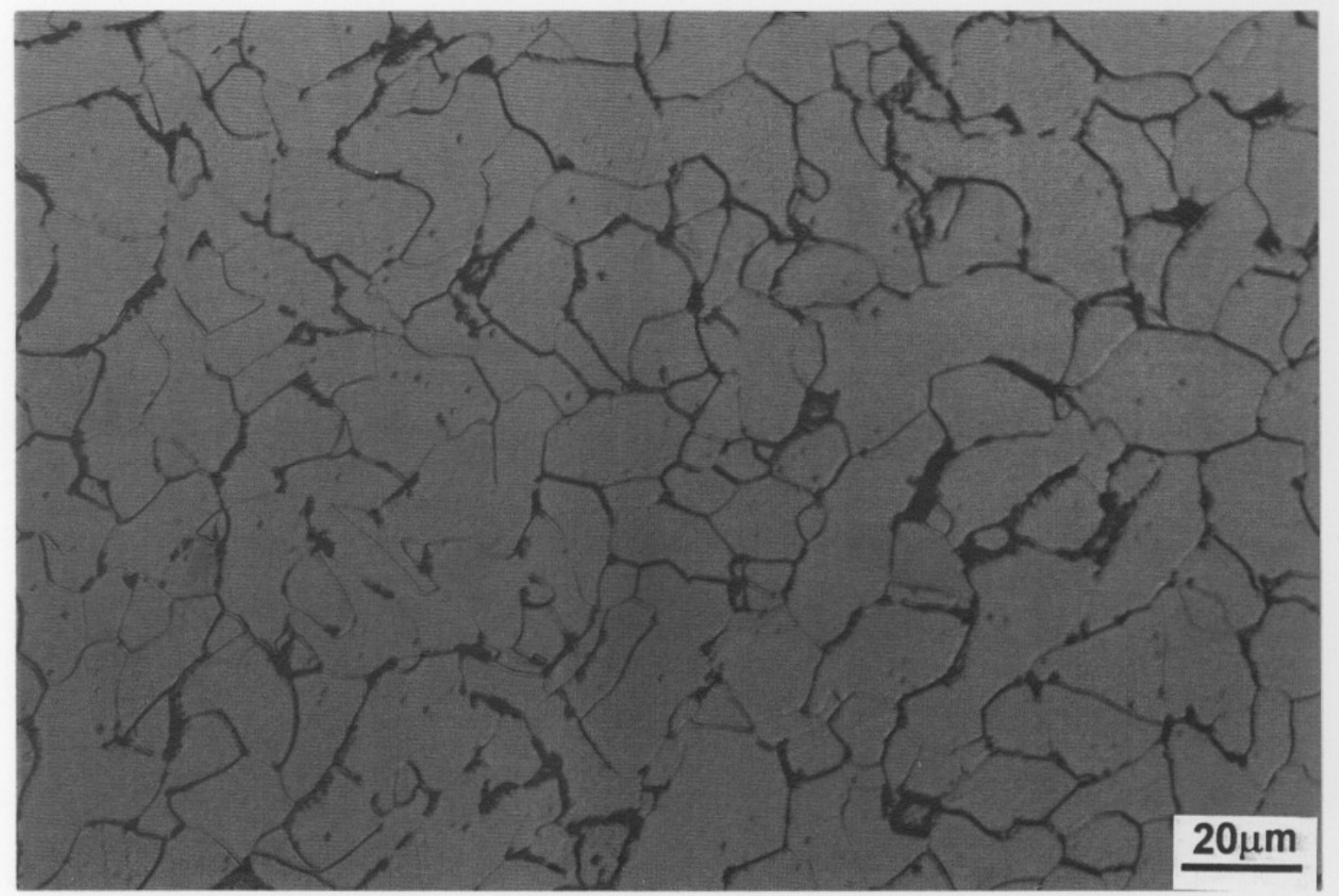

FIGURA 38 - Amostra do aço ASTM 1006; no campo 3,, ataque com Nital 2\% 


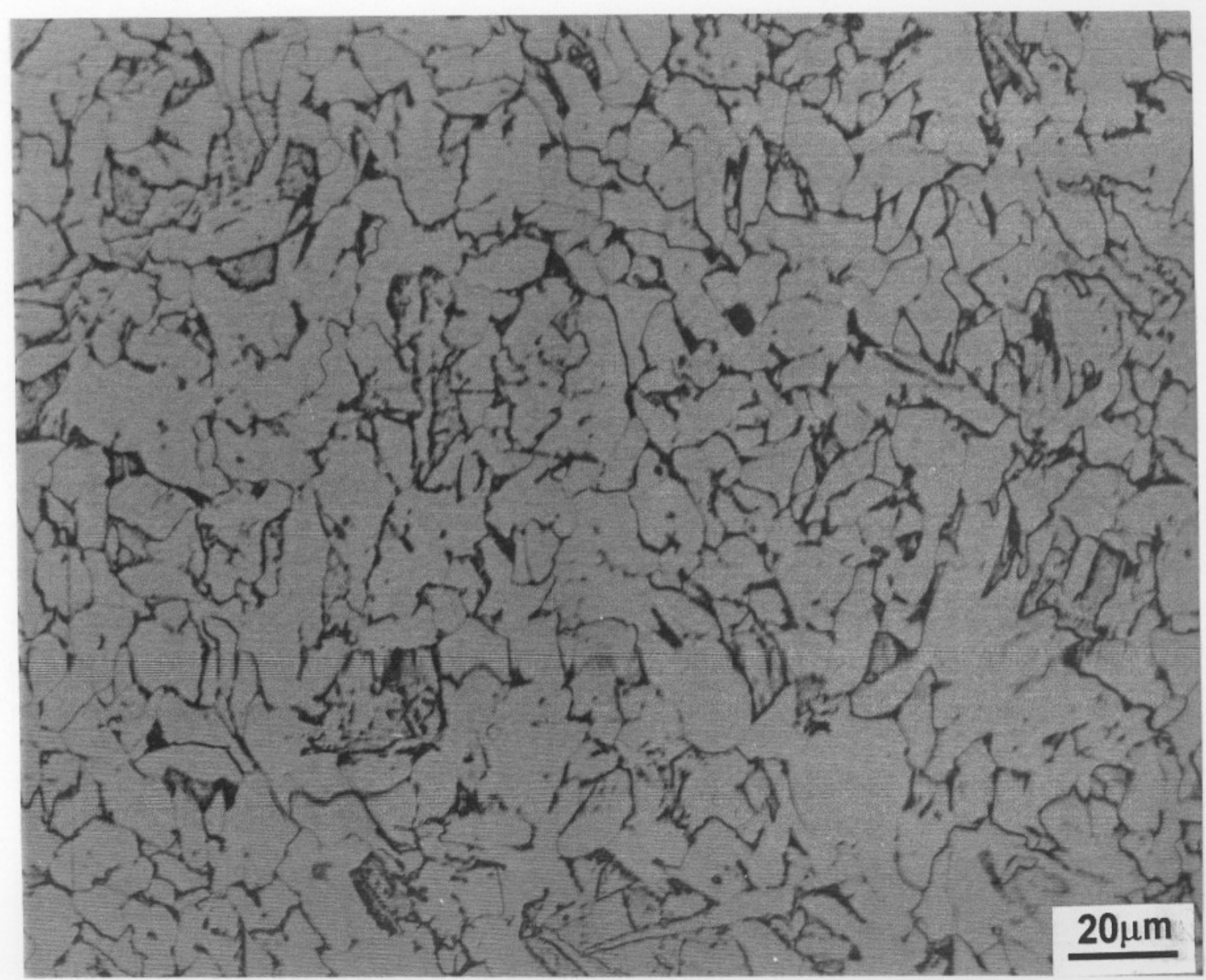

FIGURA 39 - Amostra do aço ASTM 1014; no campo 7, ataque com Nital $2 \%$.

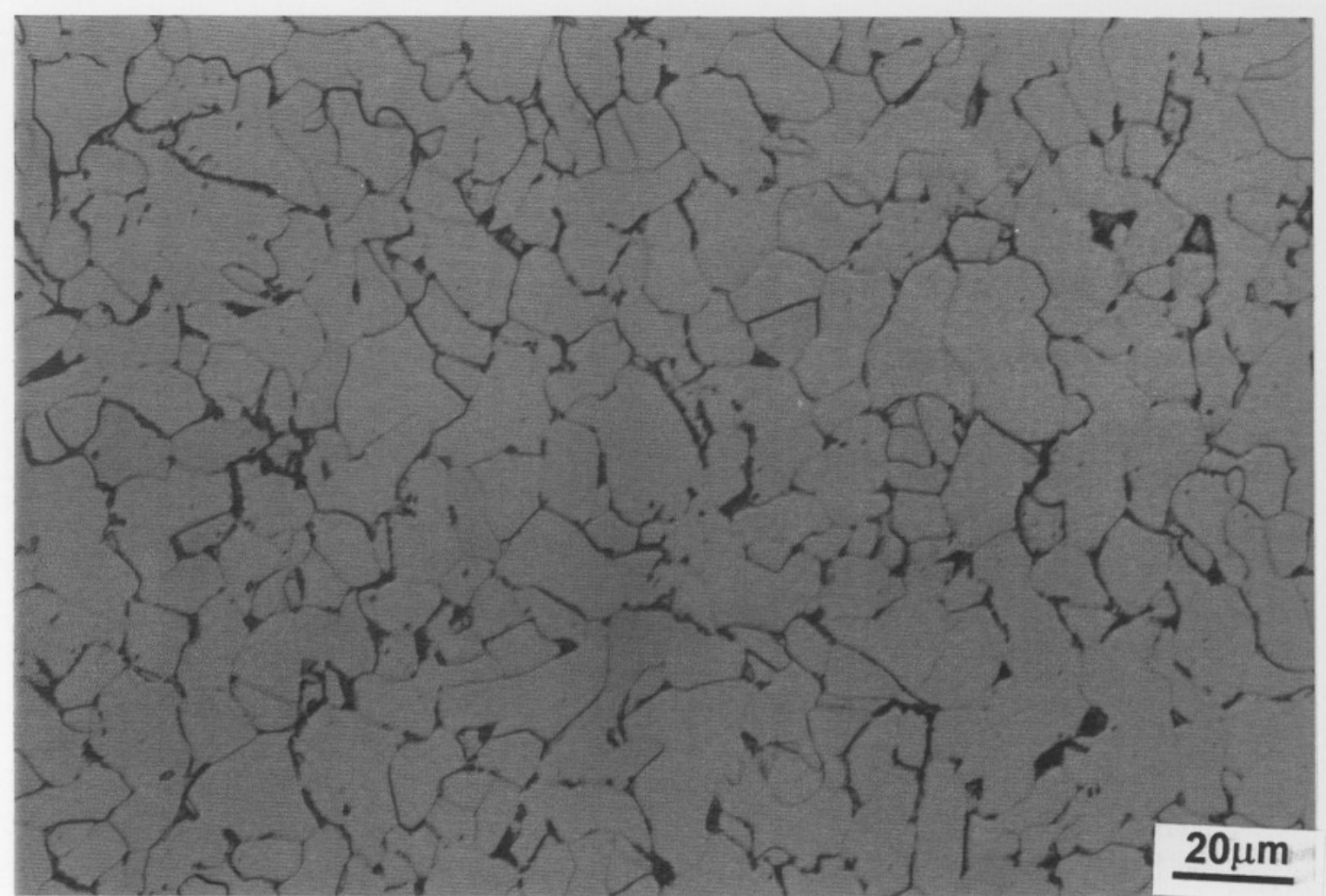

FIGURA 40 - Amostra do aço ASTM 1009, no campo 1, ataque com Nital $2 \%$. 


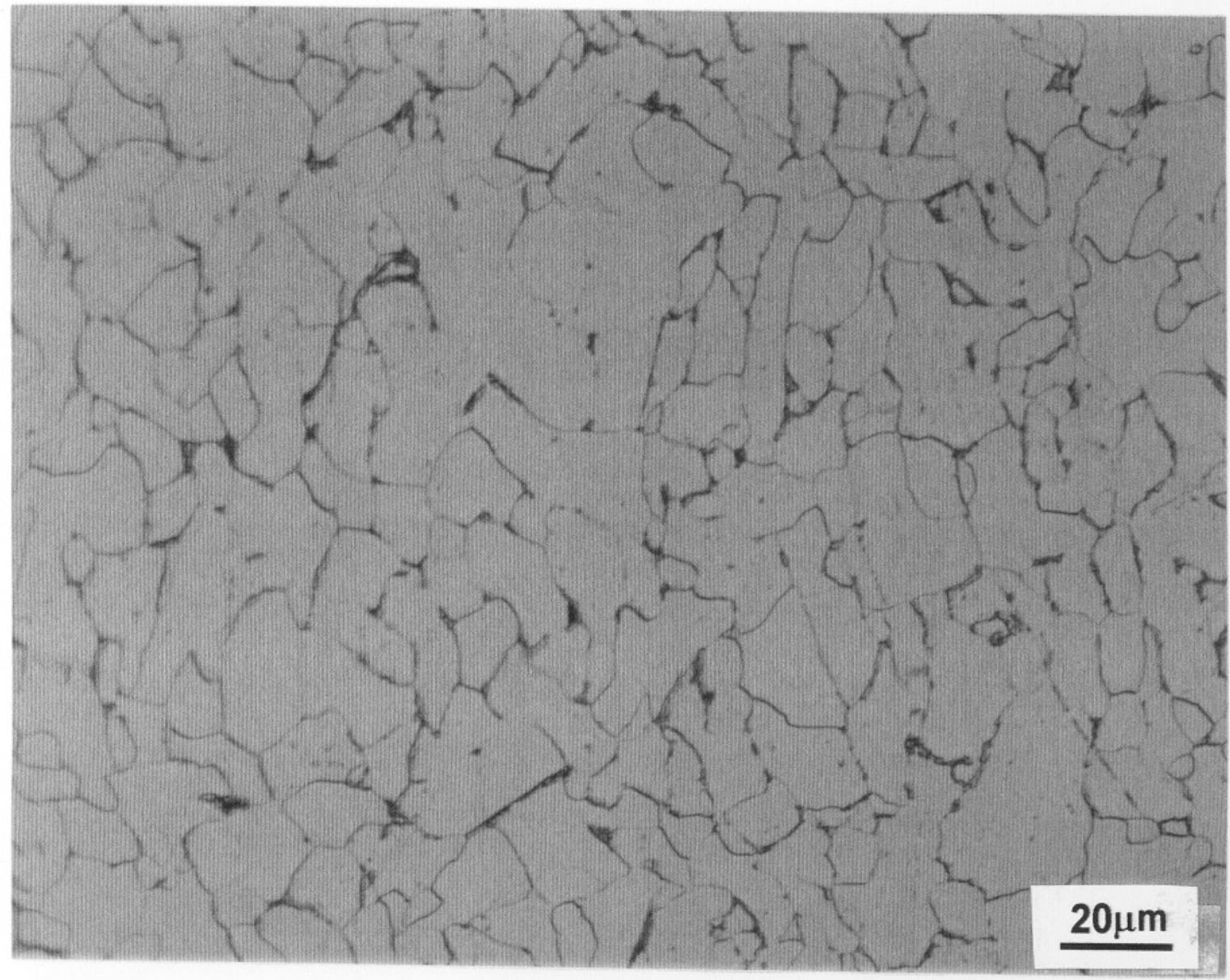

FIGURA 41 - Amostra do aço ASTM 1008, no campo 4, ataque com Nital 2\%.

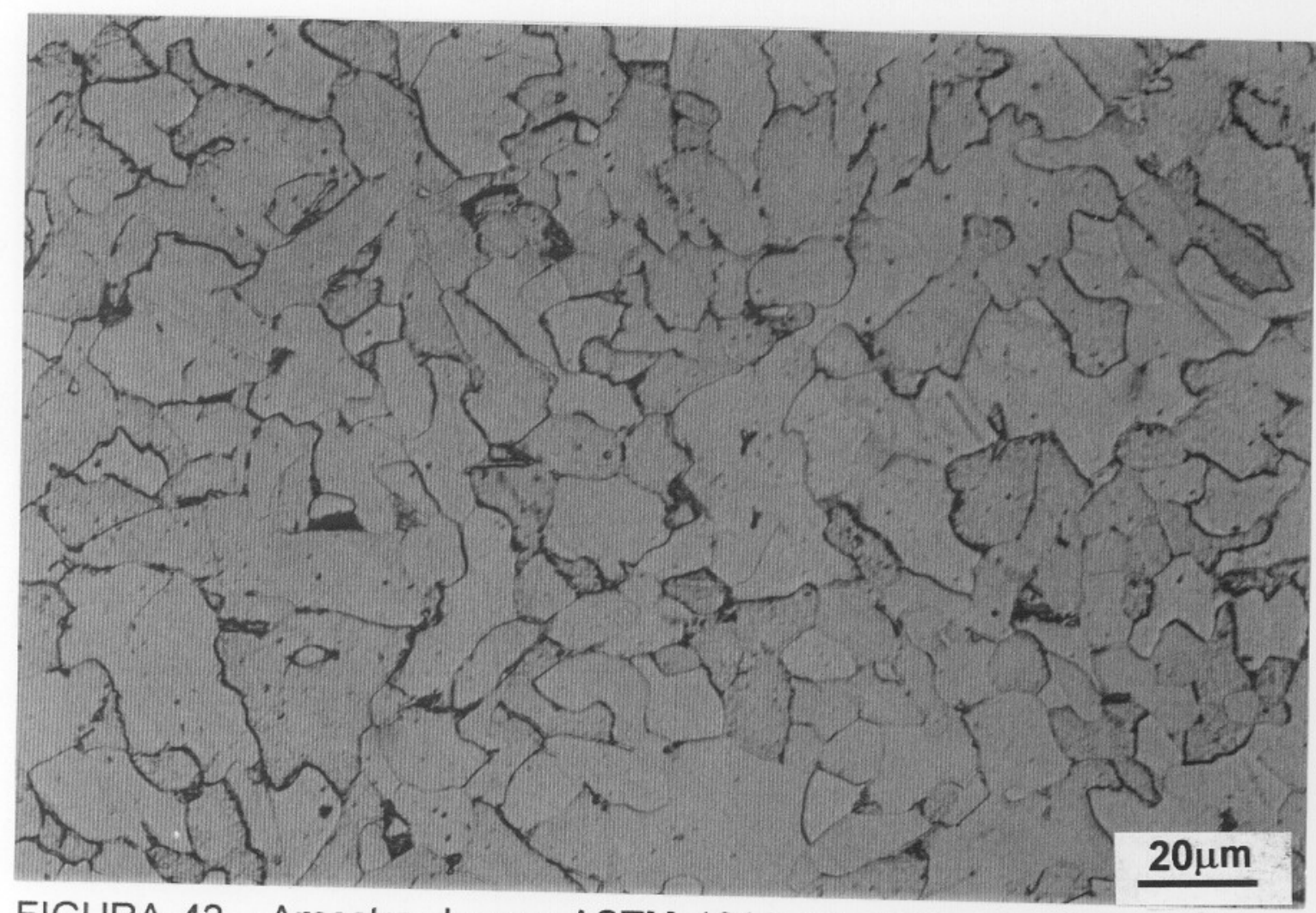

FIGURA 42 - Amostra de aço ASTM 1011, no campo 6, ataque com Nital $2 \%$. 


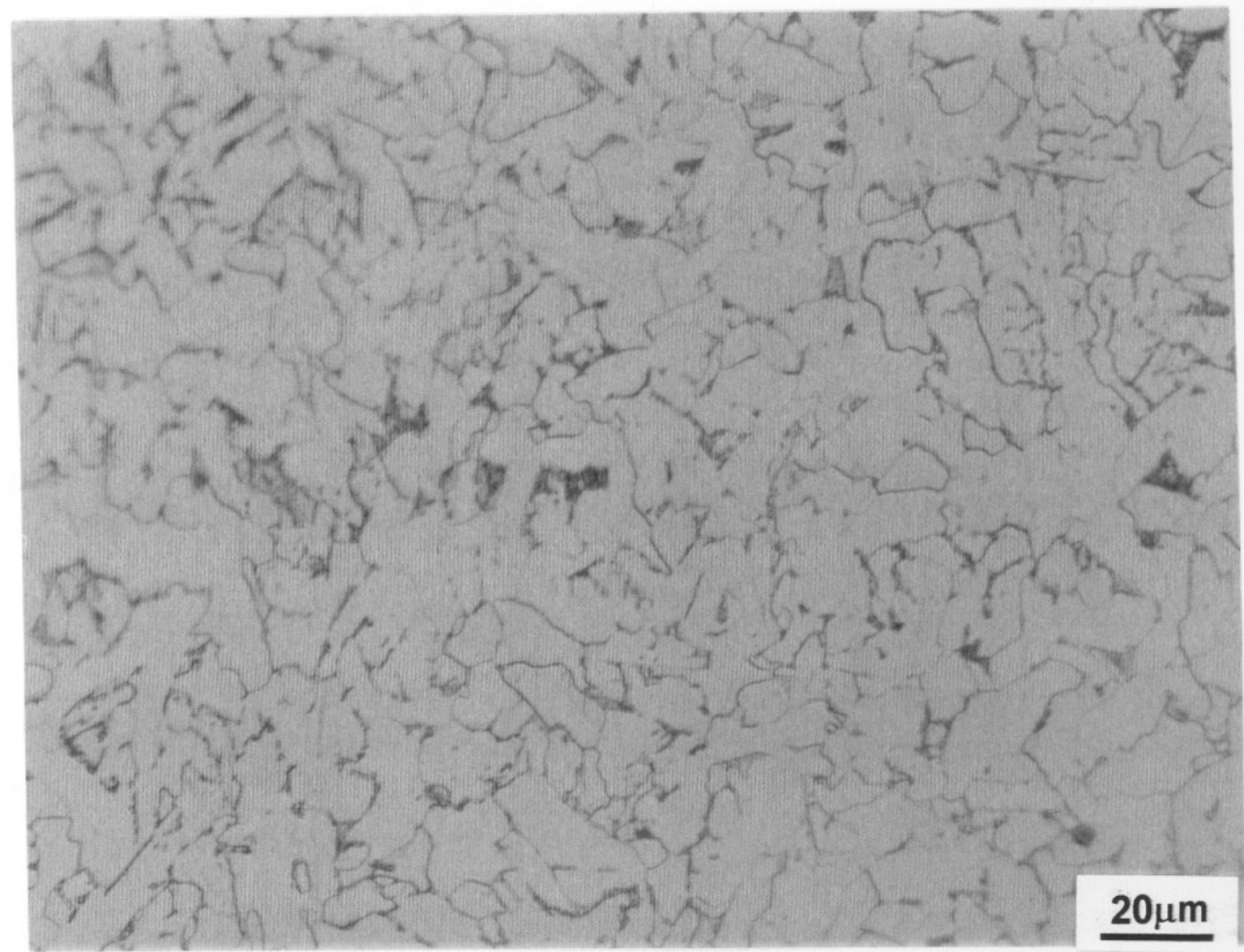

FIGURA 43 - Amostra do aço ASTM 1012, no campo 9, ataque com Nital $2 \%$.

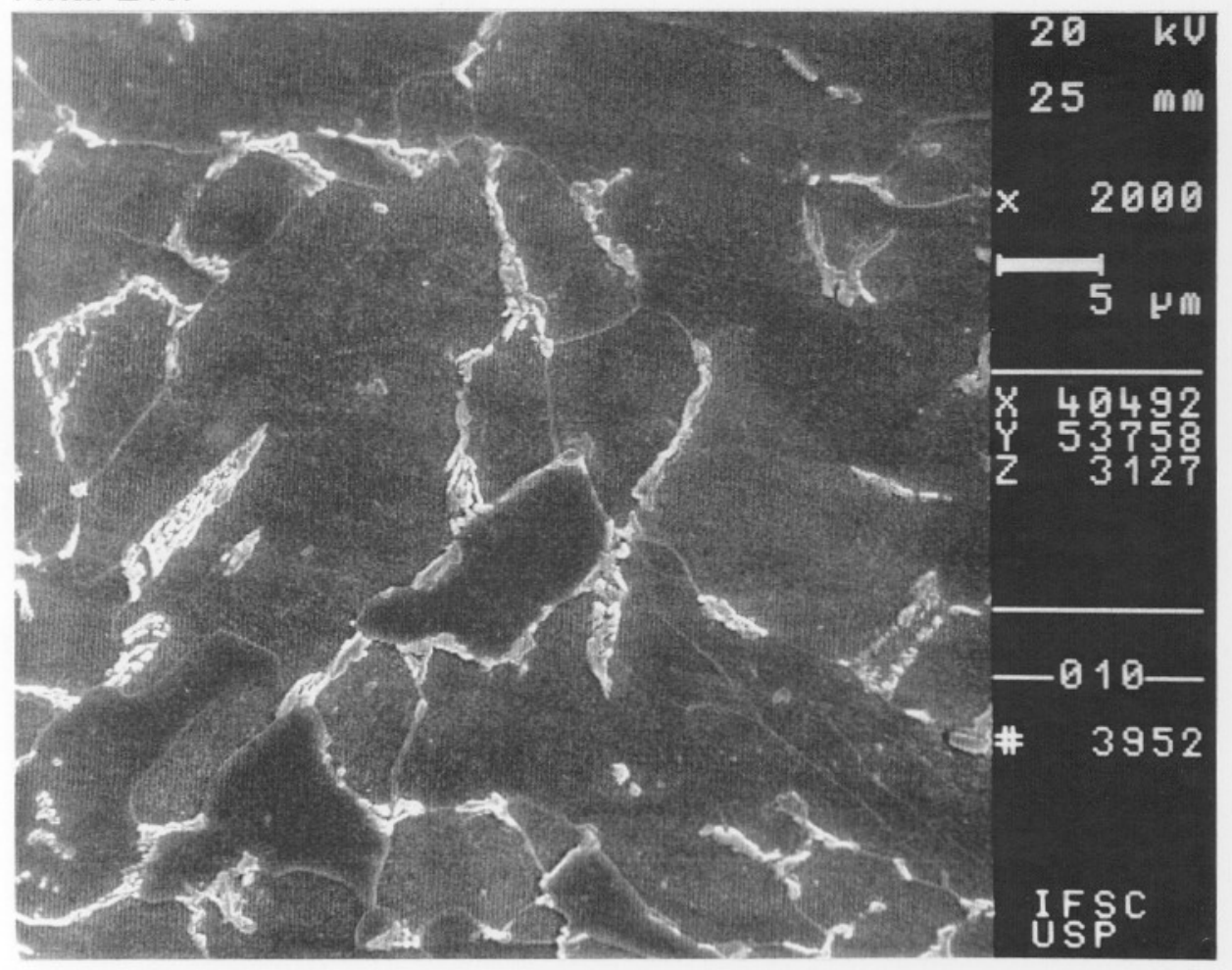

FIGURA 44 - Ilustra a perlita no contorno de grão ferrítico do aço ASTM 1012; MEV, ataque com Nital $2 \%$. 


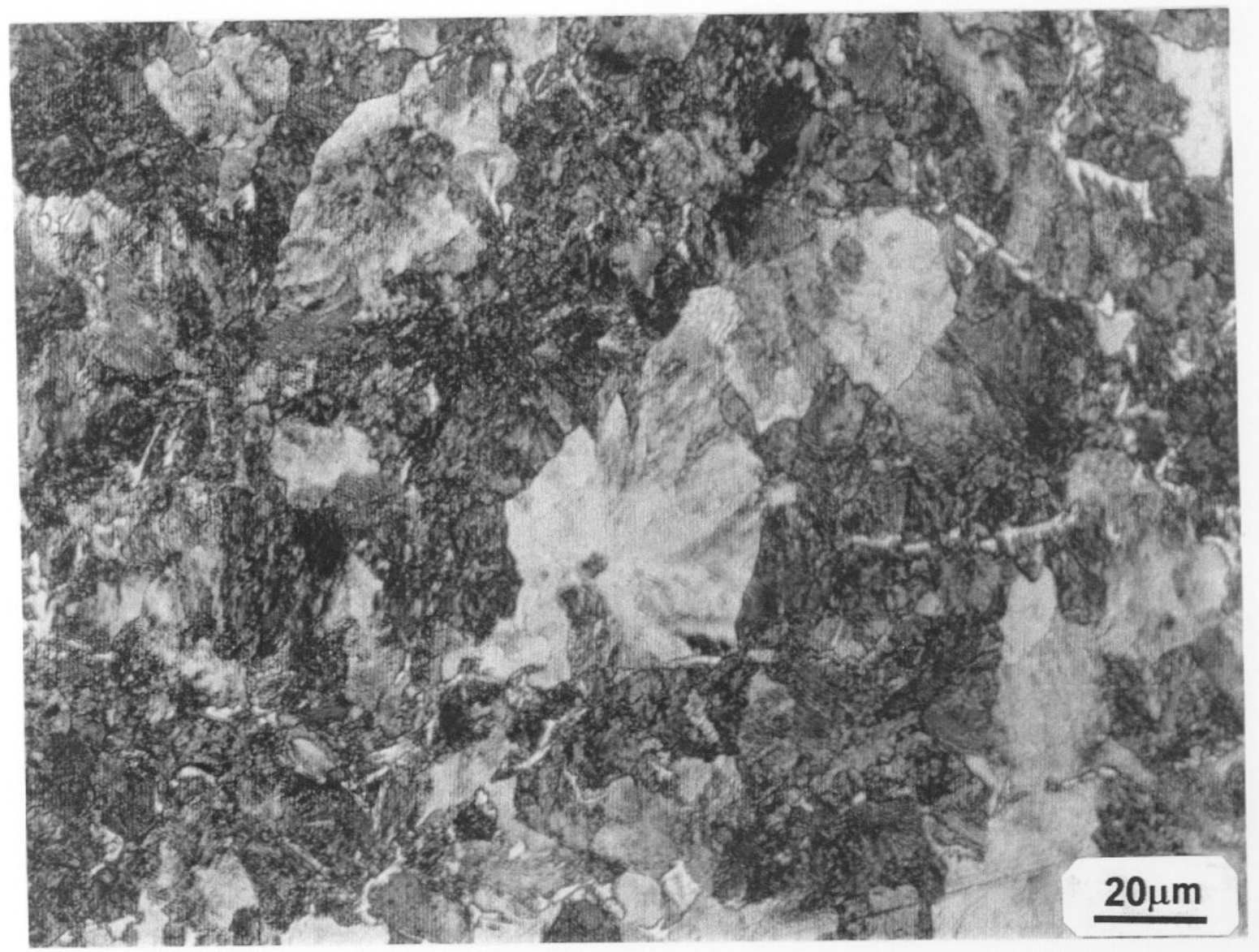

FIGURA 45 - Amostra de aço ASTM 1056, no campo 3, ataque com Nital $2 \%$.

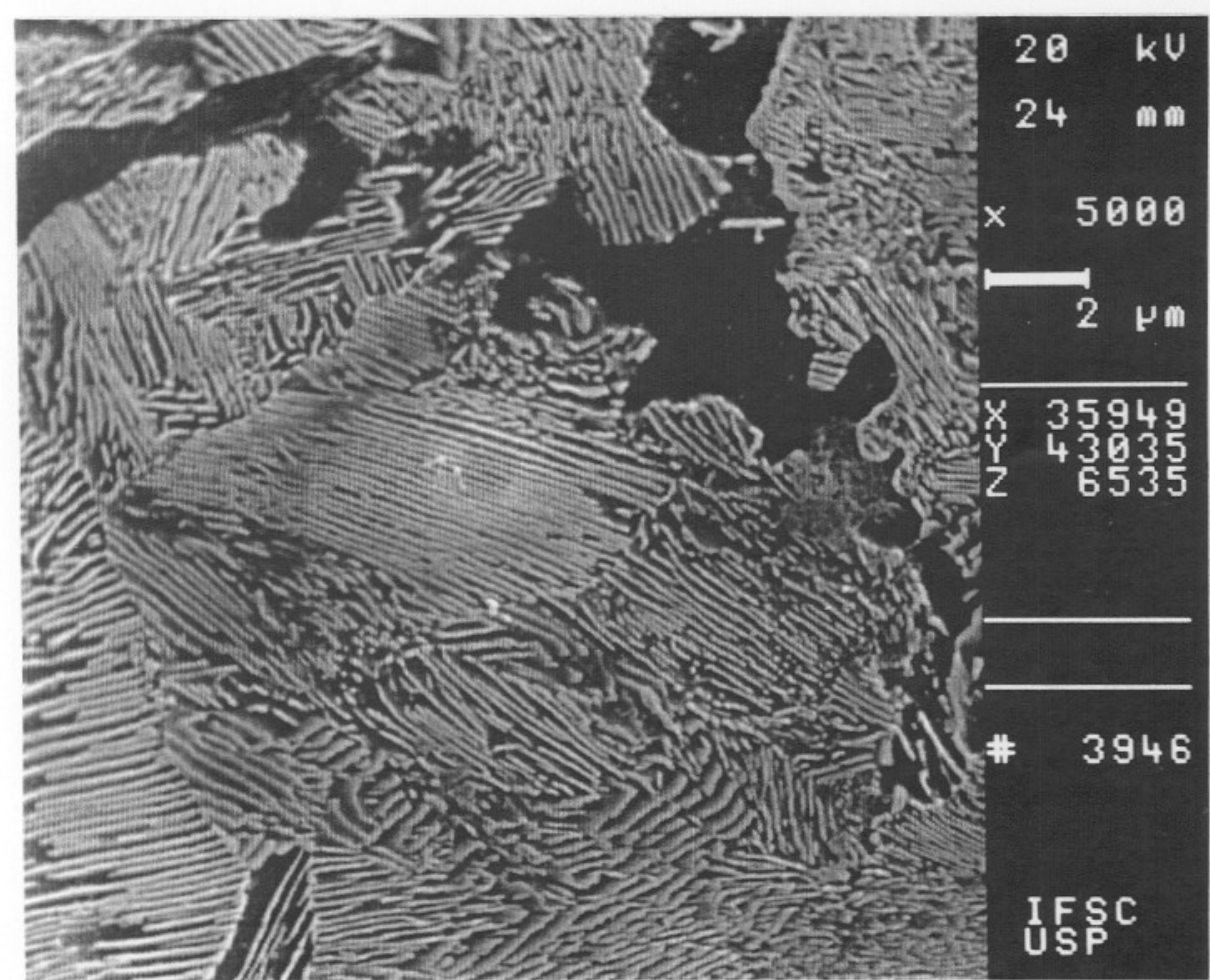

FIGURA 46 - Ilustra a perlita e a ferrita do aço ASTM 1056 (Nital 2\%, MEV), ataque com Nital $2 \%$. 


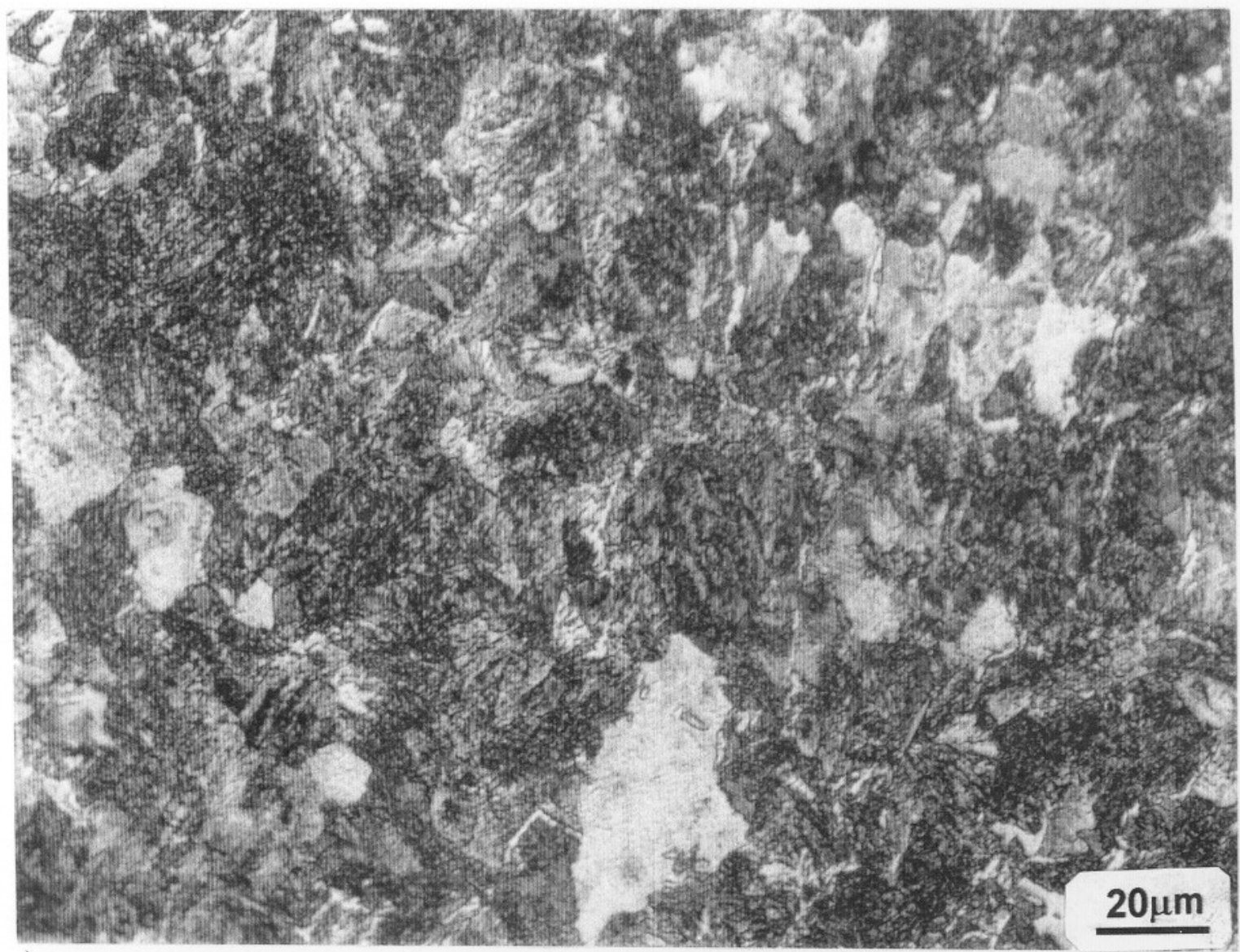

FIGURA 47 - Amostra de aço ASTM 1056, 0,7\% de manganês, campo1, ataque com Nital $2 \%$.

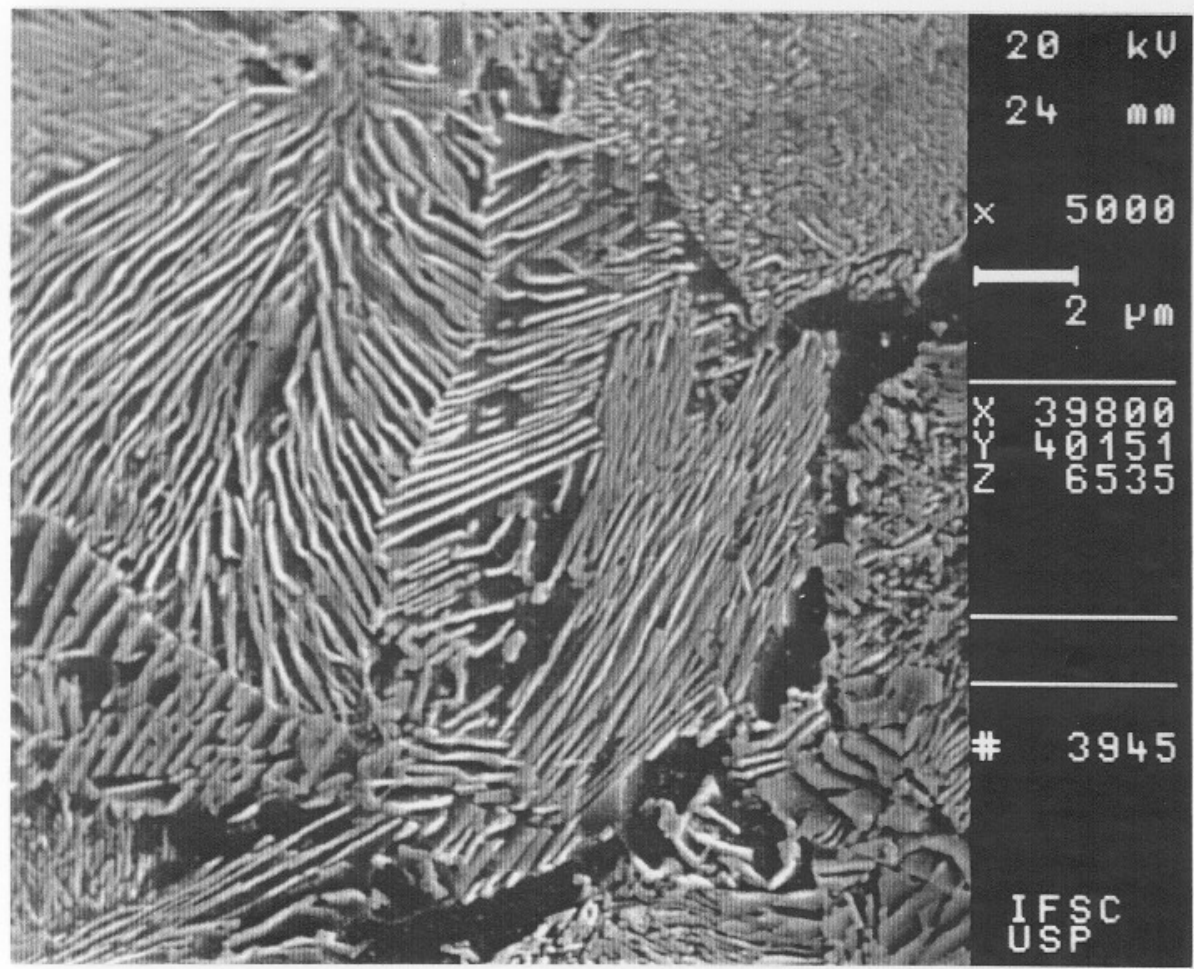

FIGURA 48 - llustra a perlita e a ferrita do aço ASTM 1056 0,7\% manganês, ataque com Nital $2 \%$. 
III.6 - Método que utiliza o sistema de análise de imagens

O sistema de análise de imagens utilizado para as medidas quantitativas das características microestruturais está esquematizado na figura 49.

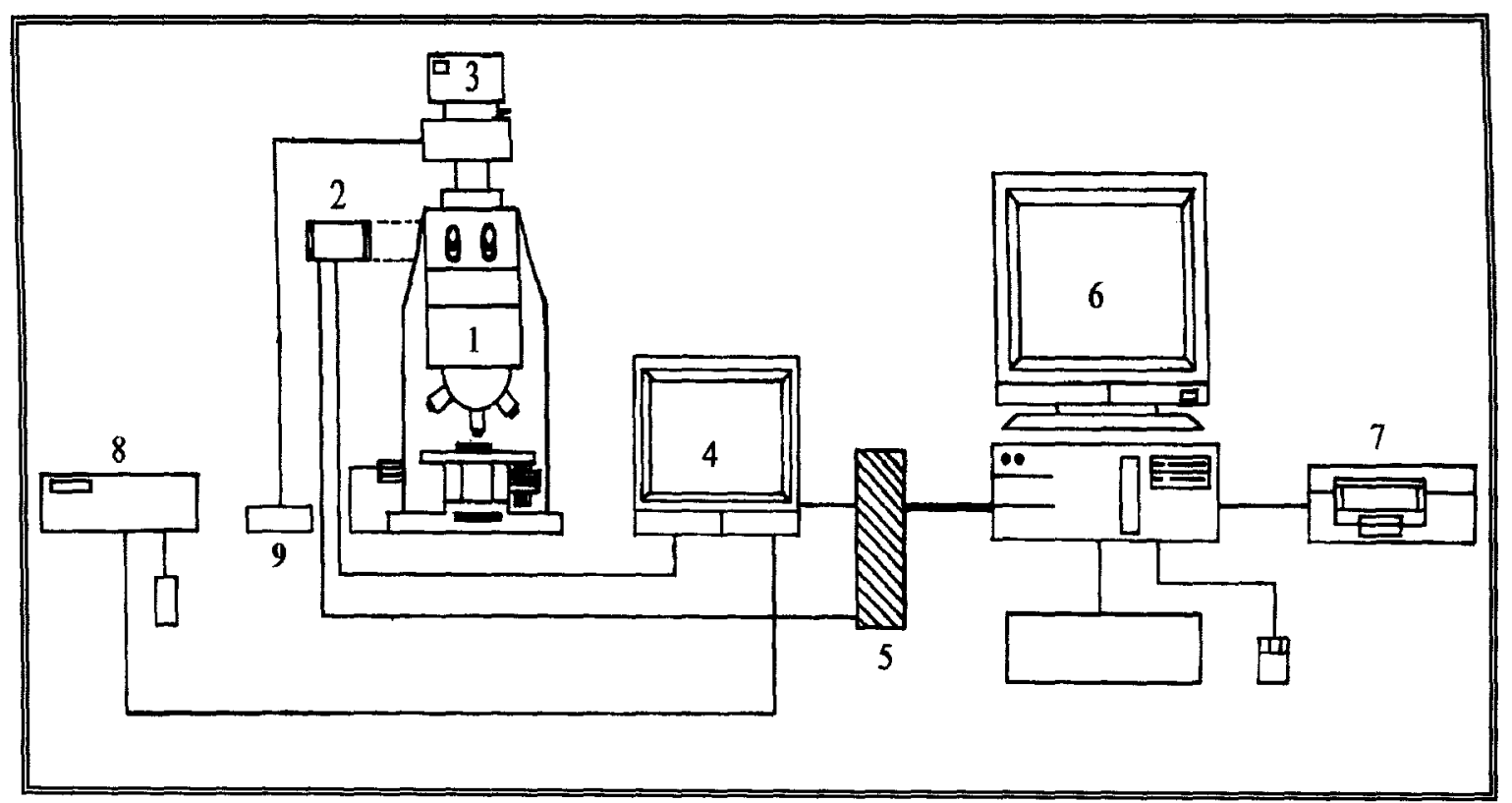

FIGURA 49 - Esquema do sistema de análise de imagem.

1 - Microscópio óptico,

2 - Câmera CCD/RGB,

3 - Máquina fotográfica,

4 - Monitor de vídeo,

5 - Placa digitalizadora,

6 - Microcomputador 486 DXR,

7 - Impressora,

8 - Impressora de vídeo,

9 - Fotômetro automático;

As amostras foram analisadas com aumento da objetiva de $500 X$.

No sistema de iluminação do microscópio óptico LEITZ-DMRX, procurou-se manter uma intensidade de iluminação o mais possível 
padronizada. O sinal de saída da câmera é normalmente proporcional à quantidade de luz refletida na amostra observada. Isto significa que é proporcional à capacidade reflectiva e à intensidade da fonte de luz. A iluminação deve ser estável e bem calibrada mas isto só não basta. Deverá ser uniforme. Isto significa que, para um objeto de cor uniforme, o sinal de vídeo não deve variar com a posição no campo das medidas. Deve-se combinar o alcance dinâmico da câmera (intensidade detectável máxima e mínima) na microestrutura observada.

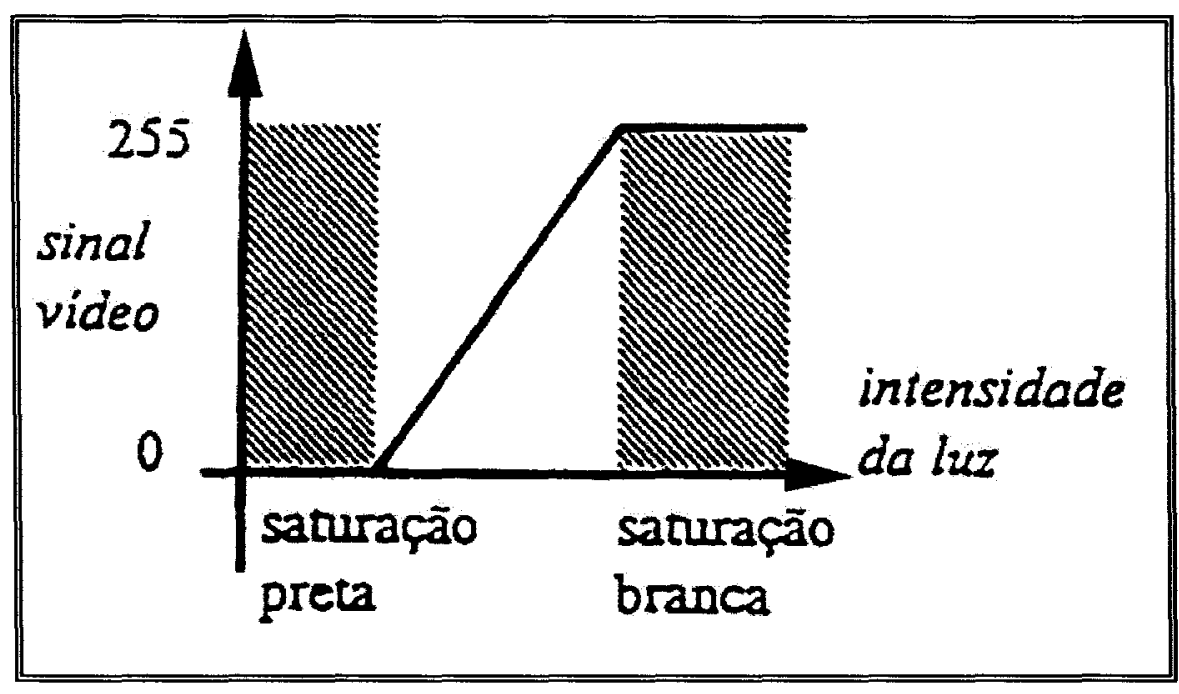

FIGURA 50 - llustra que o nível de cinza zero deve corresponder à intensidade mínima e o nivel de cinza de 255 , à intensidade máxima no campo observado.

A própria microestrutura pode criar saturações, caso grandes áreas de preto ou de branco estiverem presentes na imagem. Por isso, escolheu-se, para a calibração da intensidade de iluminação, uma imagem bem representativa da microestrutura a ser analisada.

É possivel obter informações através do histograma distributivo dos níveis de cinza, que deverá ser, no caso ideal, parecido a uma distribuição log-normal 
No microscópio óptico, utilizou-se o filtro azul, pois ele possui menor comprimento de onda, o que melhora a resolução da imagem conforme VOORT (1995). Com o auxilio de uma câmera de vídeo CCD/RGB adaptada ao microscópio óptico LEITZ DMRX, a imagem foi transferida para um monitor de vídeo colorido, que reproduz a imagem com o ajustamento do microscópio óptico. A imagem ajustada no microscópio óptico é então digitalizada através de uma placa "frame grabber" com o auxílio de um software "Mocha" Versão 1.1 "Operator s Guide,(1993) ${ }^{1}$; CASTORINO et. al. (1996), SILVA et al.(1995).

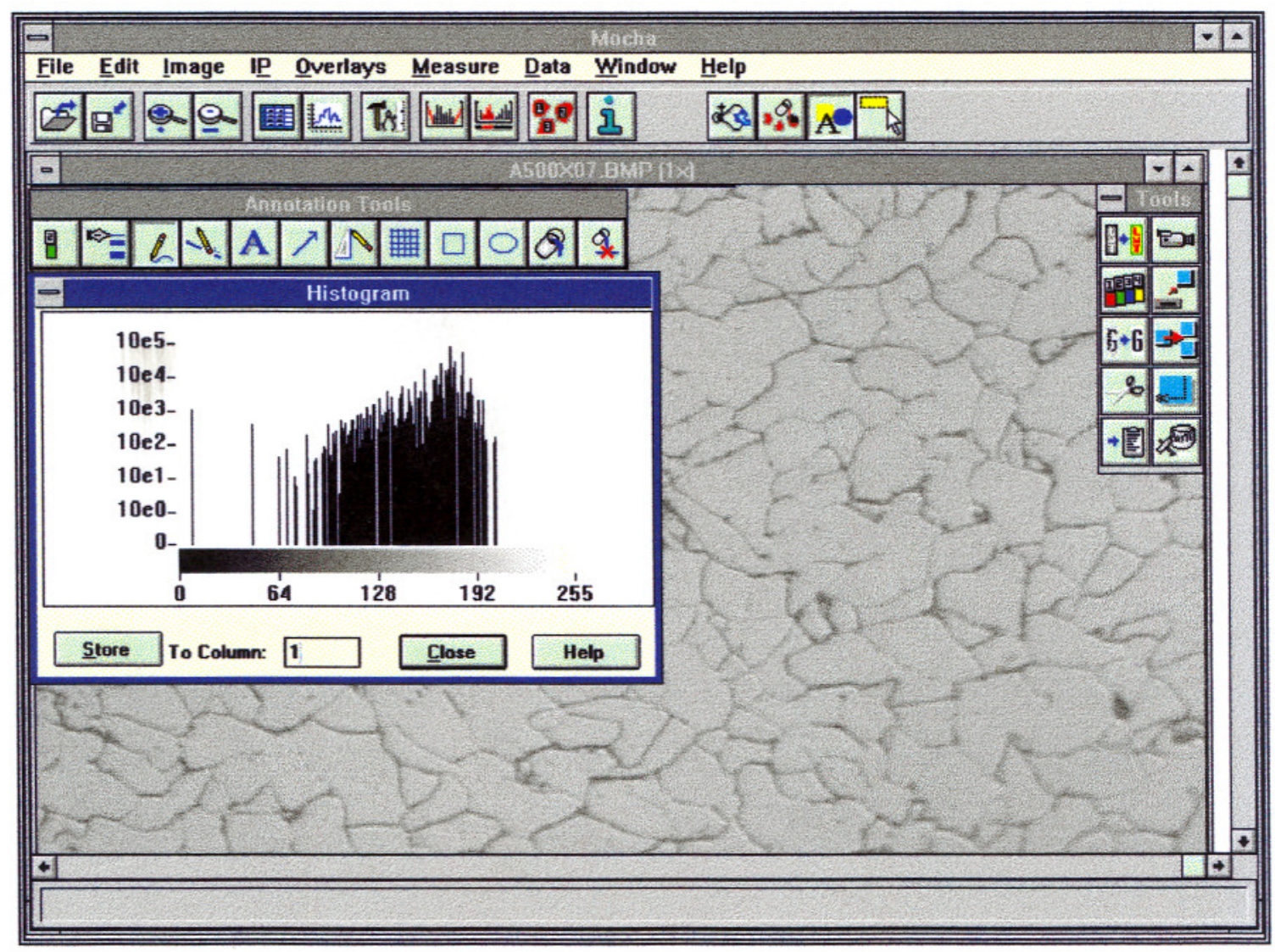

FIGURA 51 - llustra o software "MOCHA versão 1.1". Observa-se ao fundo a microestrutura do aço carbono 1005, com o histograma de distribuição de níveis de cinza.

\footnotetext{
${ }^{1}$ Este guia do usuário pode ser adquirido no laboratório de transformação de fases do Departamento de Materiais EESC-USP. Av. DR. Carlos Botelho, Cep: 13560250, São Paulo, Brasil-Telef : 016-274 3444 R $3189 \quad$ Fax: 2749213
} 
Utilizou-se, como apoio ao software "Mocha, versão 1.1", o software "Adobe Photoshop, versão 4.0" "Operator s Guide" (1997) ${ }^{2}$, CASTORINO, E. et. al. (1996), SILVA, E. C. et al.(1995), para promover a normalização das imagem.

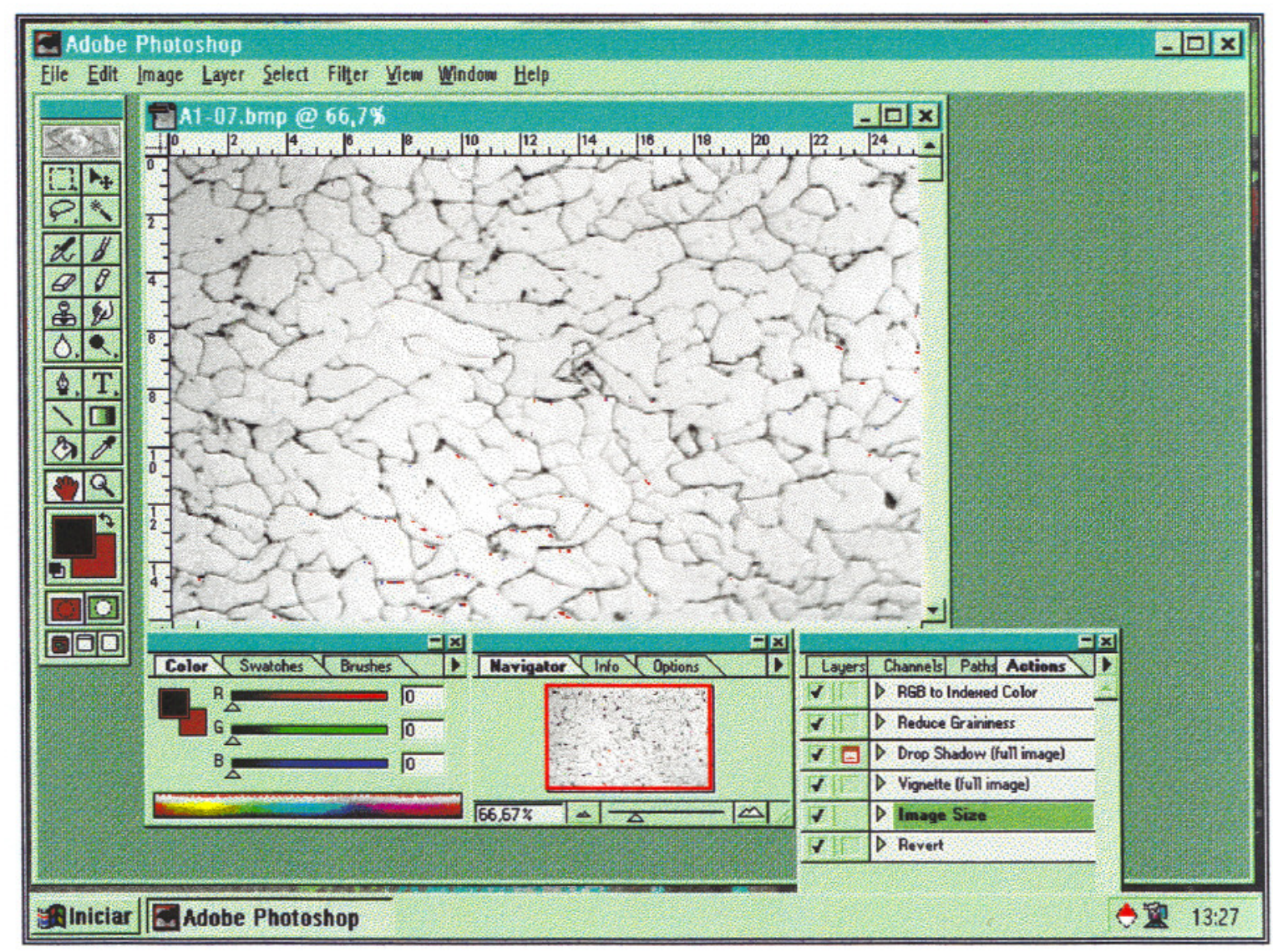

FIGURA 52 - Ilustração do software Adobe Photoshop, Versão 4.0

O "MOCHA" digitaliza imagens com extensão em (.BMP) e com uma resolução de 72 dpi (densidade de píxel por polegada).

${ }^{2}$ Este guia do usuário pode ser adquirido no laboratório de transformação de fases do Departamento de Materiais EESC-USP. Av. DR. Carlos Botelho, Cep: 13560250, São Paulo, Brasil - Telef: 016-274 3444, ramal 3189 Fax: 2749213 
A figura 53 ilustra exemplo da microestrutura das imagens da amostra 1, que foram digitalizadas pela placa "Frame grabber", com os ajustes padronizados pelo microscópio óptico.

Para cada amostra analisada foram digitalizadas 10 imagens cromática. Todas as imagem foram arquivadas em disquetes.

Em seguida, recortaram-se as bordas das imagens, retirando-se 0 risco de interferência da digitalização, conforme ilustra a figura 54 . Converteu-se cada imagem digitalizada de cromática em monocromática, conforme a figura 55.

O software "Adobe Photoshop 4.0" possui comando de correção automática da tonalidade, que define o clareamento e o escurecimento dos píxeis numa faixa intensiométrica como branco e preto na escala de cinza ( 0 a 255) e então redistribui o valor do píxel intermediário proporcionalmente. Após a correção automática da tonalidade das 10 imagens de cada amostra, elas foram colocadas lado a lado e utilizados os recursos do Software "Adobe Photoshop", versão 4.0 para promover o ajuste do brilho e contraste das imagens. Para isto, escolheu-se uma imagem como referência conforme ilustra a figura 56 e reajustaram-se as demais em função da escolhida. Após o ajuste do brilho e contraste, utilizaram-se se os recursos dos filtros, para eliminar os ruídos conforme a figura 57 a 59 , observados através de um zoom na imagem.

As imagens foram gravadas no Software "Adobe Photoshop, versão 4.0 e chamadas no software "mocha", versão 1.1". 

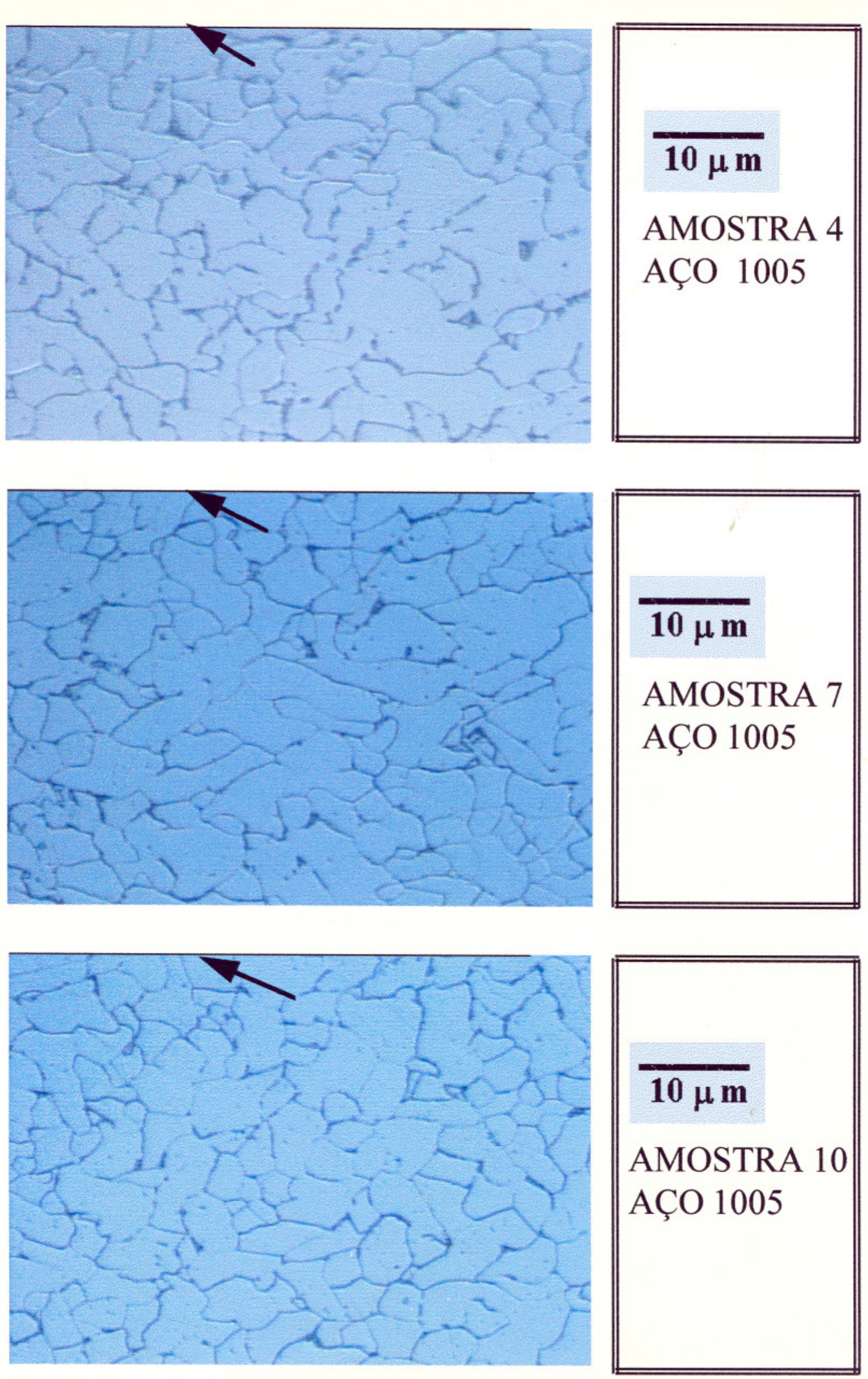

FIGURA 53 - Aço ASTM 1005, digitalizado pela placa "Frame grabber", com a utilização do software específico "Mocha", versão 1.1. Observam-se a diferença de intensidade de iluminação e o risco na bordas indicado pela seta. 

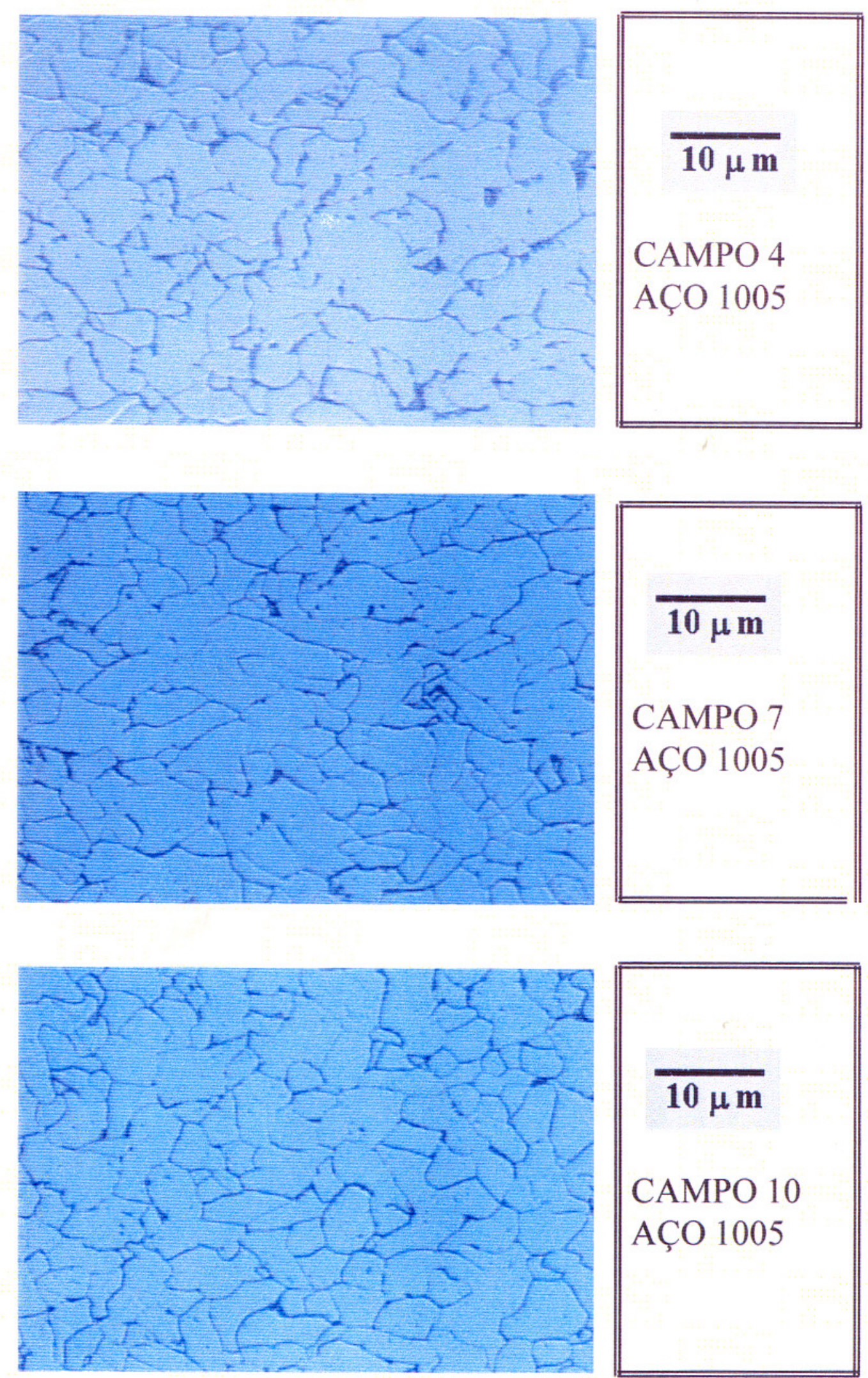

FIGURA 54 - llustra a imagem digitalizada da amostra de aço ASTM 1005, com a eliminação do risco da borda. 

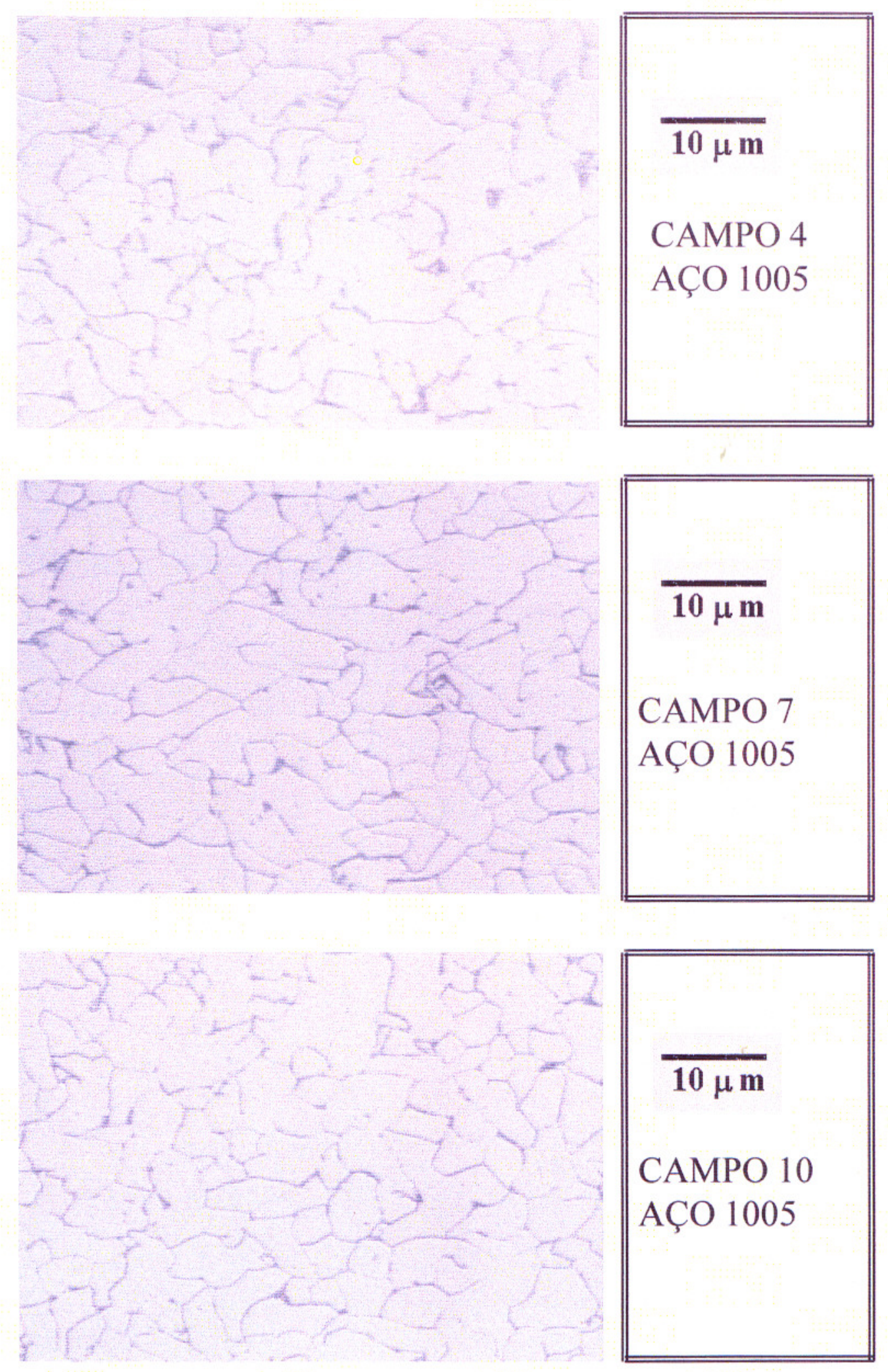

FIGURA 55 - Ilustra a imagem digitalizada da amostra de aço ASTM 1005 , com a borda cortada e convertida para monocromática. Observase a diferença da intensidade de iluminação 

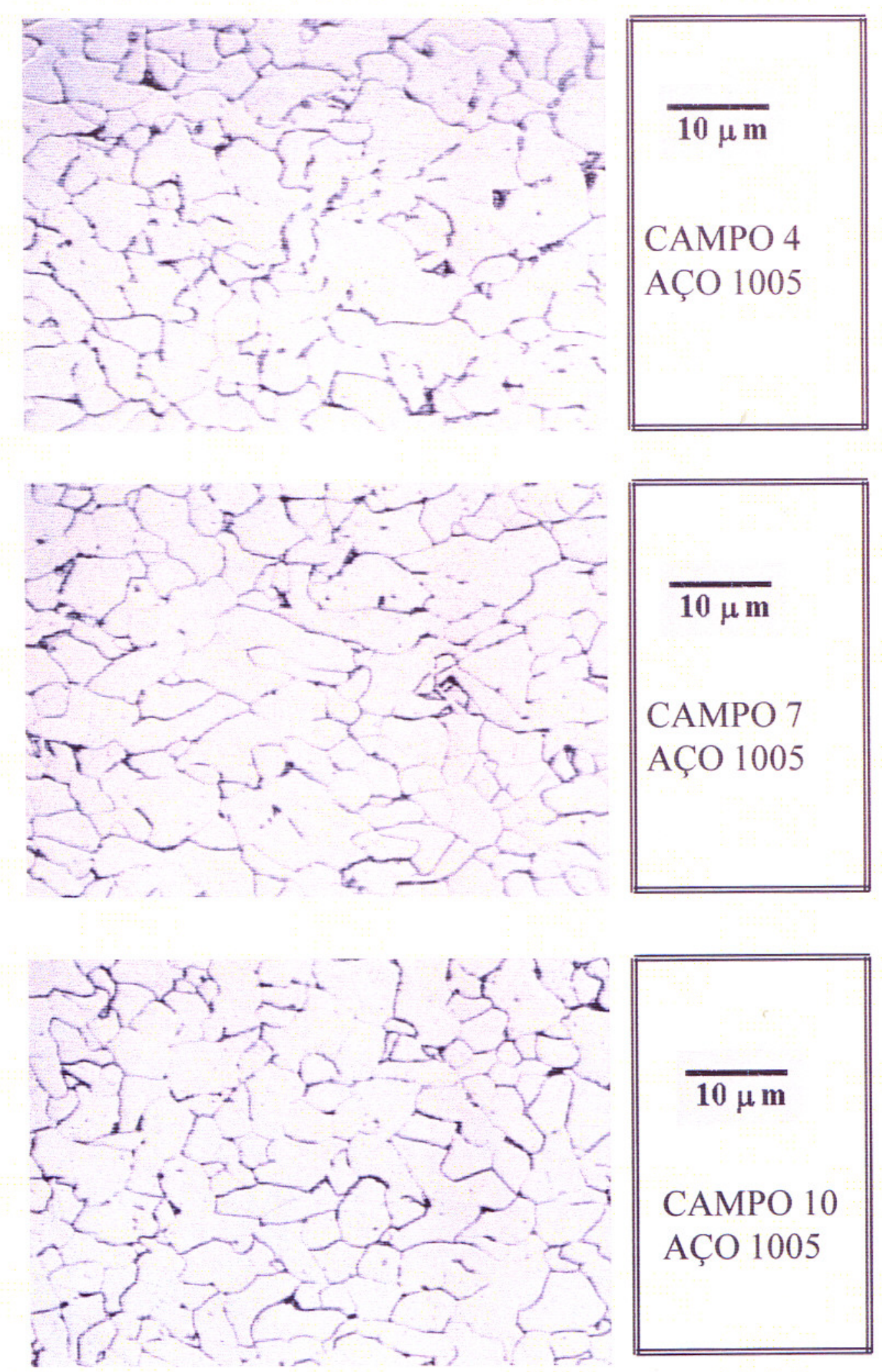

FIGURA 56 - Ilustra a imagem digitalizada do aço ASTM 1005, com um auto ajuste do histograma de niveis de cinza. 


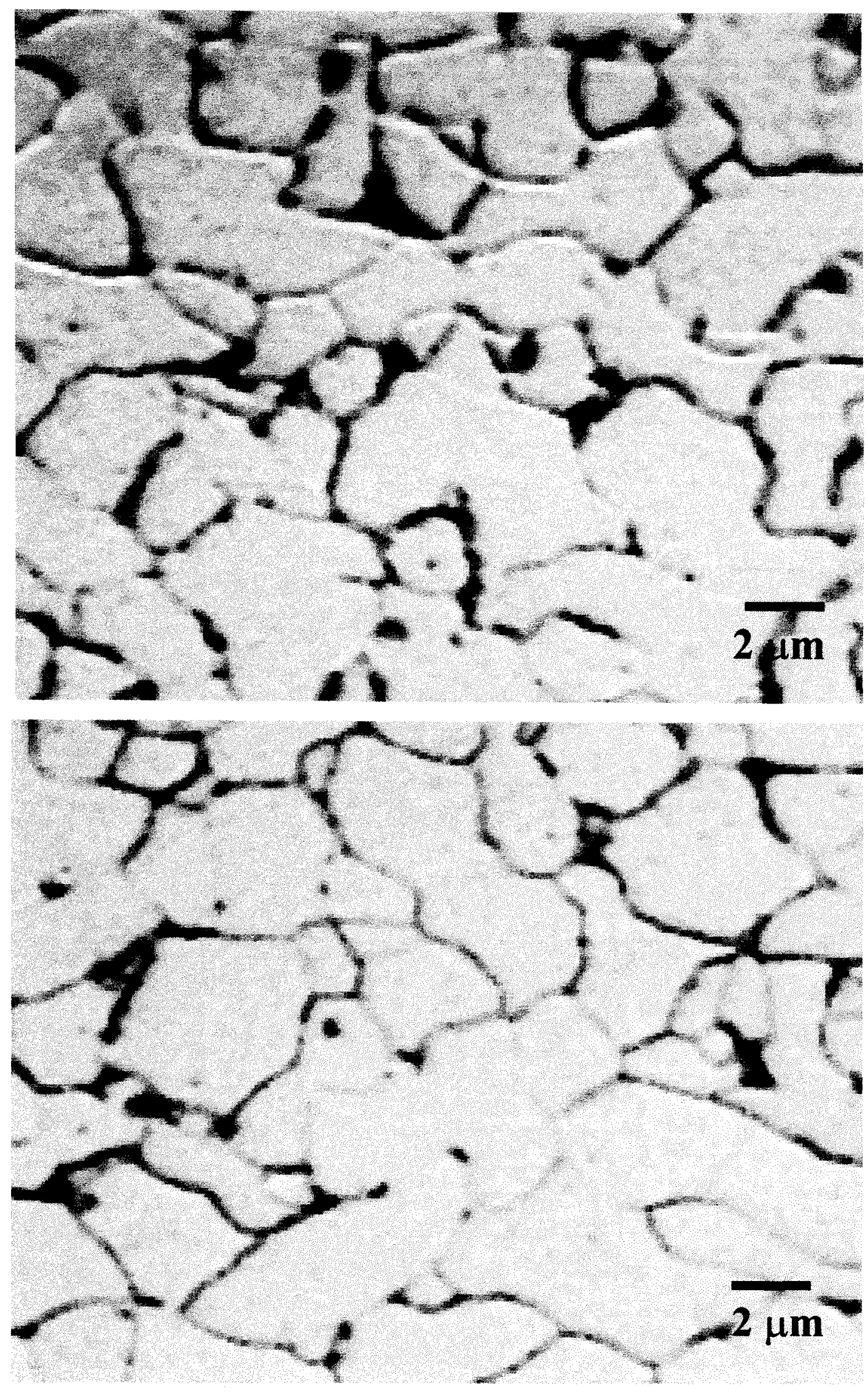

FIGURA 58 - llustra a imagem da amostra de aço ASTM 1005, campo 4 e campo 7. Detalhe de uma região amplificada da imagem original (Zoom),. Nesta se observa o efeito da utilização do filtro mediano na imagem original. 


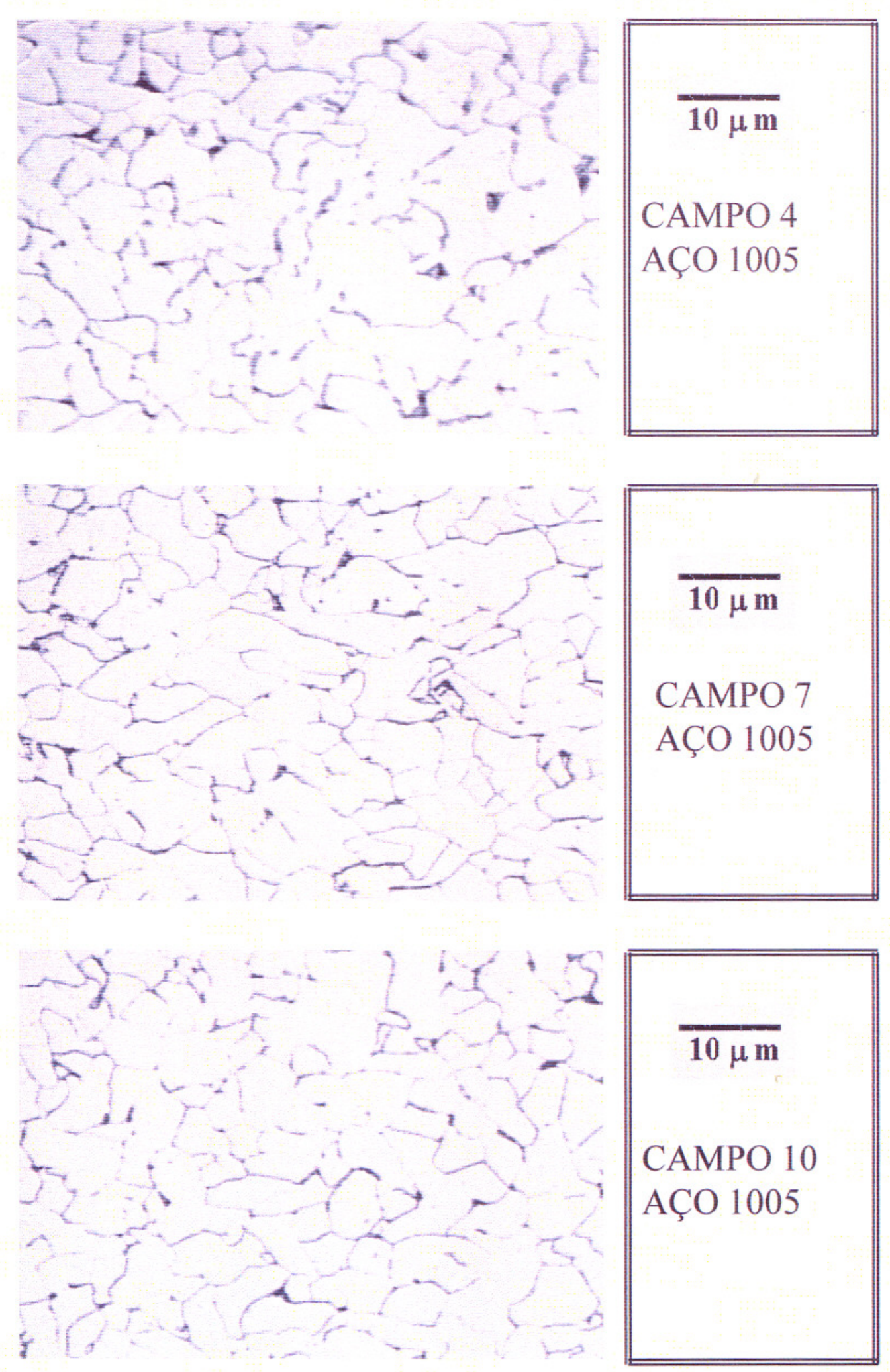

FIGURA 59 - Ilustra a imagem digitalizada da amostra de aço ASTM 1005. Observam-se a eliminação do risco, o ajuste da intensidade de iluminação, a eliminação de ruídos e o ajuste do brilho e contraste da imagem. 
A figura 59 é a imagem considerada "Imagem Normalizada", Após estes procedimento, as imagens dos 10 campos de cada amostra foram gravadas no software "Adobe photoshop 4,0"

\section{III.6.1 - Calibracão das microestruturas}

O grupo das 10 imagens de cada amostra de aços da tabela IV, normalizadas pelo software "adobe photoshop", versão 4.0 foram gravadas em disquetes. As imagens dos aços foram abertas novamente dentro do software "Mocha versão 1.1", e calibradas para o aumento da objetiva de 500X. Utilizou-se, como referência, uma régua micrométrica digitalizada com o aumento da objetiva de 500X.

Valeu-se da calibração espacial de 2 pontos para traduzir as imagens de píxel em micrômetros.

TABELA 5 - Ilustra a calibração por dois pontos em função do aumento da objetiva, medida experimentalmente com o auxilio de uma régua micrométrica.

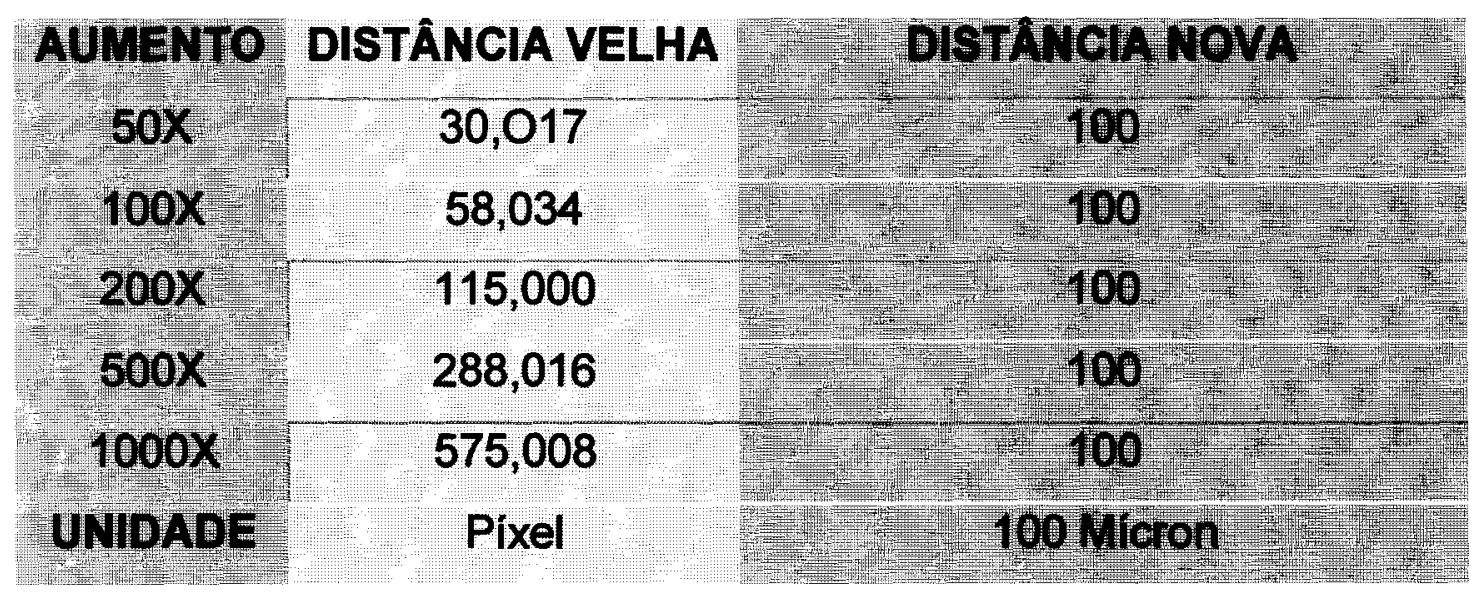

Todas as imagens digitalizadas pela placa "frame grabber" possuem uma resolução de 72 dpi (píxel por polegadas), 


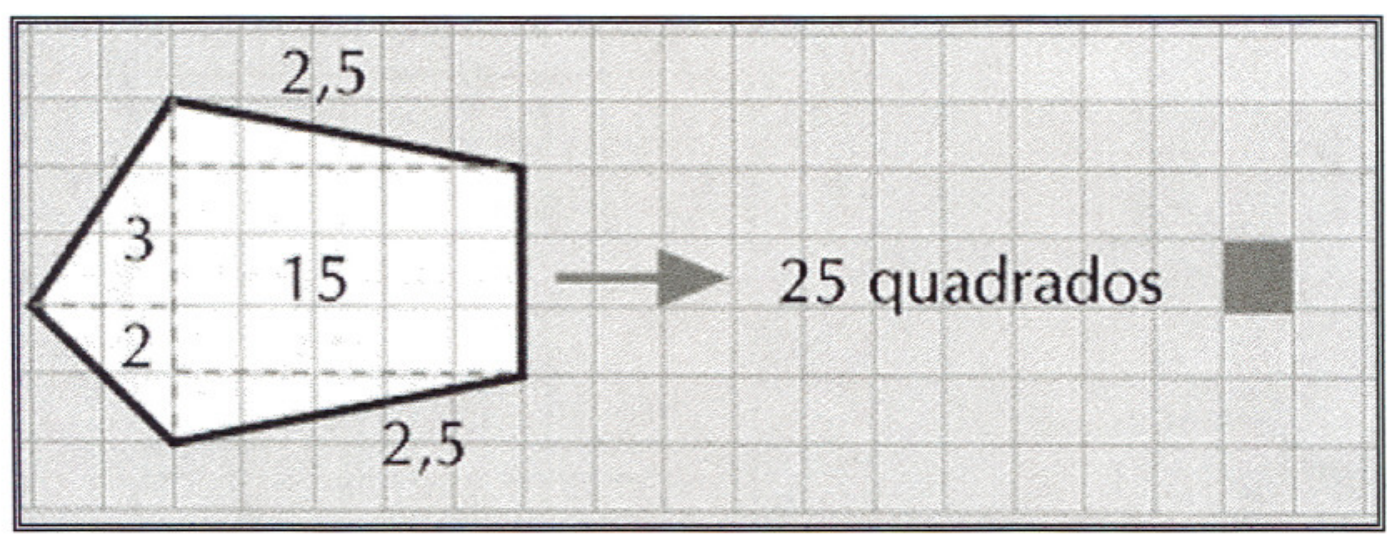

FIGURA 60 - Ilustra uma imagem de um objeto qualquer em termos de píxel. Um quadrado eqüivale a um píxel.

Utilizou-se o histograma de distribuição de níveis de cinza para delimitar os píxeis, com níveis de cinza correspondentes ao microconstituinte perlita $O$ nível de cinza, que representa melhor o microconstituinte perlita para as imagens normalizadas dos aços ao carbono comum, corresponde ao nível 100 conforme a figura 60

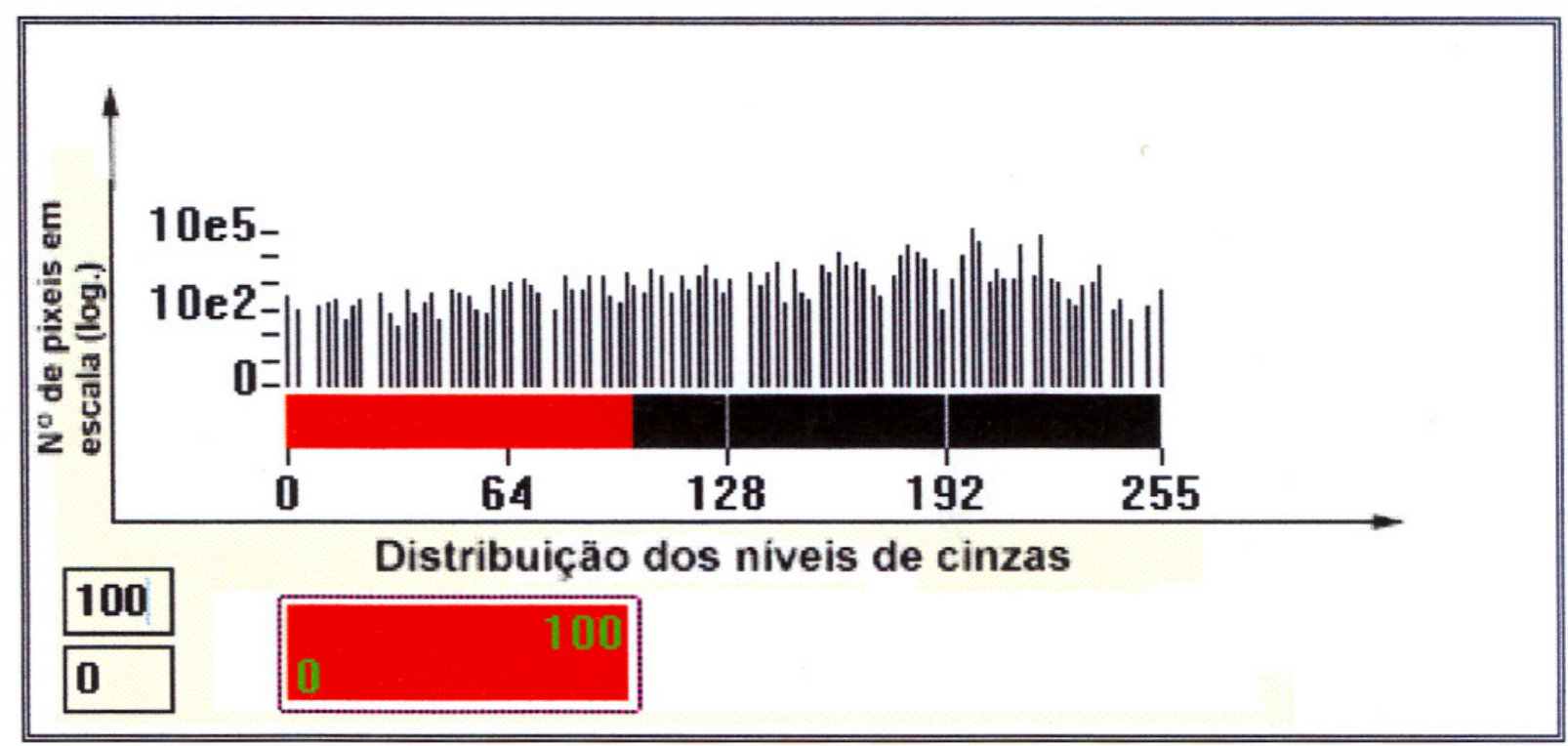

FIGURA 61 - Ilustra o nível de cinza que melhor representa os microconstituintes, na escala de distribuição dos níveis de cinza. 
Utilizou-se as ferramentas do software "Mocha" conforme ilustra os ícones da figura 61, para elimina os ricos, ruídos e artefatos indesejáveis que foram pintados a mais com o sobreplano conforme figura 65 .

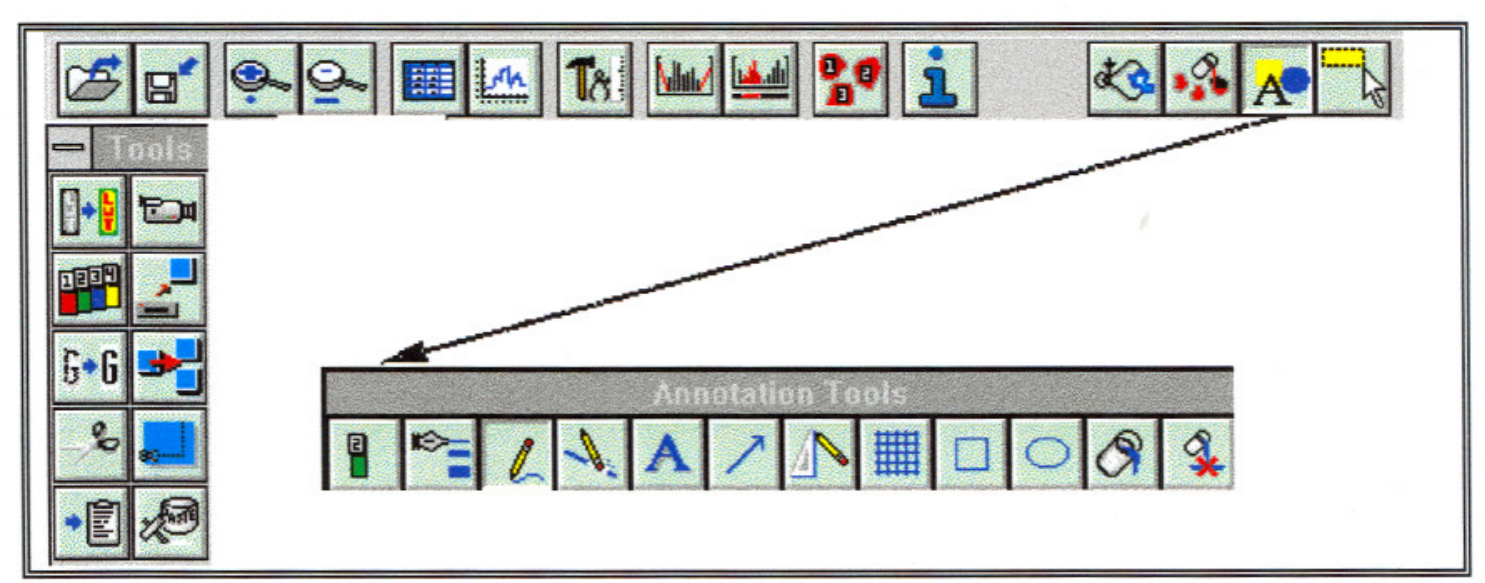

FIGURA 62 - Ilustra as ferramentas do software Mocha utilizadas na eliminação de ruídos indesejáveis que foram pintados em excesso. 


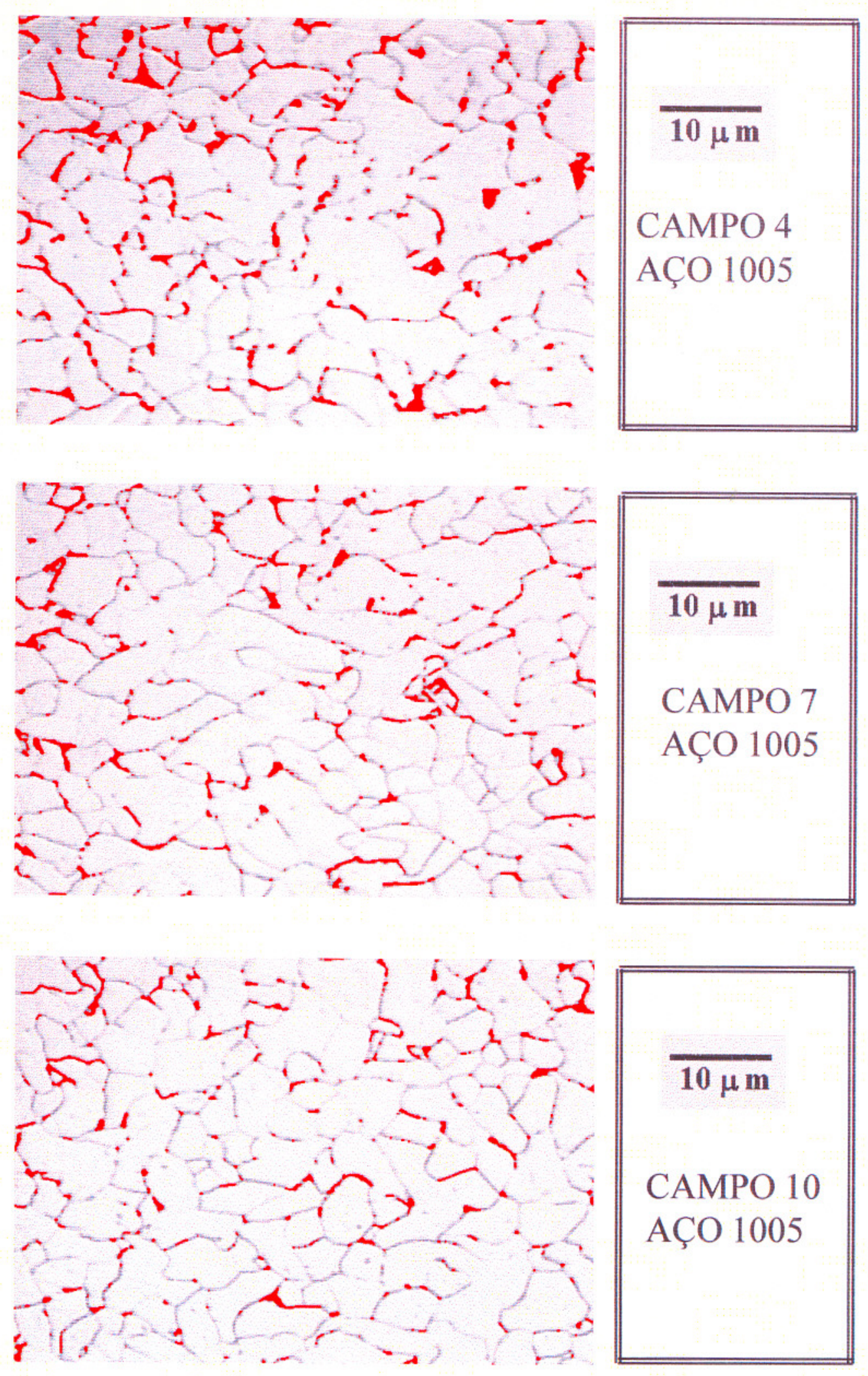

FIGURA 63 - Ilustra a imagem digitalizada e normalizada do aço ASTM 1005. Adiciou-se à imagem original um sobreplano, pintando-se os níveis de cinza de 0 a 100 , de cor vermelha, correspondendo à área da perlita no aço em questão. 

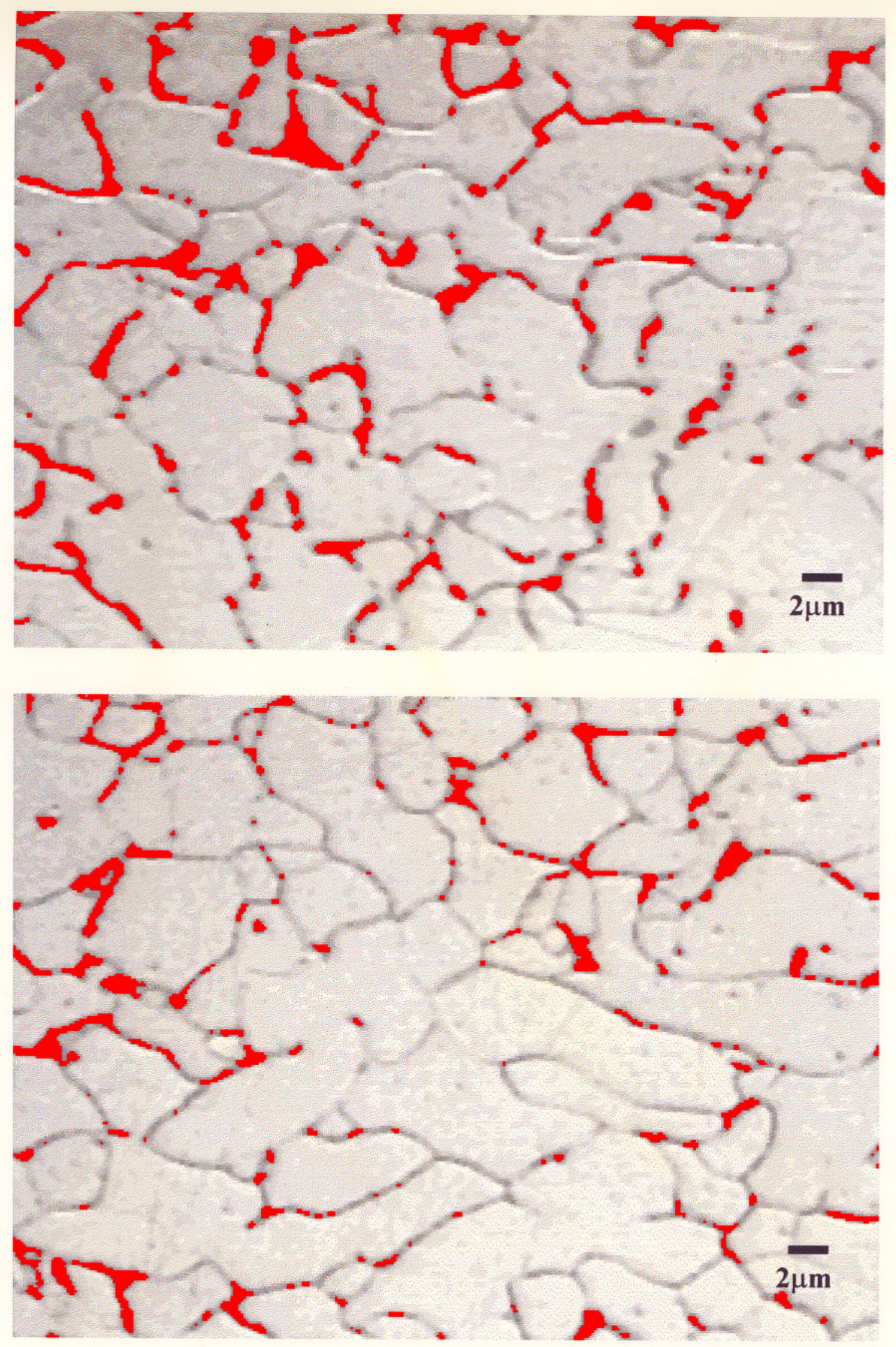

FIGURA 64 - Ilustra um detalhe, de uma região amplificada da imagem original com o sobreplano na qual se observa uma área pintada pelo sobreplano que não corresponde à área da perlita. 

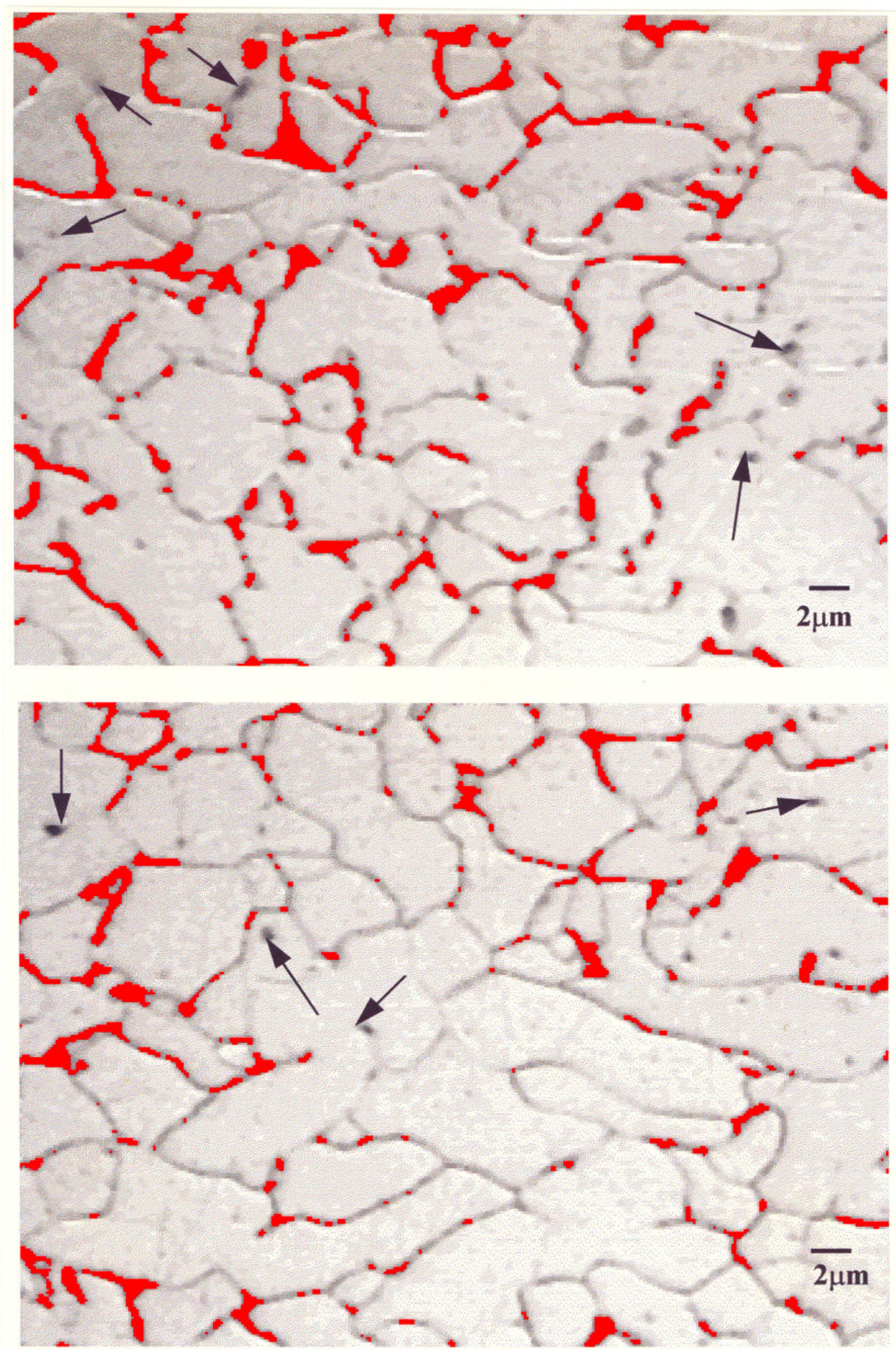

FIGURA 65. Observa-se a eliminação dos riscos e das inclusões localizada nos centros dos grãos, o qual não corresponde à área da perlita que foi pintada pelo sobreplano. 


\section{IV - RESULTADOS E DISCUSSÕES}

A análise das amostras de chapas de aços ao carbono recozidos, e laminados a quente, utilizando-se o sistema de análise de imagens, foi feito com o intuito de quantificar a porcentagem das fases, perlítica e ferrítica nas microestrutura. E a luz das relações já estabelecidas pelas experiências entre essas microestruturas e as propriedades mecânicas dos metais possibilitaram obter conclusões cabiveis para a quantificação precisa dos parâmetros microestruturais.

Dos três métodos de quantificação de fases estudados, dois já estão consagrados pela literatura conforme RHINES (1945); MEI \& SILVA (1988). O métodos teórico e o manual de contagem de pontos são muito empregados em todas a indústrias e nos meios científicos, com grandes restriçōes à sua viabilidade técnica, conforme relatam CHIAVERINI (1984), COLPAERT (1974), visto que o método teórico de quantificação de fases não considera os elementos de liga presentes. Segundo CALLISTER (1994),. VAN VLACK (1984), HONEYCOMBE \& BHADESHIA (1995). Por outro lado, o método manual de contagem de pontos utiliza técnicas visuais na quantificação de fases e microconstituintes. Desta forma, os elementos de liga são levados em consideração.

O método manual de contagem de pontos utiliza técnicas estatísticas para a quantificação das fases. Segundo MENEZES \& BASTIAN (1974), a confiabilidade dos resultados está freqüentemente associada as variáveis normais da estatística, como: suposiçōes da quantificação e ter a disposição os números elevados de campos para obter-se boa confiabilidade dos resultados.

WOLTESDORF (1992) destaca, em suas pesquisas com novos materiais, a importância de um real domínio das relações entre os parâmetros microestruturais, visto que variações sensíveis das 
propriedades mecânicas de um material estão freqüentemente associadas às pequenas variações das microestruturas, que muitas vezes são difíceis de serem colocadas em evidência, utilizando-se os métodos tradicionais.

Atualmente, com o rápido progresso da informática, que permite criar algoritmos para análise de imagem que utiliza sistema tais como o "Mocha" versão 1.1 e uma placa de digitalização "Frame grabber", para avaliações microestruturais com o emprego das técnicas de processamento digital de imagens, é possível analisar com precisão e rapidez, estruturas consideradas altamente complexas. No entanto, o sistema automático de quantificação de fases possui características próprias e certas limitações.

É a duvida persiste: Qual o melhor método a ser utilizado, quer para a rapidez, quer para a simplificação das etapas, quer para a qualidade das imagens das microestruturas, ou mesmo quais as limitações dos métodos.

Nos três métodos, em estudo teórico, contagem de pontos manual e análise de imagens pode fazer uma correlação entre eles, verificando-se as vantagens e desvantagens de um em relação ao outro.

No caso das amostras escolhidas para o estudo, optou-se pelos aços ao carbono comum, que a princípio são a base do estudo para todos os outros tipos de aços ASTM A 29/A 29M-93a.

O método teórico empregado para determinar a quantificação de fases em aços ao carbono comum utiliza essencialmente o diagrama equilíbrio ferro ao carbono. 


\section{IV.1 - Determinacão do tamanho de grão}

Conforme HONEYCOMBE \& BHADESHIA (1995), PICKERING (1978), o limite de escoamento depende do tamanho de grão da ferrita, mas dá uma menor contribuição quando o conteúdo de perlita aumenta. Essa relação pode ser observada nas figuras 6 e 7 que representam os três principais mecanismos que influenciam a resistência à tração.

$\mathrm{Na}$ determinação do tamanho de grão, usou-se uma escala padrão segundo a norma ASTM E112., adaptada na ocular do microscópio óptico e por comparação visual, verificou-se que todas as amostras analisadas apresentam tamanho de grão ASTM N`8.

E, utilizando-se uma escala de conversão do número de grão ASTM em diâmetro médio equivalente, obteve-se o seguinte resultado:

Diâmetro médio equivalente $\approx 22 \mu \mathrm{m}$ ( Para todas as amostras estudadas.)

A importância de se determinar o tamanho de grão do grupo de ligas analisada, está no fato de normalizar o grupo das amostras escolhidas. No caso, todas as amostras selecionadas sofreram o mesmo tipo de tratamento térmico e nelas se encontraram tamanhos semelhantes. 


\section{IV.2- Método teórico}

De acordo com HONEYCOMBE \& BHADESHIA (1995), MEI \& SILVA (1988) e CHIAVERINI (1984), no método teórico de quantificação de fases, cada liga requer um diagrama específico devido à influência dos elementos de ligas que estão presentes. No entanto, este método ainda é empregado na indústria e no meio científico com grandes restrições à sua viabilidade técnica, visto que os elementos de liga influenciam a extensão dos campos de formação das fases, em virtude da elevada demanda de tempo na construção de diagramas específicos.

Para quantificar a porcentagem de fases dos microconstituintes perlita e das fases ferríticas, adotou-se o diagrama de fase editado por CHIPMAN (1972), figura 2, que até nos dias atuais é o mais adotado nos meios científicos e industriais, além de servir como um "mapa", indica os campos das fases presentes e informa a composição química das ligas em questão, em dada temperatura, durante 0 resfriamento.

Contudo, pelo que foi visto, o diagrama considera a quantificação de fase de um grupo de ligas de ferro carbono, estudadas, com aproximações.

A determinação da porcentagem de fases nos aços ao carbono comum ou nas ligas metálicas em suas diversas variedades é efetuada, utilizando-se o método teórico e fazendo-se uso da regra da alavanca conforme VAN VLACK (1984), SILVA \& MEI (1988).

A regra da alavanca, segundo os autores, é um seguimento de reta que liga os pontos representativos das composições de duas fases no diagrama de equilíbrio.

De acordo com HERTZ (1995) e PORTER \& EASTERLINS (1990), isto implica que é um segmento isobárico e isotérmico, e como tal sua 
projeção vertical se apresenta em verdadeira grandeza. A regra da alavanca, de acordo com GOODMAN (1981), toma por base os conceitos termodinâmicos do princípio de conservação da matéria.

Nas nove amostras de aço ao carbono comum, selecionadas para o estudo da evolução da porcentagem de perlita utilizando o método teórico, padronizou-se a temperatura em $727^{\circ} \mathrm{C}$.

Abaixo desta temperatura, ocorre, sob resfriamento lento, a total transformação da austenita em perlita e ferrita nos aços hipoeutetóides conforme CHIPMAN (1972).

Nesta temperatura, de acordo COLPAERT (1974), temos que a porcentagem de perlita, quando a porcentagem de carbono $0,0218 \%$ correspondente a $0 \%$ do microconstituinte perlita e quando a porcentagem de carbono é de $0,77 \%$ a porcentagem de microconstituinte perlita corresponde a $100 \%$.

Aplicando-se o mesmo método nas amostras da tabela 4, obtiveram-se os resultados que estão representados pela tabela 5 .

TABELA 6 - Porcentagens de perlita e ferrita das amostras de chapas de aços ao carbono comum laminadas a quente, determinadas pelo método teórico.

\begin{tabular}{|c|c|c|c|c|c|c|c|c|}
\hline Apo & 100 & 1006 & 100 & 1009 & 1011 & 1012 & 1014 & 100 \\
\hline$\% P$ & 3,77 & 5,10 & 7,7 & 9,11 & & 13,12 & 15,79 & 7190 \\
\hline $04:$ & 96,23 & 94. & 92,2 & 90,89 & 88,22 & 80,08 & 84,41 & \\
\hline
\end{tabular}

Através dos resultados obtidos teoricamente, montou-se um gráfico de porcentagem de perlita versus porcentagem de carbono, visualizar a evolução da porcentagem do microconstituinte perlita em função da porcentagem em peso de carbono. Subseqüentemente, operou-se uma regressão linear de $1^{\mathrm{a}}$ ordem, utilizando-se para sua operacionalidade o software "origin" Versão 4.0. 


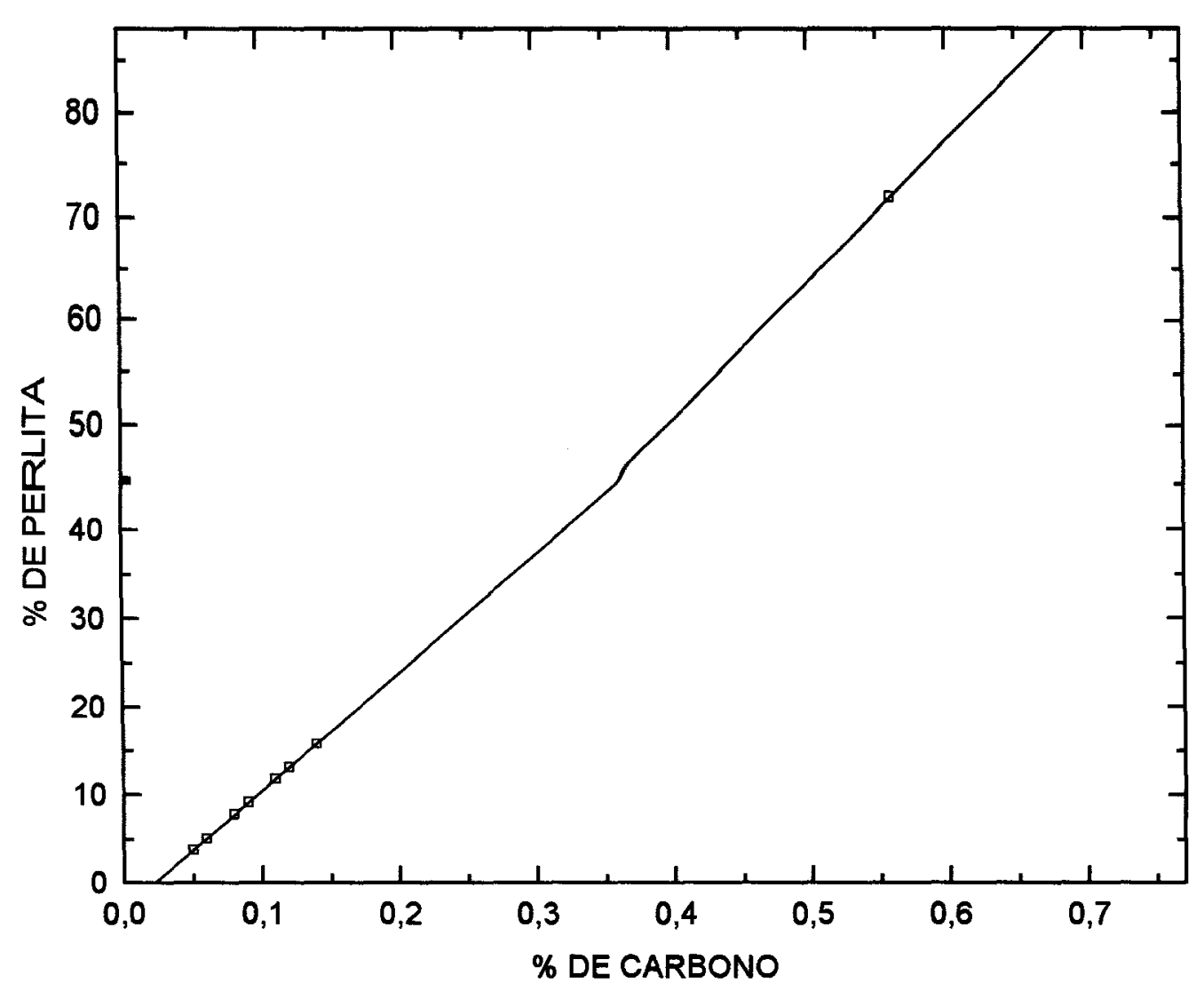

FIGURA 66 llustra o gráfico da porcentagem do microconstituinte perlita em função da porcentagem de carbono, para o método teórico

A equação linear de $1^{\mathrm{a}}$ ordem correspondente ao gráfico é:

\% DE MICROCONSTITUINTE PERLITA = - 2,91 + 133,59 X \%C

No entanto, como comentado anteriormente, o método de aplicação da a regra da alavanca não considera as pequenas variações das porcentagens dos elementos de ligas. Desta forma, todos os aços são classificados dentro de uma faixa ou grupo.

Conforme CHIAVERINI (1984),os elementos de liga residuais podem ser alfagênicos ou gamagênicos 
A presença dos elementos alfagênicos acarretam a ampliação do campo correspondente à ferrita, aumentando sua estabilidade, diminuindo o campo de estabilidade da austenita e a temperatura eutetóide e deslocado para a direita. A literatura exemplifica alguns elementos gamagênicos tais como $\mathrm{Cr}, \mathrm{Mo}, \mathrm{Ti}, \mathrm{Al}, \mathrm{W}, \mathrm{V}, \mathrm{Si}, \mathrm{Nb}$ etc.

Outros elementos de ligas classificados como gamagênicos, exemplo: $\mathrm{Mn}, \mathrm{Ni}, \mathrm{Co}$, etc.,atuam no sentido de ampliar o campo de existência da austenita, reduzindo ou mesmo eliminando o campo de existência da ferrita, conforme PEDRAZA et al.(1983)

A equação mostrou-se satisfatória para determinar a porcentagem dos microconstituintes perlita e ferrita, se quisermos trabalhar com resultados dentro de uma faixa de aproximação.

\section{IV.3 - Método de contagem de pontos}

Conforme PADILHA (1997), a necessidade de se quantificar a porcentagem de ferrita e do microconstituinte perlita, presentes nas ligas metálicas, nas quais se leva em consideração a porcentagem dos elementos presentes, levou a metalografia quantitativa a desenvolver técnicas visuais de quantificação de fases.

COLPAERT (1957), baseando-se no recorte das fotomicroestruturas, observou que a diferença entre 0 peso total do papel e o peso do papel correspondente aos microconstituintes perlita, representa a porcentagem de área dos aços ao carbono comum hipoeutetóide, recozidos e resfriados lentamente. Notoriamente esta técnica empregada pelo mesmo autor exige um número considerável de fotomicroestruturas, pois pode-se correr o risco de obter-se uma porcentagem dos microconstituintes que não corresponde ao valor real. Isto porque, nos aços ao carbono comum hipoeutetóides resfriados lentamente, temos determinadas regiões que são aleatórias 
com respeito à concentração do microconstituinte perlita, que poderiam fornecer resultados falsos.

Posteriormente, conforme GLAMAN \& WOODHEAD (1960), UNDERWOORD (1995) e HEIN et al. (1994), a metalografia quantitativa desenvolveu métodos que empregam técnicas desenvolvidas com o auxílio de cálculos estatísticos. De acordo com ASTM E 562-89, EXNER et al.(1993), a utilização deste método necessita de um número relativamente grande de medidas, para permitir o uso dos conceitos estatísticos. O que limita a aplicabilidade deste método na rotina industrial. Conseqüentemente é sua confiabilidade é a inabilidade do técnico responsável, que restringe ainda mais a reprodutibilidade dos resultados. Conforme MENEZES \& BASTIAN (1974), os métodos de contagem de pontos manuais são bastante lentos e cansativos. Lentos, devido à necessidade de revelação de fotomicrografias e montagem das redes de contagens de pontos, cansativos, pois, mesmo colocando-se a rede de pontos na ocular do microscópio, como forma de simplificação, o processo de revelação de inúmeras fotomicrografias, seria inevitável e com isto, seriam necessárias horas para a observação do conjunto.

Conforme Doc.No.IX-1533-88), MENEZES \& BASTIAN (1974) e BARCELOS et al. (1977) desenvolveram um método alternativo, muito empregado nos meios industriais e científicos, para agilizar o processo de quantificação de fase. Este método consiste em fixar uma rede de 100 pontos e o número de campos em 10 para efetuar as medidas dos parâmetros metalográficos.

Os resultados da análise de porcentagem dos microconstituintes perlita para os dez (10) campos analisados, encontram-se representados na tabela 6 , desta feita em porcentagem de área.

Este método empregado pela metalografia quantitativa, leva em consideração os efeitos dos elemento de liga adicionados. 
TABELA 7 - Porcentagem do microconstituinte perlita para os 10 campos das amostras de chapa de aço analisadas, determinadas pelo método de contagem de pontos.

\begin{tabular}{|c|c|c|c|c|c|c|c|c|c|}
\hline $\begin{array}{l}\text { AMOSTRA } \\
\text { DE CHAPA } \\
\text { DE ACO }\end{array}$ & 1005 & 1000 & 1008 & 1009 & 1011 & 1012 & 1014 & 1006 & 1056 \\
\hline CAMPO-1 & 5 & 11 & 15 & 15 & 9 & -44 & 13 & 75 & 70 \\
\hline CAMPO 2 & 6 & $7=$ & 8 & 10 & 11 & 13 & 1 & 64 & 68 \\
\hline $\mathrm{CAMPO}_{3}$ & 4 & 8 & 9 & 6 & 13 & 18 & 14 & 75 & 69 \\
\hline $\mathrm{CAl}$ & 9 & 5 & 6 & 8 & 12 & 13 & 14 & 69 & 74 \\
\hline & 5 & 5 & 7 & 9 & 9 & $=11$ & 18 & 67 & 71 \\
\hline CA & 3 & 9 & 9 & 10 & 9 & $=11$ & 1 & 74 & 74 \\
\hline CA & 5 & 10 & 12 & 6 & 14 & 12 & 18 & 62 & 79 \\
\hline & 7 & 7 & 8 & 8 & 15 & 15 & 22 & 71 & 80 \\
\hline & 7 & 6 & 7 & 13 & 1 & 40 & & 72 & 78 \\
\hline & 6 & 7 & 8 & $7=$ & 1 & 7 & & 68 & 61 \\
\hline ME & 5.70 & 7.50 & 8.90 & 9.20 & 11.4 & 124 & 15.6 & 169.5 & 72.2 \\
\hline
\end{tabular}

Utilizando-se os resultados da tabela 6, montou-se um gráfico, observando-se o aumento da porcentagem de perlita em função da porcentagem em peso de carbono nas chapas de aço ao carbono recozidas e laminadas a quente, conforme ilustra a figura 66. Para a montagem do gráfico, adotou-se o mesmo procedimento adotado no caso anterior, ou seja, a utilização do software "origin" Versão 4.0. 


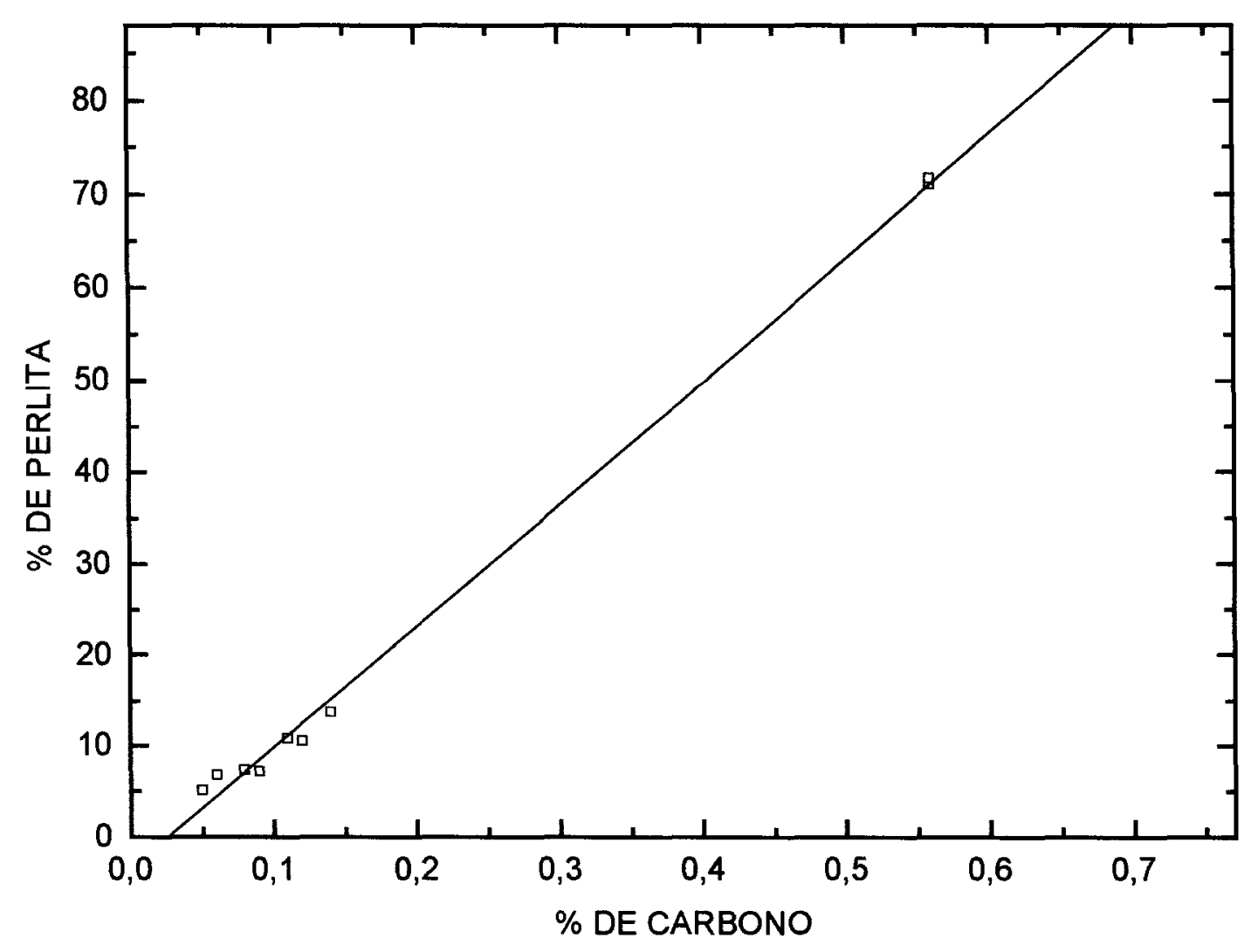

FIGURA 67 - O gráfico ilustra a porcentagem de microconstituinte perlita em função da porcentagem de carbono.

PORCENTAGEM DE PERLITA $=-1,87+129,5 X$

Dentre os materiais estudados, a técnica de contagem de pontos manual proposta pela norma da ASTM E 562-89, foi efetuada na amostra 1. Fixou-se a precisão de $10 \%$, de acordo com recomendações da própria norma, porém a rede recomendada pela norma seria de 49 pontos de acordo com a TABELA 3, que recomenda as redes correspondentes. Desta forma o número de campos calculado de acordo com a equação 6 foi de 128, para se obter uma confiabilidade de $95 \%$. 
O valor da fração volumétrica média encontrada, segundo os métodos estatísticos recomendados pela norma ASTM E 562-89, é de 0,059. Segundo o método de contagem de ponto que fixa o número de campo em 10 e o número de pontos da rede em 100, com confiabilidade de $75 \%$, o resultado da fração volumétrica foi de 0,057 . Avaliado-se ambos os resultados, conclui-se que o erro cometido encontra-se na $3^{a}$ casa decimal. Este resultado levou a adotar-se 0 método de contagem de pontos que fixa o número de pontos da rede $\mathrm{e}$ o número de campos.

\section{IV.4 - Método que utiliza o sistema de análise de imagens}

Conforme HEIN (1995), ROCHA \& PACIORNIK (1994), HETZNER (1992), PINTO \& BRESSIANI (1994), SANTOS et al (1995), IMAGE- PLO-PLUS (1995), LEGO INSTRUMENTS LIMITED (1991); CASTORINO \& ROLLO (1996), RICHTER, J. ; WENDROCK, H. (1992), os diversos sistemas de análise de imagens desenvolvidos para a avaliação microestrutural são, na sua maioria, baseados na digitalização das imagens e processamento das mesmas, para se obterem as medidas dos parâmetros microestruturais com precisão e rapidez. Estes sistemas de avaliação microestrutural vêm se apresentando como uma alternativa bastante viável nos últimos anos, em conseqüência da drástica redução de preços dos computadores de pequeno e médio porte. E a popularização da informática, conforme HEIN (1995), reduziu consideravelmente as despesas com o treinamento de pessoal.

Os dispositivos de digitalização modernos garantem uma alta fidelidade na representação digital de uma imagem real, com a utilização de programas de melhoramento de imagens e 
reconhecimento de padrões que permitem corrigir defeitos e realçar características de interesse para a análise quantitativa posterior.

Mas sua grande vantagem sobre os demais métodos tradicionais, de acordo com HETZNER (1992), BRESSIANI \& PINTO (1994), BARCELOS et al. (1977), está na reduzida interferência do usuário sobre o levantamento dos dados, o que limita as fontes de erros subjetivos, sem prejudicar um alto controle sobre as informações.

Os resultados obtidos da análise da porcentagem do microconstituinte perlita nas nove amostras de aços estudados, utilizando-se o método de análise de imagem, encontram-se na tabela 7. Cada campo dos microconstituintes analisados pelo método de contagem de ponto foi o mesmo analisado pelo método que utiliza o sistema de análise de imagem. Ambos os métodos caracterizam-se pela determinação visual da microestrutura e levam em consideração os efeitos dos elementos de liga adicionados.

TABELA 8 - Resultados obtidos para os 10 campos de cada amostra analisada, pelo método do sistema de análise de imagens.

\begin{tabular}{|c|c|c|c|c|c|c|c|c|c|}
\hline$P \mid=$ & 1005 & $100 \mathrm{~s}$ & 1008 & 1009 & 1011 & 1012 & 1014 & $108 \beta^{14}$ & 1056 \\
\hline 1 & 3.91 & 6.52 & 8.85 & 837 & 9.79 & 1184 & 14.25 & 7669 & 70.08 \\
\hline 2 & 4.62 & 7.15 & 7.35 & 750 & 10.27 & 11,39 & 9.69 & 663 & 62.27 \\
\hline 3 & 4.98 & 7.21 & 7.95 & 5.33 & 12.33 & 1421 & 13.55 & 79.28 & 67.07 \\
\hline 4 & 6.92 & 6.29 & 5.67 & 725 & 11.34 & 1060 & 10.44 & 69.4 & 68.84 \\
\hline 5 & 4.53 & 7.12 & 5.79 & 7.37 & 8.73 & 8.18 & 10.07 & 67.89 & 72.06 \\
\hline 6 & 3.84 & 4.55 & 8.11 & 7.38 & 12.48 & 10.1 & 16.98 & 7085 & 73.32 \\
\hline 7 & 4.54 & 5.33 & 8.14 & 6.48 & 12.93 & 10,14 & 16.78 & 6033 & 77.25 \\
\hline 8 & 5.87 & 624 & 7.45 & 7.30 & 9.8 & 13.93 & 17.22 & $7: 27$ & 78.07 \\
\hline 9 & 5.99 & 7.33 & 6.52 & 769 & 10 & 839 & 14.27 & 7460 & 75.14 \\
\hline 10 & 5.18 & 7.29 & 7.63 & 7,13 & 10.5 & 6.38 & 13.97 & 6782 & 61.5 \\
\hline$(\mathbf{P p})$ & 5.04 & 6.70 & 7.35 & 7.19 & 10.8 & 10.5 & 13.7 & 70.9 & 71.58 \\
\hline
\end{tabular}




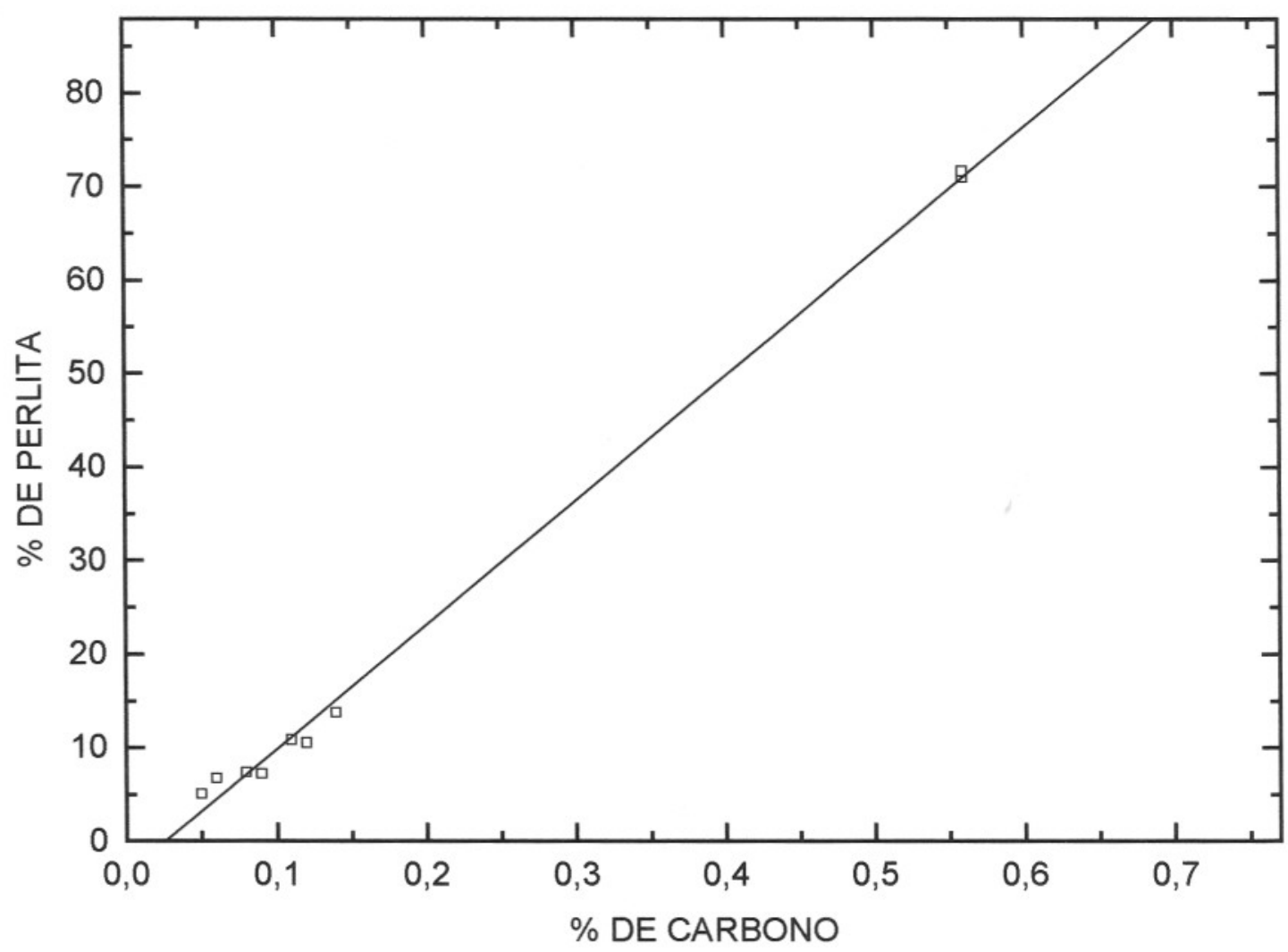

FIGURA 68 - llustra o gráfico da porcentagem em peso do microconstituinte perlita em função da porcentagem em peso de carbono.

De posse dos resultados da porcentagem dos microconstituintes perlita das nove amostras de aço ao carbono comum, operou-se uma regressão linear de $1^{a}$ ordem da porcentagem de microconstituintes em função da porcentagem em peso de carbono.

PORCENTAGEM DE PERLITA = -3,5 + $133 \mathrm{X}$

Para melhor visualizar a correlação entre os três métodos analisados, montou-se um gráfico com os três, conforme figura 61 . 


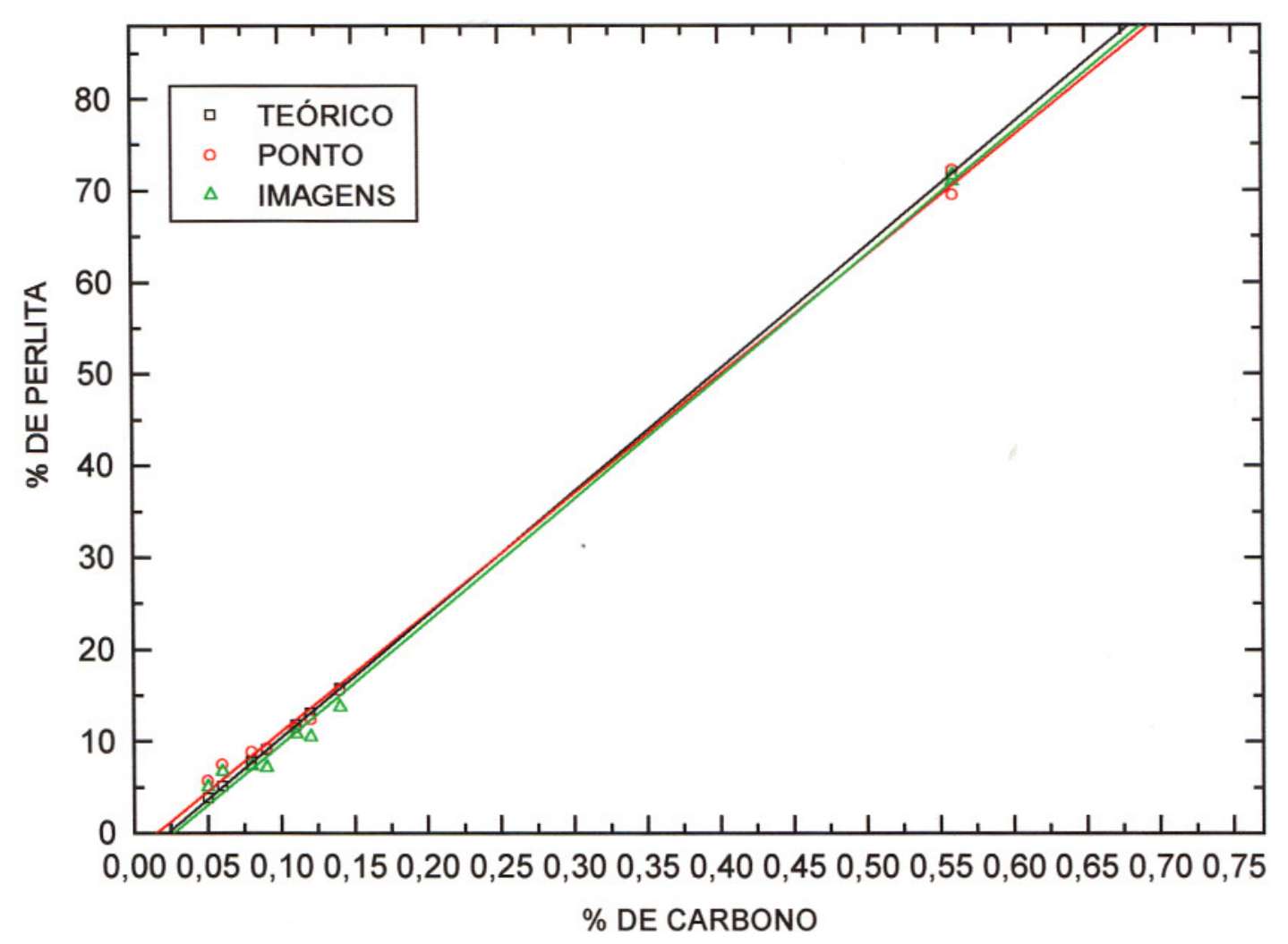

FIGURA 69 - llustra as equações lineares de $1^{\text {a }}$ ordem dos três métodos estudados.

Nas correlações entre os três métodos estudados, verificou-se que para os aços ao carbono recozidos e laminados a quente, as três equações lineares de $1^{a}$ ordem estão muito próximas. No entanto, a preocupação fundamental dos três métodos está no caminho percorrido durante o processo.

O método teórico não levando em consideração os elementos de liga, reproduz, desta forma, os mesmos resultados das amostras 8 e9, que possuem a mesma porcentagem de carbono, porém com elementos de liga diferentes.

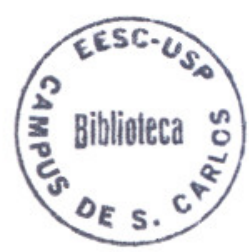


Na correlação entre o método de contagem de ponto e o método que utiliza o sistema de análise de imagem, observou-se um ligeiro aumento na porcentagem do microconstituinte perlita, como pode ser notado na figura 9. Conforme COLPAERT (1974), o elemento Manganês, que dificulta a difusão do carbono nos contornos de grão da austenita, conseqüentemente, faz o aço "parecer", ter um teor de carbono mais elevado do que realmente apresenta. Nas figuras 39 e 41 , obtidas por microscopia eletrônica, esta diferença é claramente percebida visualmente.

Com relação ao tempo na determinação da porcentagem de fases, o sistema de análise de imagem mostrou-se rápido, com uma boa confiabilidade na determinação do microconstituinte perlita e com qualidade de imagens considerada de alto padrão. 


\section{V - CONCLUSÃO}

- O conhecimento do microscópio óptico e de seus recursos, tais como filtros, polarizadores, controle de intensidade de luz, lentes auxiliares são fundamentais para se obter uma boa qualidade das imagens.

- Os assuntos da quantificação de fases, com a utilização dos os métodos tradicionais, existem e estão disponiveis, mas o conhecimento não se encontra organizado, dificultando o acesso às informações, e com a compilação das pesquisas, pode verificar lacunas em diversos aspectos desses métodos.

- Na quantificação de fases, principalmente quando se trata de utilizar o sistema de análise de imagens, a intensidade do ataque químico deve ser controlada e fixada. Como também reduzir os defeitos de polimento

- Os presentes resultados da correlação entre os métodos tradicionais de quantificação de fases e o método que utiliza o sistema de análise de imagens, representam um dos primeiros trabalhos na área.

- Na correlação entre os três métodos para as nove amostras analisadas os resultados das equações mostra-se satisfatório. Pode-se comprovar que a influência dos elementos de liga é relativamente baixa. 
- O programa "Mocha", versão 1.1, constitui-se uma ferramenta simples para as medidas dos parâmetros microestruturais a partir de imagens digitalizadas. Apesar de apresentar algumas lacunas, elas podem ser facilmente contornadas quando o software "Mocha" é associados ao programa "Adobe Photoshop" versão 4.0.

- Observa-se uma boa reprodutibilidade dos resultados, pois reduz o erro humano, utilizando o sistema de análise de imagens.

- A comprovação da validade destes métodos permitirá que tanto as grandes indústrias metalúrgicas, fornecedoras de matéria-prima, quanto pequenas e médias empresas de transformação adotem os mesmos padrões para a determinação dos parâmetros microestruturais para 0 controle de qualidade de produtos metalúrgicos, abandonando o uso dos métodos tradicionais de aplicação manual. 


\section{VI - SUGESTÕES PARA TRABALHOS FUTUROS}

- Verificar a validade da equação de HALL-PETCH, utilizando-se recursos do sistema de análise de imagens na determinação do tamanho de grão e do espaçamento interlamelar.

- Desenvolver algoritmos de medidas de parâmetros microestruturais de imagens cromáticas e padronizar a seqüência mais adequada das técnicas de processamento.

- Fazer correlação entre os diversos algoritmos de análise de imagens existentes no mercado. 


\section{V - REFERÊNCIAS BIBLIOGRAFIAS}

AMERICAN SOCIETY FOR METALS (1972) Metals Handbook Engineering properties of steel. 8ed. Metals Park, v.8. Ohio. p.1 - 72.

AMERICAN SOCIETY FOR TESTING AND MATERIALS (1970). E407/70. Standard methods for microetching Metals and Alloys, Metallography non-destructive testing. In: Annual book of A.S.T.M. standards. Philadelphia. p. 280-305.

AMERICAN SOCIETY FOR TESTING AND MATERIALS (1986). E3/86. Standard methods of preparation of metallographic specimens Philadelphia. (CD ROM).

AMERICAN SOCIETY FOR TESTING AND MATERIALS (1986). E883/86 Standard Guide for metalollographic photomicrography Philadelphia.( CD ROM).

AMERICAN SOCIETY FOR TESTING AND MATERIALS (1988) E112/88 Standard test Methods for determining average grain Size. Philadelphia. (CD ROM).

AMERICAN SOCIETY FOR TESTING AND MATERIALS (1989). E562/89. Standard test for method determining volume fraction by systematic manual point count. Philadelphia. (CD ROM).

AMERICAN SOCIETY FOR TESTING AND MATERIALS (1993) A29/A29M/93a Standard Specification for Steel Bars, Carbon and Alloy, Hot-Wrought and cold-Finished. Philadelphia. (CD ROM).

AMERICAN SOCIETY FOR TESTING AND MATERILS (1993) A566/A568M/93a.- Standard specification for steel, sheet, carbon, and High-Strength, Low-Alloy, Hot-Rolled and Cold-Rolled, Philadelphia. (CD ROM). 
AZEVEDO, HEIN, L. R. O F; AMMANN. J.J.; NAZAR,A.M. (1994) Técnica da análise de imagens aplicados na caracterização microestrutural de cerámicas avançadas. In: Anais CONGRESSO BRASILEIRO DE CERÂMICA, 38, Blumenau S. C.

BARCELOS, E. J.B.V; ABRÓZIO FILHO, F.; CUNHA, R.C. (1977) Aplicações da metalografia quantitativa automática, , Metalurgia ABM, v.33, n 231. p. 93-99. Fevereiro.

CALLISTER Jr, W. D.; (1994) Materials Science and engineering. New York, John wiley.

CALVO, M; GAUTIER. E; SIMON. A (1991). Association of polarised light. Metallography which quantitative image analysis for the characterisation of microstructures. Journal of Materials Science v. $26, \mathrm{n} 5$, p. $1236-1246$.

CASTORINO, E.; ROLLO, J.M.D. A.; DI LORENZO, P. L (1996). Aplicabilidade do sistema de análise de imagens para avaliação de parâmetros metalográfico. In: CONGRESSO BRASILEIRO DE ENGENHARIA E CIÊNCIA DOS MATERIAIS, 12., Águas de Lindóia, . Anais. São Paulo, ABM.

CASTORINO, E.; ROLLO, J.M.D.A. (1996). Evaluation of metalographic parameters using a image analysis system. Acta microscopia, v.5, supl.B, p. $176-177$, Oct.

CHIAVERINI, V. (1984) Aços e ferros fundidos 5 ed., São Paulo, ABM.

CHIPMAN; J.; (1973) Phase diagrams of binary alloy systems metallography, Structures and Phase Diagrams. In: AMERICAN SOCIETY FOR METALS. Metals handbook. 8. ed. Metals Park,. Ohio. v.8. p. $275-278$.

CHERMANT, J. L., COSTER, M. GOUGEON, G. (1989) Morphological Analysis of Al-Si Alloys by fully automatic image analysis. Practical metallography v.26. p. 415-427.

GLADMAN, T.; WOOHEAD, J.H. (1960) The accuracy of point counting in metallographic investigations. Journal of the iron and steel institute. v. 194, Pt 2, p.189-193 
COCHRANE, R.C (1988) Microstrutuctural Characterisation. Characterisation of high temperature materials. The institute of metals. London, p 43-79.

COLPAERT, H. (1974) Metalografia dos produtos siderúrgicos comuns; 3. Ed. São Paulo, Edgard Blücherlt.

EXNER, H.E et al.(1993) Quantitative description of microstructural geometry a practice guide to manual processes. Practical Metallography, v. $30, n^{\circ} 5$, p. $217-226$.

FASANO, D. A. TV (1980). A prática metalográfica. São Paulo, Hemus, p.179- 214

GOODMAN, D. A.CAHN, J.W.; BENNETT, L.H (1981) The Centennial of the gibbs- konovalov rule for congruent points: its underlying theoretical basis and its applications to phase diagram evaluation. Bulletin of alloy phase diagrams v.2, n1, p. $29-34$.

HEIN, L.R.O; AMMANN, J,J; SILVA, F. A.; NAZAR, A. M. M; (1994) Perspectivas sobre à aplicação dos métodos de análise numérica de imagens na caracterização de produtos metalúrgicos. In: CONGRESSO ANNUAL DA ABM, 49. , São Paulo, 1994. Anais. São Paulo, ABM. v1, p.33- 44.

HERTZ, J. (1992), Josiah willard gibbsand teaching thermodynamics of materials (history). Journal of Phase Equilibrium , v. 13, n5, p.450 - 458, Oct.

HETZNER, D. W. (1992) Quantitative image analysis procedures for evaluating steel products. Iron \& Steelmaker, v.19; n1; p. 2128. Jan.

HONEYCOMBE, R.W.K.(1982) Aços microestrutura e propriedades. Tradução de M. Amaral fortes e A. Cabral ferro. FUNDAÇÃO CALOUSTE GULBENKIAN / LISBOA.

HONEYCOMBE, R.W.K., BHADESHIA, H.K.D.H. (1995). Steels microstructure and properties. 2.ed. London, Edward Arnold.

IMAGE-PRO.PLUS; MEDIA CYBERNETICS THE IMAGING EXPERTS (1995). The proven solution for image analysis. Maryland. /folder/. 
INTERNATIONAL INSTITUTE OF WELDING (1988) Guide to the light microscope examination of ferritic steel weld metals. (Doc. $\mathrm{n}^{\circ} . \mathrm{IX}$ 1533-88 IXJ - 123-87. June (1988).

KEHL; G.L. (1949) The Principles of Metallographic Laboratory Practice. 3ed. New York. Chapter 3.

LEGO INSTRUMENTS LIMITED (1991) ASTM E-45.and JK routings by image analysis. Advanced materials of processes. v.139. $n$ 6 , June.

MAKEMSON, J, SLAUGHTER,J., YONG, M. (1995) The Microscope: na Edmund scientific publication, Barrington, New Jersey.

MANGONON, P. L., OAKWOOD, T. G., SHAPIRO, J. M. (1973) Ferrous Eutectoid, Structures, In: AMERICAN SOCIETY FOR METALS. Metals handbook. 8. ed. Metals Park, Ohio. v.8, p.188 -191.

MENEZES, R. A.; BASTIAN, F. L. (1974) Metalografia quantitativa aplicada ao controle de inclusões não metálicas em aços. Metalurgia ABM. v 30. n197. p. $243-250$. Abr.

MEI, P. R. (1990) Efeito da microestrutura na resistência mecánica de aços com médio e alto teores de carbono microligados com nibbio. Encontro de tecnologia e utilização dos aços nacionais. Aços microligados, Soldagem, Aços ferramentas e tecnologia, Seleção e desenvolvimento de produtos. In: 45 CONGRESSO ANUAL ABM. P 37-55.

Operator's Guide (1993) Mocha Image analysis software. Jardel scientific.

PACIORNIK, S. (1996) Digital Microscopy mini - course sociedade brasileira de microscopia eletrônica. DCMM PUC-Rio /notas de aulal.

PADILHA, A.F (1997) Materiais de engenharia \& microestrutura e propriedades. ed. HEMUS. São Paulo, p.223 - 235.

PADILHA, A.F.; FILHO AMBROZIO, F. (1985). Técnicas de análise microestrutural. São Paulo. Hemus. p.113-141. 
PAZ, E.P.; CUNHA, T.N. (1988). Iniciação ao processamento digital de imagens. In: CONGRESSO C.B.C.,8, JORNADA DE ATUALIZAÇÃO EM INFORMATICA, 7., Rio de Janeiro, 1988. Anais. Rio de Janeiro, UFRJ/NCE.

PEDRAZA, A. J.; COUTINHO, C.A.B.; SILVA, E.M.P. (1983) Tratamentos térmicos dos aços. Belo Horizonte, U.F.M.G. Escola de engenharia. Departamento de Eng. Metalúrgica.

PICKERING, F. B. (1978) Physical metallurgy and the design of steels. London, Applied Science.

PINTO, L. C. M.; BRESSIANI, J. C. (1994) Quantificação de microparticulas com o analisador microestrutural quantikov; In: CONGRESSO ANUAL DA ABM, 49, São Paulo, 1994. Anais São Paulo, ABM. v. 3, p. 247 - 252.

PINTO, L.C.M et al Desenvolvimento de um Analisador de Imagens de Materiais. CONGRESSO BRASILEIRO DE CERÂMICA 35. E IBEROAMERICANO DE CERÂMICA, VIDRO E REFRATÁRIO, 3.

PORTER, D. A.; EASTERLING, K. E. (1990) Phase transformations in metals and alloys, New York, Chapma and Hall.

PUJOL, J.C.F et. al. (1992); Um Analisador de Imagens de Materiais para Avaliação Quantitativa de Microestruturas. In CONGRESSO ANUAL DA ABM, 47 São Paulo, 1992. Anais. São Paulo, ABM. v.1, p. 541-553.

RHINES, F. N. (1945). Diagramas de Equilíbrio de ligas metálicas. Trad. por João Mendes França. São Paulo. E.P.U.S.P.

RICHARDSON, J. H. (1971); Optical Microscopy for the Material sciences.

RICHTER,J.; WENDROCK, H. (1992) Microstructural inhomogeneity in Steels Practical Metallography n9. p. 460-470.

ROCHA, A.C.; PACIORNIK, S. (1994). Levantamento de parametros e implementação de cálculos de metalografia quantitativa por processamento digital de imagens. In: CONGRESSO ANUAL DA ABM 49, São Paulo. Anais. v.3, p 233 - 245.

RUSS, J. C. (1995) The Image processing Handbook 2ed., Boca Raton, C.R.C. Press. 
SANTOS, A. M. M.; LAMEIRAS, F.S.; BRAGA, I. D. (1994). Aplicação do método de Saltykov para determinação da distribuição volumétrica de poros e grãos. In: CONGRESSO BRASILEIRO DE CERAMICA, 35; IBEROAMERICANO DE CERÂMICA, VIDRO E REFRATARIO, 3., Anais p. 626-628.

SAVARY, G. (1995), Introdução à análise de imagens em ciência dos Materiais; $3^{\circ}$ ed. Rio de Janeiro, PEMM/ COPPE/UFRJ.

SHIRO BAN-YA; ELLIOTT, J. F.; CHIPMAN.J. (1970) Thermodynamics of Austenitic Fe-C alloys. Metallurgical transactions, v.1; p. 1313-1320. October.

SILVA, A. L. C., MEI, P.R.; (1988) Aços e ligas especiais. 2ed. Sumaré. Eletrometal: Metais especiais.

THOMAS; E. J. (1995) History of the light microscope; http://MWW.duke.edu/\%7etj/hist/hist_mic.html (18 Feb.)

UNDERWOOD, E. E. (1995) Quantitative Metallography. In: AMERICAN SOCIETY FOR METALS. Metals handbook. 9. ed. Metal Park, Ohio. v.9; p. 123-134.

VOOT, G. F. V.; (1995) Metallography and Microstructures; Optical Microscopy; Metals Handbook; AMERICAN SOCIETY FOR METAL, Metals handbook. 9. ed. Metal Park, v.9; p. 71 - 88

WEST, D.R.F.(1982); Ternary equilibrium diagrams 2 ed. New York, Chapman \& Hall.

WESZKA, J.S.; ROSENFELD, A. (1978) Threshold evaluation techniques. IEEE Transactions on Systems, Man, and Cybernetics. v.8. n.8. p. $622-629$.

WOLTERSDORF, J.; PIPPEL, E. (1992) Ceramic materials, microstructural and interface analysis as the prerequisite for the optimisation of microstructures. Practical metallography, v. 29 , n.4, p. 204 - 211. 